\title{
Crawling to connectivity? \\ The direct-developing journey of the spotted whelk (Cominella maculosa)
}

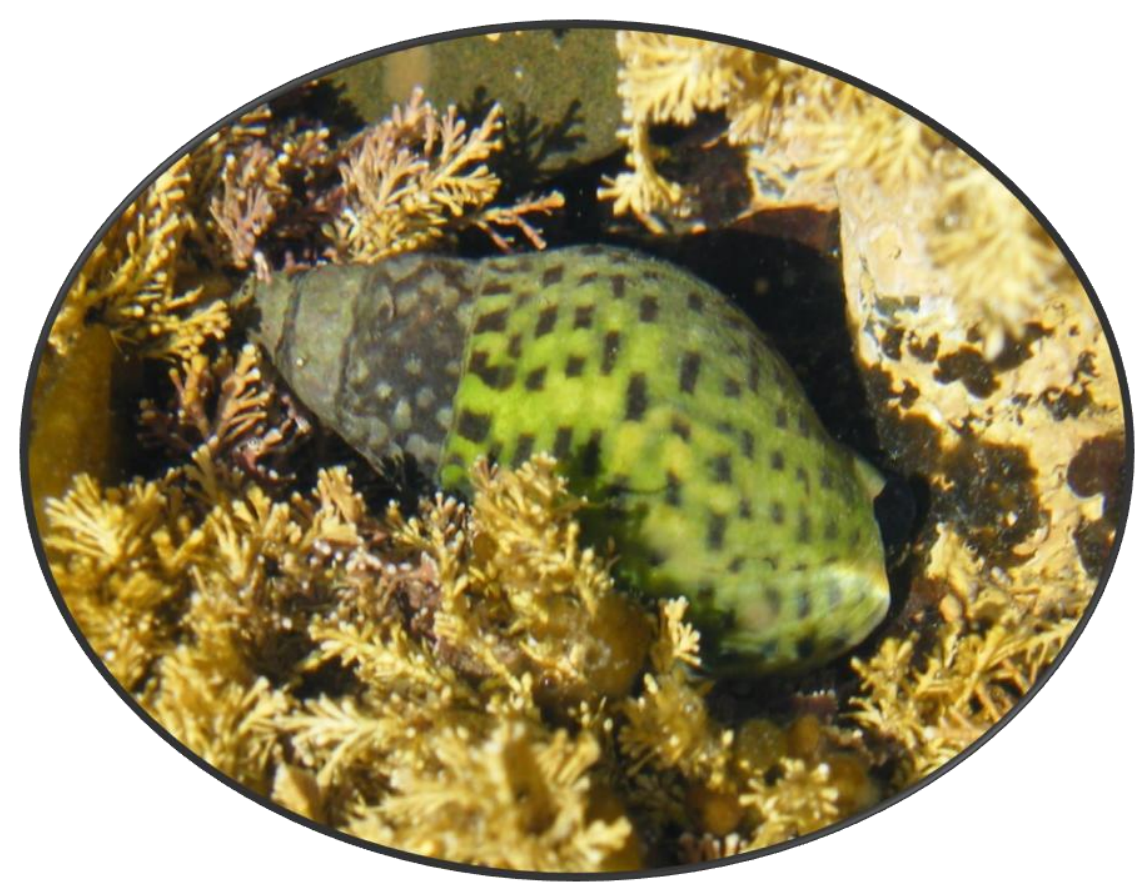

\section{Melanie Dohner}

A thesis submitted to Victoria University of Wellington in partial fulfilment of the requirements for the degree of Master of Science in Marine Biology

Victoria University of Wellington 


\section{Acknowledgements}

I am immensely grateful to my family and my parents for always encouraging me to go after what makes me happy. I couldn't have taken the first steps of returning to school without my mom's financial support. Thank you to my amazingly patient husband, David Milner, for talking out thesis concepts with me and accompanying me on whelk collecting excursions.

I'd like to thank my supervisors for giving me the opportunity to work on such a fun project and for being such great people with which to work. Thank you to Nicole Phillips and Peter Ritchie for sharing your knowledge, being so easy to chat with, and buying me coffees during our meetings. I am so grateful to both of you that I was able to work on a project involving genetics.

I am so appreciative of having found such good friends as Ali Duncan and Jana Wold during my time at VUW. You two awesome scientists have helped me collect whelks, conduct better experiments, interpret my data, and proof read my chapter drafts. All while keeping me sane and laughing with afternoon coffees and nights out.

My field adventures in the remote Wairarapa are the best memories from my thesis. I would like to thank Glenburn, Glendu, and Pahaoa Stations for the use of their roads to access several field sites. I greatly appreciate everyone who sacrificed their time to collect whelks: Ali Duncan, Jana Wold, Gustav Kessel, Kerry Walton, Juliette Champagnat, Angela Fleming, and John van der Sman. I am so extremely grateful for everyone at VUCEL and in the genetics lab that made my time indoors entertaining.

Huge thanks to Angela Fleming for teaching me DNA extraction and sequencing techniques and to Balam Jimenez Brito for ordering supplies and answering my myriad of questions in the genetics lab. A very large thank you goes to the VUCEL technicians for helping me build experiments and find equipment. Particular thanks to the senior students in the Phillips lab for helping me find supplies or statistics guides; Agnes Rouchon and Paul Wolf. I'd like to acknowledge Lisa Woods, the university stats consultant, for her huge help in analyzing my ecology data and coding $\mathrm{R}$.

Finally, I would like to thank Victoria University of Wellington for their support through the Master's by Thesis scholarship. 


\section{Abstract}

The exchange of individuals between populations influences demographic connectivity on the ecological scale and genetic connectivity on the evolutionary scale. In some circumstances there are similarities between demographic and genetic connectivity, but in others there are differences. Whenever genetic differentiation is found between populations demographic uncoupling can also be inferred, but when gene flow is found there is uncertainty about whether populations are demographically connected or not. Marine invertebrates typically have large population sizes and many opportunities for dispersal. However, species that have limited planktonic dispersal power are often characterized by genetically and demographically discrete populations that exhibit an isolationby-distance (IBD) pattern of gene distribution. Alternative methods of dispersal, such as rafting or drifting, produce departures from this expected pattern for species lacking planktonic larvae. Examining genetic patterns at fine geographic scales can identify key dispersal barriers and may give clues to alternative dispersal methods influencing large scale processes.

The endemic, direct-developing spotted whelk, Cominella maculosa, is found in the intertidal rocky shores throughout most of New Zealand. This distribution makes it ideal for studying a species expected to exhibit low realized dispersal by crawling and is unlikely to experience dispersal by rafting. The first aim of this study was to investigate genetic patterns between two genetically distinct populations along the Wairarapa Coast of the North Island to determine if a barrier to dispersal was present or if the expected IBD pattern was observed. The second aim was to determine the likelihood of individual hatchlings undertaking long distance dispersal by drifting in the water column. The mitochondrial DNA COI gene was sequenced using 324 whelk samples collected at seven sites along 125 $\mathrm{km}$ of Wairarapa shoreline. No significant level of genetic isolation-by-distance or discontinuity in haplotype distribution was observed. Instead, two sites in the middle of the region form a contact area where the dominant northern and southern haplotypes coexist. To investigate dispersal by drifting in the water, three experimental trials were conducted with hatchlings obtained from field-collected egg capsules. When subjected to wave forces, or deposited directly in flow, hatchlings remained suspended and were carried a short distance. However, hatchlings circulated in currents and left for a longer period (12 hours) were rarely found drifting after this period. These trials indicate that wave dislodgement and local flow regime may result in small-scale displacement of hatchlings, but longdistance dispersal by drift is unlikely. Plankton sampling was also conducted at two sites with four nearshore traps. The rare capture of a related Cominella virgata hatchling supports the finding that hatchlings can be dislodged, but prolonged drift cannot be inferred. The findings from this study support the assumption that crawling is the dominant dispersal mechanism for C. maculosa. Crawling 
between sites best explains the blending of haplotypes in the middle of the Wairarapa and the genetic differentiation between populations. Crawling-mediated connectivity is unlikely to occur at the ecological scale; therefore populations are expected to be demographically isolated. The results of this research support the general findings in the literature that populations of direct developing species are often demographically isolated and have low levels of genetic connectivity. 


\section{Table of Contents}

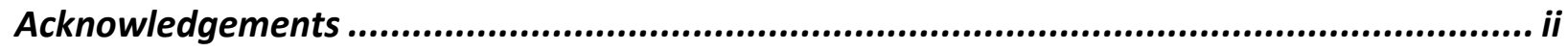

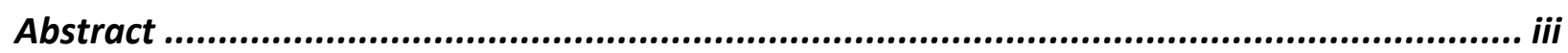

Table of Contents..........................................................................................

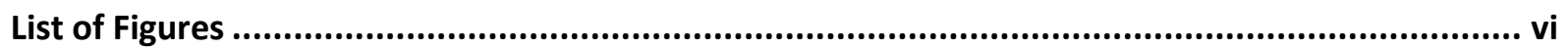

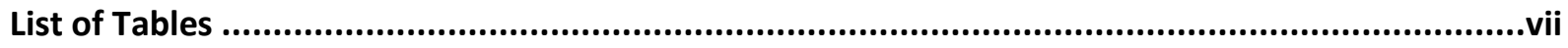

Chapter 1 Population Connectivity in the Marine Environment ...................................... 1

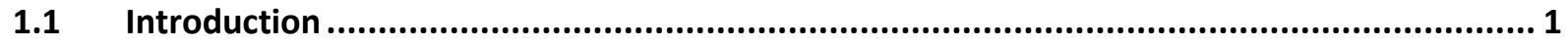

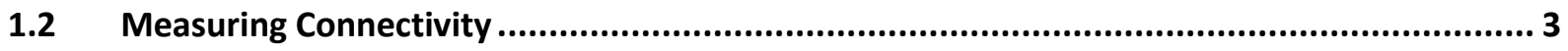

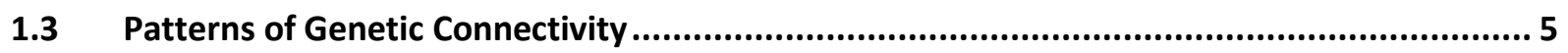

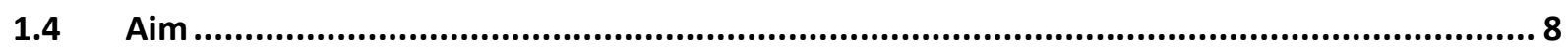

Chapter 2 Genetic Connectivity in a Direct Developing species, Cominella maculosa .......... 10

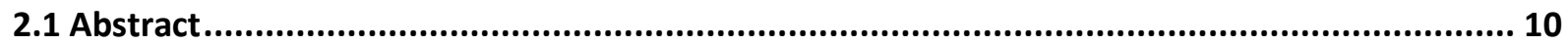

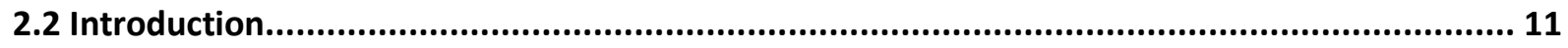

2.3 Spotted Whelk Connectivity on the North Island ................................................................. 13

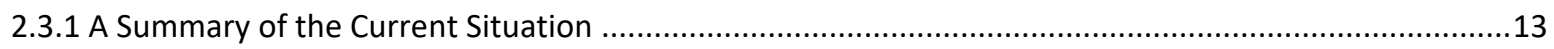

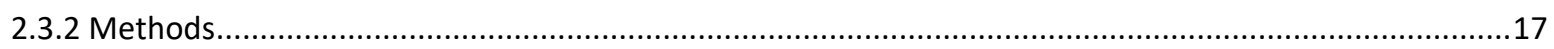

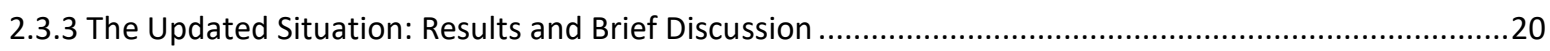

2.4 Fine Scale Connectivity along the Wairarapa Coast .......................................................... 27

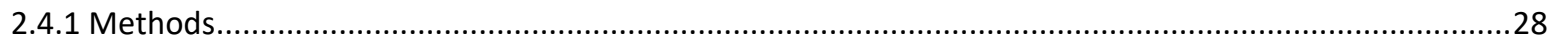

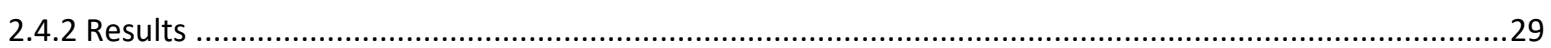

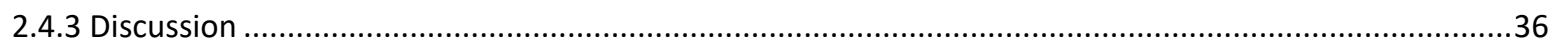

Chapter 3 Dispersal Potential for Cominella maculosa Hatchlings by Drifting..................... 41

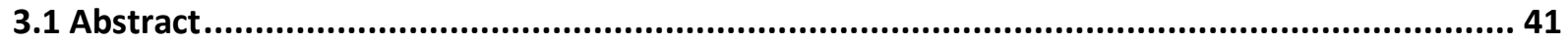

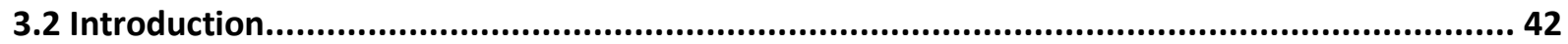

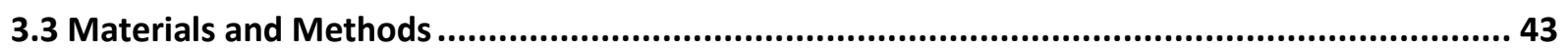

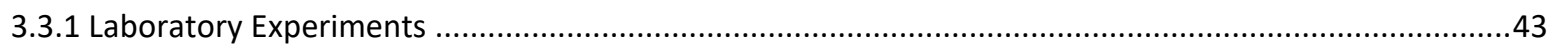

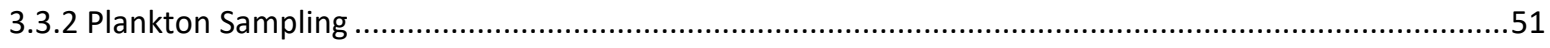

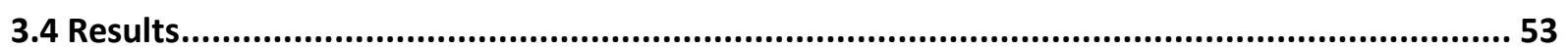

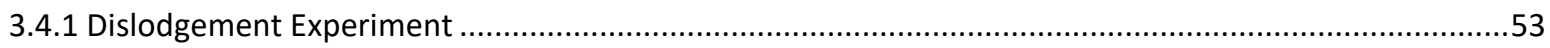

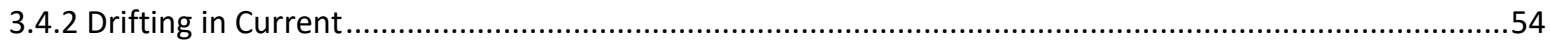

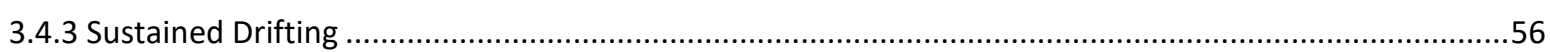

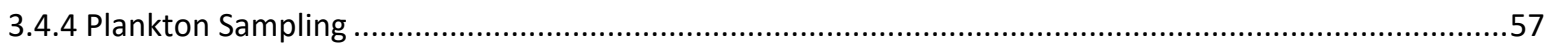

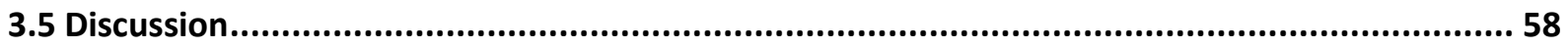

Chapter 4 General Discussion ................................................................................. 64

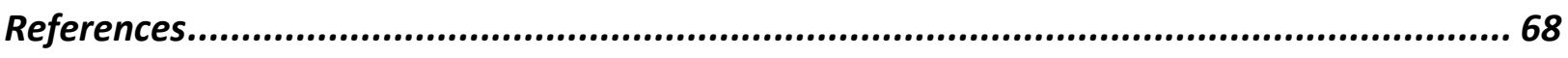

Appendix Mismatch distributions for combined Wairarapa populations and separated by populations. ...... 77 


\section{List of Figures}

Figure 1.1 Three patterns of population structure that can occur throughout a species range.

Figure 1.2 Four population structures that could occur for a coastal species dispersing by intermittent rafting

Figure 1.3 The spotted whelk, Cominella maculosa

Figure 2.1 A) Major currents around the coast of New Zealand. B) Biogeographic provinces and regions identified for mainland New Zealand.

Figure 2.2 Haplotype distribution of a 610bp CO1 fragment for Cominella maculosa. A) Haplotype distributions for original 17 locations. B) Haplotype distributions with new site locations.

Figure 2.3 Rarefaction curve for Cominella maculosa sampled in the North Island and Nelson 20

Figure 2. 4 Haplotype network for a 610bp fragment of $\mathrm{CO} 1$ gene from Cominella maculosa sampled in the North Island and Nelson. A) The original network for 17 sample locations. B) Minimum spanning network created in PopART using expanded dataset from 22 locations.

Figure 2. 5 Distribution of $\mathrm{CO} 1$ haplotypes for Cominella maculosa. Inset is the North Island distribution found in Figure 2. 2B. Expanded is the Wairarapa Coast distribution

Figure 2.6 Rarefaction curve for haplotypes sampled along the Wairarapa of the North Island

Figure 2.7 Haplotype diversity versus percentage nucleotide difference plots. A) Cominella maculosa groups reported in this study and B) other New Zealand species and direct developing species found globally.

Figure 2. 8 Minimum spanning network for $\mathrm{CO} 1$ haplotypes from Cominella maculosa. A) Network for samples long the Wairarapa Coast of the North Island. B) Network for all North Island and Nelson samples discussed in this study

Figure 2.9 Bathymetry around at the Cook Strait and Wairarapa Coast of the North Island... 39

Figure 2.10 Variable coastlines of New Zealand through over the last six million years (Mya). 40

Figure 3.1 Dislodgement experiment diagram $(\mathrm{mm})$ with inset of concurrent replicates at shallow depth

Figure 3.2 Drift in current experiments. A) Side view diagram with bucket and outflow trap dimensions $(\mathrm{mm})$. B) Top view of the fast treatment for the circular water current experiment. C) Three treatments running concurrently.

Figure 3.3 Experimental set up for the sustained drifting experiment. A) Diagram showing jar dimensions, water level created with $3 \mathrm{~L}$ of water, and position of air tube $(\mathrm{mm})$. B). Mixing treatments were created by connecting hoses to an air pump.

Figure 3.4 A) One of four intertidal plankton traps deployed at two sites in Wellington. B) Deployed in the field at Point Halswell during low tide

Figure 3.5 Average proportion of hatchlings captured in outflow traps for dislodgement experiments with wave and still treatments, separated by tank depth.

Figure 3.6 Average proportion of hatchlings captured in outflow traps for drift in current experiments with fast, slow, and still current treatments.

Figure 3.7 Hatchling dispersal after an hour in the still treatment for drift in current experiment ........ 56

Figure 3.8 Average proportion of hatchlings found drifting for sustained drifting experiments with strong, weak, and still mixing treatments. 


\section{List of Tables}

Table 2.1 Sample sites and molecular diversity indices for Cominella maculosa at 22 locations on the North Island and Nelson.

Table 2.2 Cominella maculosa haplotypes for a 610 bp CO1 fragment at North Island and Nelson locations

Table 2.3 Neutrality statistics and corresponding p-values for a $610 \mathrm{bp}$ fragment of the $\mathrm{CO} 1$ gene for Cominella maculosa sampled throughout the North Island and Nelson.

Table 2.4 Pairwise comparison from a 610bp fragment of the COI gene for Cominella maculosa sampled around the North Island and Nelson.

Table 2.5 Analysis of Molecular Variance and Spatial Analysis of Molecular Variance for population structure in C. maculosa using 610bp fragment of the COI gene. A) Analysis performed with original 17 locations. B) Analysis performed on expanded dataset of 22 locations.

Table 2.6 Sample information, genetic diversity indices, and neutrality tests for Cominella maculosa sampled along the Wairarapa Coast of the North Island of New Zealand.

Table 2.7 Haplotype counts from a 610 bp CO1 fragment for Cominella maculosa sampled along the Wairarapa Coast of the North Island.

Table 2.8 Reference information for points plotted in Figure 2. 7B

Table 2.9 Pairwise comparison $\left(\phi_{S T}\right)$ for Cominella maculosa sampled along the Wairarapa Cost of the North Island

Table 2.10 Analysis of molecular variance (AMOVA) and spatial analysis of molecular variance (SAMOVA) for C. maculosa sampled along the Wairarapa coast.

Table 3.1 Full GLMM model results for the dislodgement experiment.

Table 3.2 GLMM model results for the drift in current experiment. 55

Table 3.3 GLM model results for the sustained drift experiment. 57 


\section{Chapter 1 \\ Population Connectivity in the Marine Environment}

\subsection{Introduction}

The spatial distribution and temporal stability of a population is influenced by life history traits, habitat characteristics, individual interactions with conspecifics and heterospecifics, and unpredictable environmental conditions. Within the range of a species distribution, populations can be defined as a group of individuals that live close enough together to facilitate intraspecific interactions and random mating (Waples and Gaggiotti 2006). The demographic and genetic aspects of each population can be influenced by the exchange of gametes, larvae, juveniles, or adults between populations. This linking of populations through dispersal is called population connectivity (Lowe and Allendorf 2010). Connectivity can prevent local extinction, facilitate recolonization of habitat, increase adaptability, and prevent genetic divergence through isolation (Brown and Kodric-Brown 1977, Lowe and Allendorf 2010, Turgeon and Kramer 2012, Ovenden 2013).

The demographic rates of a population (birth, death, reproduction, immigration) operate over the relatively short generational time frame that influences the population's growth and stability at an ecological scale. Demographic connectivity is the measure of influence that dispersal creates on the demographic rates and intraspecific interactions of populations (Lowe and Allendorf 2010, Schaub et al. 2011). Because individuals compete for resources and interact with conspecifics, demographic connectivity is influenced by total population and the effects of immigration will be relative to preimmigration population size (Waples and Gaggiotti 2006, Ovenden 2013). When population sizes are known, an immigration rate of $10 \%$ is generally considered the threshold at which demographic connectivity is achieved (Waples and Gaggiotti 2006, Ovenden 2013). A collection of demographically connected populations is referred to as a metapopulation (Levins 1970). Metapopulation processes are beyond the scope of this paper, but can be influenced by landscape features, habitat patchiness, species dispersal potential, and habitat quality (Hanski and Gilpin 1991, Kritzer and Sale 2004). Detecting demographic connectivity can identify source-sink dynamics that can predict local extinction and recolonization probabilities. Conversely, identifying demographically isolated populations is important for preventing overharvest of resources such as fish stocks. 
While demographic connectivity considers populations at an ecological scale, genetic connectivity describes the degree to which gene flow through dispersal affects a population on the evolutionary time scale (Lowe and Allendorf 2010). Unlike demographic connectivity, genetic connectivity is not influenced by population size and is dependent on the reproductive success of individuals (Lowe and Allendorf 2010, Ovenden 2013). A migration of 10 reproductively successful individuals per generation can maintain genetic homogeneity between large or small populations (Lowe and Allendorf 2010). However, if the migrants carry an advantageous allele, on which the process of selection can act, then the allele may spread with as little as one migrant every 10 generations (Rieseberg and Burke 2001). Genetic differentiation is measured from 0 to 1 by the family of F-statistics (Wright 1951, Holsinger and Weir 2009). Higher values reflect a restriction of gene flow while lower values reflect on-going reproductively successful migrants. Restricted gene flow allows the processes of drift and mutation to operate independently, which results in the accumulation of new alleles and changes in the frequencies of shared alleles (Slatkin 1987). The longer gene flow is restricted, the greater the level of genetic differentiation will become between populations. Prolonged periods of restricted gene flow can eventually lead to speciation (Slatkin 1987). The strength of genetic connectivity can also influence the probability of populations experiencing inbreeding depression or adapting to changing environmental conditions (Mills and Allendorf 1996, Hauser et al. 2002).

While genetic and demographic connectivity are both influenced by dispersal rates, the differing effect of population size and necessity of reproductive success on each type of connectivity means that detecting connections at one level does not ensure connectivity is occurring at the other level. Since very few migrants are required for genetic connectivity, it is generally accepted that populations exhibiting strong genetic differentiation are also not exchanging migrants at the level required to create demographic connectivity (Ovenden 2013). However, a similar inference cannot be made when genetic connectivity is detected. The genetic similarity created by the immigration of 10 individuals per generation would need to occur in a population of 101 individuals to affect the vital rates of the population. Immigration of 10 individuals into a larger population would not achieve the $10 \%$ proportion of migrants required for demographic connectivity. Populations that exhibit genetic connectivity without demographic connectivity are very difficult to detect. Populations exhibiting this "crinkled connectivity" should not be managed as one stock, regardless of the genetic connectivity, since overharvest of demographically isolated populations could cause the collapse of one or both of the populations (Waples 1998, Ovenden 2013). Ironing out crinkled populations will require the creation of demographic models on which genetic predictions can be tested (Ovenden 2013).

As the majority of marine species disperse gametes, fertilized eggs, or larvae into the water column to drift in the plankton, the dispersal of these offspring through large, connected bodies of water was 
traditionally thought to be unconstrained. However, realized dispersal of individuals is influenced by trans-oceanic currents, seasonal currents, local eddies, and environmental conditions (Palumbi 1994, Gilg and Hibish 2003, Galindo et al. 2006, Selkoe et al. 2010). Species-specific characteristics, such as swimming capability and developmental history, also have a strong influence on population connectivity (Palumbi 1994, Higgins et al. 2013). Rather than acting as passive particles, many larvae are capable of changing their position in the water column which may greatly change the direction and speed of dispersal (Shanks 1986, Levin 2006). The length of time larvae remain in the water column varies widely between species, with non-feeding lecithotrophic larvae generally settling faster than feeding planktotrophic larvae. Increased time spent in the water column can subject larvae to possible long-distance dispersal, but the chance of being dispersed into unsuitable habitat or becoming prey is also increased. Isotopic analysis has detected self-recruitment occurring more frequently than expected in many planktonic dispersing taxa (Almany et al. 2006, Manríquez et al. 2012), which can greatly alter the realized dispersal of the species. Therefore, fewer populations are considered to be as "open" as previously believed. Conversely, species that lack planktonic larvae, direct developers, are expected to have low dispersal capabilities. Yet, genetic analysis has detected greater than expected movement between populations for some direct developing species (e.g. Nikula et al. 2010).

\subsection{Measuring Connectivity}

Capture-mark-recapture (CMR), radio telemetry, and GPS tracking are common methods for directly observing movement for terrestrial species (e.g. Elliot et al. 2014, Fattebert et al. 2015). GPS and satellite trackers are unable to transmit through water, but longer battery life and automatic detachment technologies are increasing their use in marine research. Satellite tags are becoming increasingly common for tracking large marine species, such as sharks, billfish, and marine mammals (Gunn and Block 2001, Ortiz et al. 2003, Vincent et al. 2002, Weng et al. 2007, Andrews et al. 2008, Bonfil et al. 2010). The large size of these tags limits their use to larger mobile species, so it is no surprise that the data often elucidates migration patterns of adults rather than dispersal events of offspring. Dispersal events are difficult to track due to the prevalence of small larvae, high mortality rates, and the vast ocean area. Off-bottom collectors and plankton sampling have been used to identify the presence of larval molluscs in the water column of near-shore habitat, but the source and fate of these individuals can rarely be directly tracked (Martel and Chia 1991a, McQuaid and Phillips 2000, Cañete et al. 2007). Artificial tags have been used with CMR methods to elucidate adult dispersal abilities for multiple gastropod species (reviewed by Henry and Jarne 2007) and reproductive effort for hawksbill sea turtles (Eretmochelys imbricata) (Prince and Chaloupka 2012). Chemical tags are commonly used to measure growth by marking or staining the hard structure of an individual (e.g. otolith, shell) (Wilson et al. 1987, Moran 2000, van der Geest et al. 2011). While these tags can also be 
used to batch mark larvae for dispersal studies, tracking the end fate of the offspring remains difficult (reviewed by Thorrold et al. 2002). Due to high larval mortality and large potential dispersal distances, batch marking appears best suited to quantifying local recruitment of larvae (e.g. Almany et al. 2007).

Naturally occurring differences in chemical isotope compositions creates an "isoscape" through which individuals travel (Reichlin et al. 2010). The continuously growing structures of an animal (e.g. otolith, shell) can reflect the isotopic composition of the environment in which it was formed; acting as a record of an individual's movement (Reichlin et al. 2010, Hussey et al. 2012, Schmidt et al. 2014, West et al. 2006). Assuming a settlement or hatchling mark can be identified on the structure, different environmental signatures before this mark can indicate a dispersal event. The ability to accurately locate natal origins requires that the chemical signature of the natal site is known and that it differs from the settlement location. Chemical analysis was able to detect both dispersal and self-recruitment in the common triplefin fish, Forsterygion lapillum, (Shima et al. 2015) and in two mussel species, Mytilus californianus and M. galloprovincialis (Carson et al. 2011). The inability to detect movement may confirm a lack of demographic connectivity, but inferences about genetic connectivity should be made with caution. Since genetic connectivity occurs over long evolutionary time scales and can be highly influenced by sporadic long distance dispersal events, gene flow does not need to be continually occurring and could easily be missed when observing the "normal" conditions of undisturbed populations (Slatkin 1987, Johnson and Black 1995, Jacobson and Pres-Neto 2010).

Indirect measures of connectivity using genetic markers is becoming one of the most common methods for managing fisheries stocks, developing marine reserves, and understanding the processes of speciation (Bell 2012, Donald et al. 2015, Ovenden 2015). The information gained from molecular studies is dependent on the marker that is used (Féral 2002, Hall and Beissinger 2014). Markers related to functioning genes (e.g. allozymes) are subjected to purifying selection and accumulate differences at a slower rate than markers found in the neutral areas of the genome (e.g. microsatellites). Markers from the nuclear genome (nuDNA) undergo meiotic recombination which can create homogeneity between populations faster than markers from the non-recombinant mitochondrial genome (mtDNA). The biparental inheritance of nuDNA increases the number of alleles available for analysis and reflects the influence of both sexes in connectivity. The maternally inherited, circular mtDNA produces only one allele per individual and only reflects long-term gene flow of female lineages. Ideally, markers from both genomes are used to detect historic patterns of connectivity (phylogeography) and contemporary gene flow (population genetics). While it may seem that contemporary gene flow would be of the greatest interest to managers, historic patterns of connectivity can be used to estimate past demographic trends such as bottlenecks or rapid expansions (Drummond et al. 2005, Ho and Shapiro 
2011). Relating these demographic events to past environmental conditions can facilitate a better understanding of how populations will respond to future changes.

Theoretically, the number of migrants $(\mathrm{Nm})$ between populations can be calculated from the measure of genetic differentiation (Wright 1951, Slatkin 1987, Mills and Allendorf 1996). The method of converting $\mathrm{F}_{\mathrm{ST}}$ into $\mathrm{Nm}$ is based on Wright's island model (Wright 1931). The assumptions of this model (no mutation or selection, infinite populations, equal dispersal probability) are often violated, reducing the confidence of the estimate (Whitlock and McCauley 1999). Additionally, the non-linear relationship between $\mathrm{F}_{\mathrm{ST}}$ and $\mathrm{Nm}$ produces problems when differentiation is less than 0.03 (Lowe and Allendorf 2010). For an $F_{s t}=0.02$, the estimated number of migrants may lie anywhere between 12 and 10,000 (Palumbi 2003). Populations exhibiting such low levels of differentiation are well connected genetically, but demographic connectivity cannot be inferred. This is the gray area in which the "crinkled" populations exist. The use of multiple methods could clarify the presence of genetic and demographic decoupling. Such an example can be found in the cephalopod Macroctopus maorum around Tasmania. Chemical analysis of stylets suggested discrete demographic structure, but microsatellite analysis indicated the species was well connected genetically (Higgins et al. 2013). Ideally, estimates of vital rates would produce demographic models that could be used to test predictions of genetic connectivity and clarify the grey area of low molecular differentiation measures (Ovenden 2013).

\subsection{Patterns of Genetic Connectivity}

Patterns of genetic connectivity are influenced by the life history of the species, habitat quality, habitat patchiness, and random events. In the marine environment, it is intuitive to expect that the longer larvae drift in the water column the more likely it is to observe population connectivity. While pelagic larval duration (PLD) has been negatively correlated to population differentiation for many species (Bohonak 1999), a meta-analysis of 300 studies indicates PLD is often a poor predictor of connectivity (Weersing and Toonen 2009). In fact, the molecular marker used to test connectivity was the best predictor of differentiation, with mtDNA producing higher values of $F_{S T}$ than microsatellites and allozymes (Weersing and Toonen 2009). That is not to say that all studies should use only mtDNA. As previously mentioned, each marker can inform different aspects of a species past and contemporary connectivity. Differing patterns of connectivity between markers may well be more informative about the life history of a species than the occurrence of similar patterns.

The most extreme pattern of genetic connectivity is the one migrant every 10 generations required to spread an advantageous allele. Complete isolation of nearby populations is rare, but even low levels of gene flow between populations can cause significant differentiation between geographically separate 
populations (Figure 1.1A). Patterns of distinct populations are found in species with low dispersal potential (e.g. Cumming et al. 2014) or specific habitat requirements (e.g. estuarine clams, Ross et al. 2012). When viewed from a larger spatial scale, distinct populations may produce an isolation-bydistance (IBD) pattern where neighbour populations are more similar to each other than to populations farther away (Figure 1.1B). Patterns of IBD occur when dispersal events take place between nearby populations more frequently than between distant populations and are common for weakly dispersing species (Bird et al. 2007, Veale and Lavery 2012, Muteveri et al. 2015). Finally, species that are able to exchange genes between all locations exhibit a pattern called panmixia (Figure 1.1C). Panmictic populations are genetically similar to each other and will exhibit the low levels of differentiation where demographic connectivity may or may not occur. Therefore, a panmictic population requires a more detailed level of investigation to determine the level of demographic connectivity. Using multiple molecular markers can identify historic or contemporary patterns of differentiation. Panmixia across a large distribution using a conservative marker (e.g. allozyme or mtDNA) may indicate historic connectivity, but may not reflect the contemporary connectivity of neutral nuDNA markers (e.g. microsatellites). Gardner et al. (2010) suggest accepting a panmictic pattern only when a large number of populations (>20) have been sampled throughout the known distribution of the species and the pattern is suggested by multiple markers.
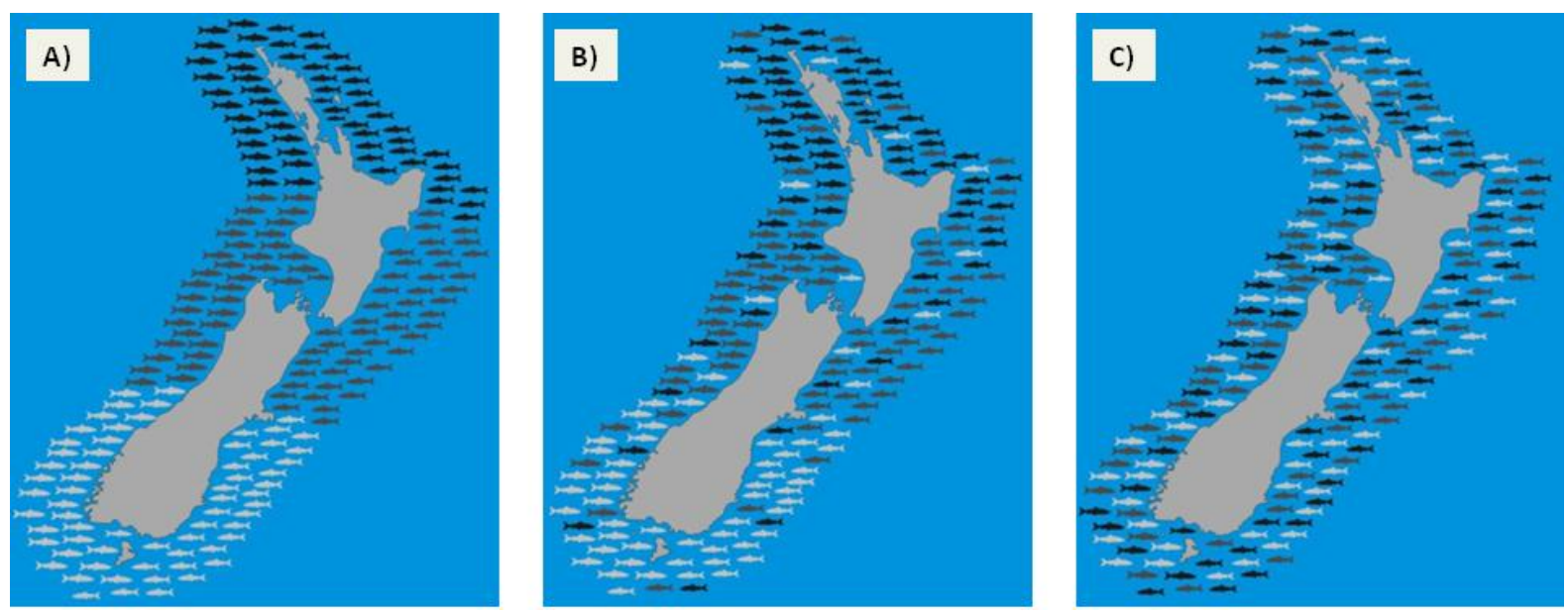

Figure 1.1 Three patterns of population structure that can occur throughout a species range. A) Genetically disconnected populations experiencing extremely low levels of gene flow (distinct). B) High gene flow with nearest neighbours but low gene flow with distant populations (isolation-by-distance). C) High gene flow and strong genetic connectivity (panmixia). Figure adapted from Laikre et al. 2005.

Unlike planktonically dispersing species, direct developing species complete development in a brood chamber or egg capsule before emerging as fully formed miniature adults. These species are often associated with the benthos and exhibit low vagility. Unsurprisingly, the majority of these species exhibit genetic patterns of distinct populations and IBD. These species likely disperse across inhospitable habitat by chance and then successfully settle into pockets of favourable habitat in a 
"stepping stone" pattern (Palumbi 2003). Direct-developers often have widespread distributions separated by large distances of open water (Johannesson 1988, Barbosa et al. 2013). The most common explanation presented to explain the presence of direct developing species in "far flung" locations is that they have attached themselves to floating substrata and rafted on the water (Johannesson 1988, Hoskin 1997, Thiel and Gutow 2005). Patterns of genetic differentiation are able to suggest when such dispersal pathways are occurring. Intermittent rafting dispersal can create intermediate connectivity in species expected to have low connectivity (Thiel and Haye 2006). Depending on the configuration of the currents being used for rafting, an IBD pattern can either be enforced or disrupted (Figure 1.2, Thiel and Haye 2006). A pattern of IBD in a direct developing species is to be expected, so rafting dispersal using alongshore currents may not be detected. However, a disruption to the IBD pattern could be indicative of this alternative dispersal pathway.
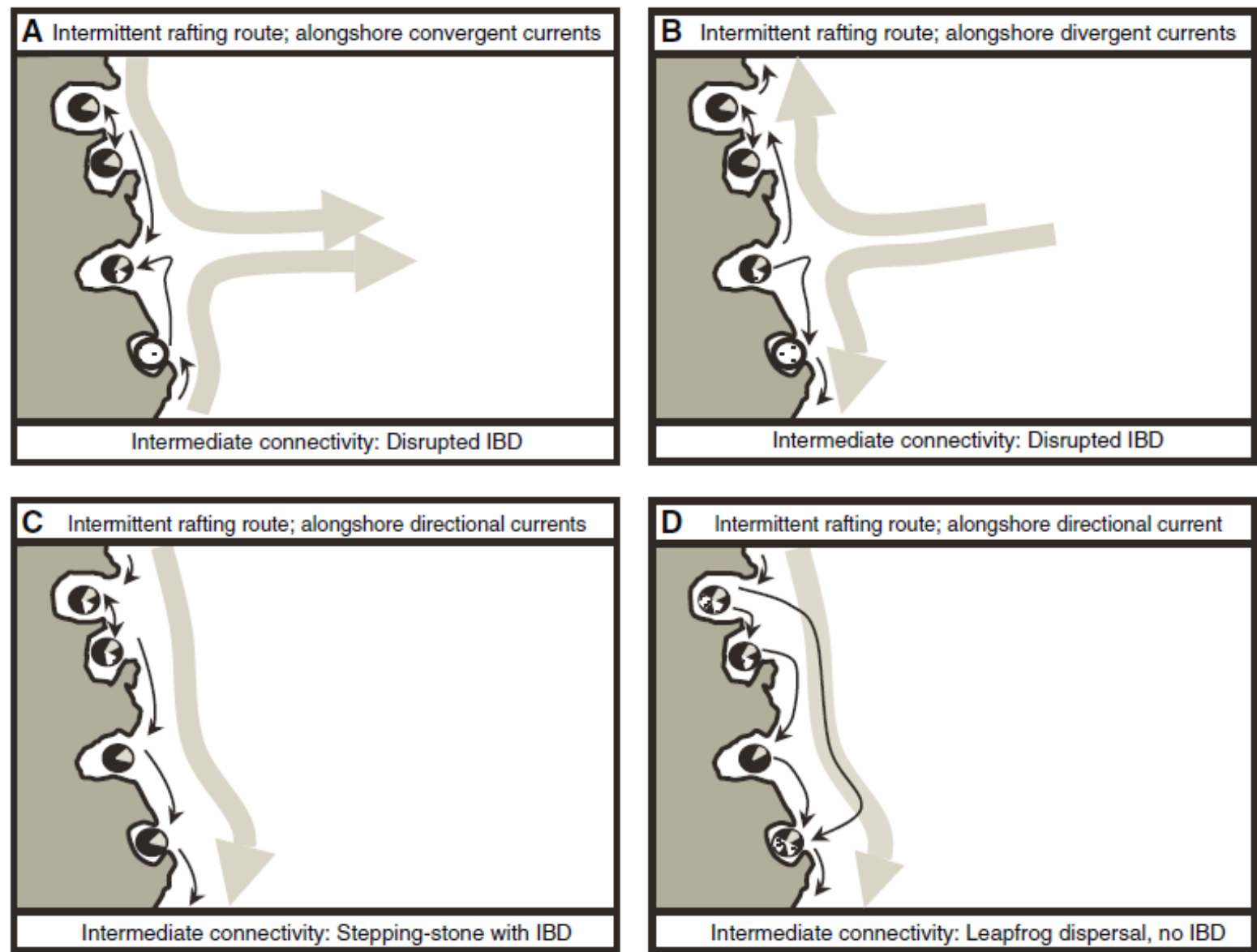

Figure 1.2 Four population structures that could occur for a coastal species dispersing by intermittent rafting. Isolation-by-distance patterns are expected to be disrupted if dispersal occurs along convergent (A) or divergent (B) currents. Intermittent rafting on alongshore currents can either maintain IBD patterns (C) or disrupt IBD patterns by bypassing neighbour populations and settling at more distant locations (D). Figure taken from Thiel and Haye 2006. 


\subsection{Aim}

The spotted whelk (Cominella maculosa) is an endemic, direct developing gastropod found throughout the North Island, the top of the South Island, and the Chatham Islands (Figure 1.3). This whelk is a carnivorous scavenger found in rocky intertidal and subtidal habitats (Morton and Miller 1968). The continuous distribution of the spotted whelk is ideal for investigating realized dispersal of a species with low dispersal potential. Genetic analysis of North Island populations identified several locations where the IBD pattern was disrupted by a genetic disjunction over a short distance (Fleming et al. in prep). Recently, direct developing gastropod species that are highly associated with bull kelp (Durvillaea antaractica) have been shown to disperse on the holdfasts of detached kelp (Cumming et al. 2014). However, spotted whelks are not associated with algae, so the potential for rafting should be quite limited. Rafting is not the only method by which species without planktonic larvae can disperse. Passive drifting by unattached individuals could lead to a similar disruption in the IBD pattern and contribute to wide spread haplotype sharing. Several mollusc species have been observed to drift using gas bubbles (Cañete et al. 2007) and mucus threads (Vahl 1983, Cummings et al. 1993, Martel and Diefenbach 1993). The tiny C. maculosa hatchlings have been observed to briefly float when dislodged in the lab environment, which indicates a potential for drifting dispersal.

Examining dispersal at a small spatial scale can provide insight into the dispersal mechanisms that facilitate greater than expected realized dispersal. Studies of direct developing connectivity at a fine scale are relatively rare, but indicate that populations are often highly differentiated and influenced by temporally stable alongshore currents (Hoskin 1997, Hoskin 2000). The aim of this study was to investigate the genetic pattern of $C$. maculosa at a fine spatial scale to determine if crawling is the main dispersal mechanism of if an alternative dispersal strategy is operating. Genetic analysis at one of the genetically disjunct regions was conducted in Chapter 2 . Large sample sizes were collected at a fine spatial scale to determine if an IBD pattern is actually occurring, if a barrier to crawling dispersal is operating, or if dispersal is facilitated by a mechanism other than crawling. Experiments and field samplings were conducted in Chapter 3 to determine if hatchling dislodgment and drifting could act as an alternative dispersal strategy to crawling along the coast. 

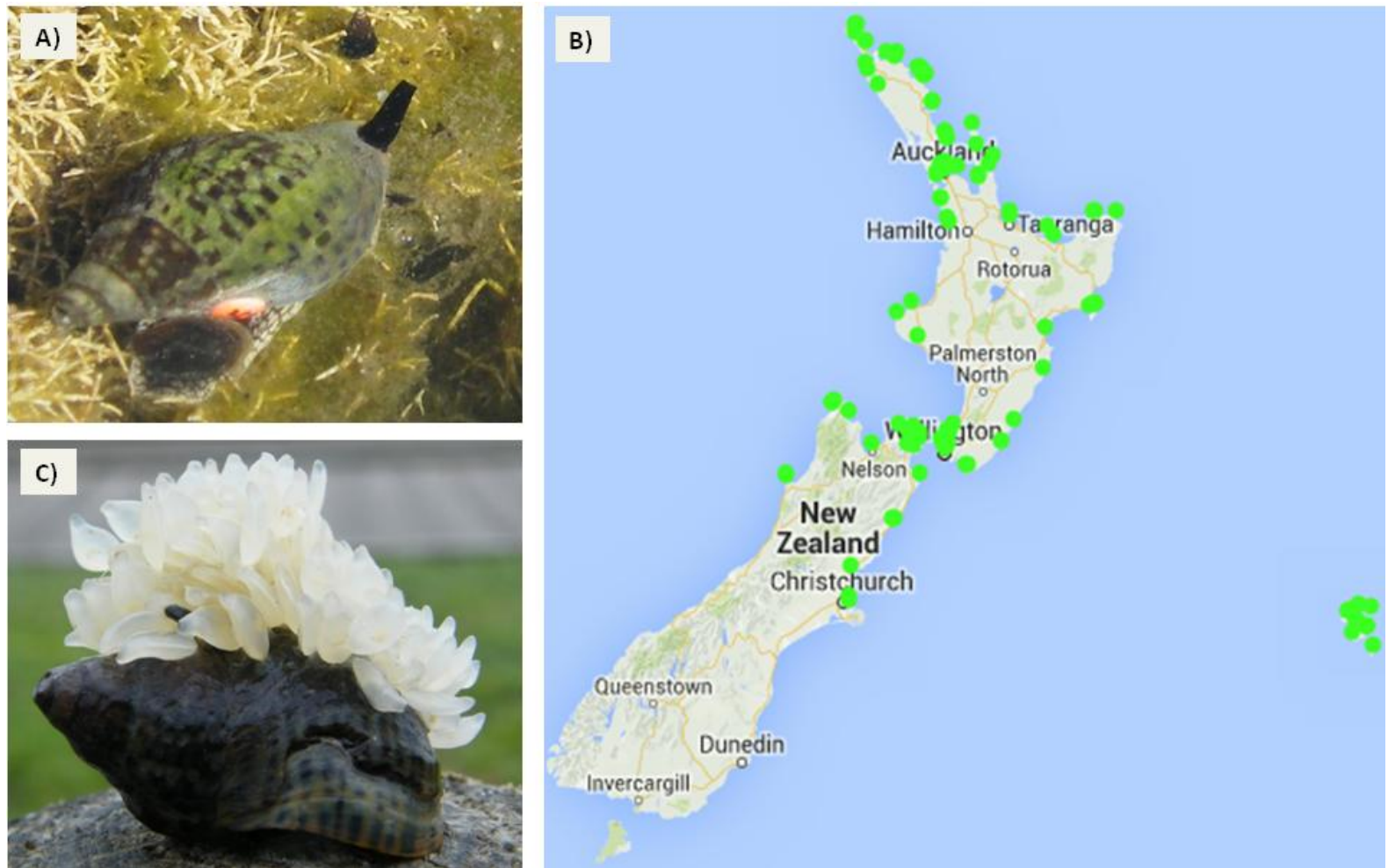

Figure 1.3 The spotted whelk, Cominella maculosa A) Tagged adult in a tide pool with coralline turf. B) Egg capsules attached to another adult whelk during communal laying. C) Location for all collections of spotted whelks held in the Museum of New Zealand Te Papa Tongarewa. Distribution map sourced on 21/4/2016 from http://collections.tepapa.govt.nz/taxon/49444. 


\section{Chapter 2 \\ Genetic Connectivity in a Direct Developing species, Cominella maculosa}

\subsection{Abstract}

Species with low vagility and direct development are expected to have limited dispersal potential. This assumption is often consistent with the levels of genetic differentiation reported for direct developers. A recent genetic study of the endemic, direct-developing spotted whelk, Cominella maculosa, identified genetic structuring of populations throughout the North Island range. Three locations also had significant genetic disjunctions over a small spatial scale. Here, fine scale sampling was undertaken around one of those breaks, along the Wairarapa coast, to clarify whether the previous findings were either due to small sample sizes along an IBD pattern or if they reflected historic barriers to dispersal. Sequencing of mitochondrial DNA from the cytochrome $c$ oxidase subunit 1 (CO1) gene was used on large sample sizes to determine the extent of a southern population and its disconnection from the northern populations. Sequences from seven locations spread across $125 \mathrm{~km}$ were used to determine diversity indices, conduct pairwise comparisons, run analysis of molecular variance tests, and create a haplotype network. Pairwise comparisons indicated that the four northern sites were genetically differentiated from each other and from the southern sites. The three southern sites showed no genetic differentiation and consistently clustered into a strongly supported group. The southern populations were characterized by low haplotype and nucleotide diversity, small frequencies of private haplotypes, and high frequency of a shared southern haplotype. This southern haplotype was highly divergent from all northern haplotypes. The two sites located immediately north of the southern group lacked private haplotypes and contained high frequencies of the dominant northern and southern haplotypes. This blending of haplotypes could occur from a slow dispersal northward and/or southward by crawling along the coast. Since crawling dispersal is associated with discrete population structure, it is unlikely that the southern populations are genetically connected. Rather, the genetic similarity and low diversity of these southern populations is likely due to founding events by sporadic episodes of egg capsule rafting. 


\subsection{Introduction}

Phylogeography uses the spatial distribution of genetic information to investigate the processes that promote gene flow, isolate populations, and result in speciation. Species that are able to disperse between populations can facilitate genetic connectivity and contribute to increased diversity levels. Low levels of genetic differentiation may indicate demographic connectivity and a metapopulation network, but it may also reflect low dispersal rates that maintain genetic mixing while resulting in demographic isolation (Ovenden 2013). Gene flow can be limited by geographic barriers to dispersal, life history traits, and physical characteristics of a species. Genetically differentiated populations are unlikely to be demographically coupled and will function as separate groups. In the marine environment, understanding genetic connectivity is useful for aligning harvesting pressure to natural boundaries and preventing stock collapse from overharvest (Waples 1998, Ovenden et al.2015). Marine reserve networks are best designed when they facilitate connectivity for multiple species with varying life history strategies so both genetic and biological diversity can be conserved (Palumbi 2003, Bell 2008). Patterns of genetic connectivity can be used to test assumptions about dispersal or illuminate dispersal routes in environments where the direct observation of movements is difficult.

In New Zealand, species with planktonic dispersal strategies generally exhibit a negative correlation between genetic differentiation and pelagic duration (Ross et al. 2009). Species with direct development typically have patterns of low connectivity, with discrete populations creating an isolation-by-distance (IBD) pattern (Ross et al. 2009). Interestingly, both developmental strategies tend towards a broad pattern of clustering into northern and southern populations, with the Cook Strait region dividing the two groups (Ross et al. 2009, Trewick and Bland 2012). The location of the Cook Strait boundary is believed to occur at the South Island locations of Cape Campbell (east coast) and Westhaven (west coast) (Ross et al. 2009, Martin 2011, Wei et al. 2013). However, variable sampling scales and locations make accurate detection of the boundary difficult. The Cook Strait divide may be an artefact from sampling an IBD pattern at a large spatial scale (Rabone et al. 2015), it may reflect the historic presence of a land bridge between the two islands during the last glacial maximum (LGM) (Trewick and Bland 2012), or it may be the effect of upwelling processes acting on planktonically dispersing species (Ayers and Waters 2005).

Ocean currents are likely to influence population structure of planktonic dispersers, but they can also facilitate connectivity for direct developers when algae-associated species raft on detached algae caught in surface currents (e.g. Cumming et al. 2014). The Cook Strait differentiation may be strengthened by the East Cape Current that moves south before turning east at the mouth of the Cook Strait (Figure 2.1A). Transport within this current could promote dispersal from northern populations, 
but the offshore movement at the Cook Strait and the strong circular Wairarapa Eddy would prevent species from arriving at the South Island (Ross et al. 2009). Similarly, the East Cape Eddy in the north could transport oceanic dispersers offshore near the East Cape (Figure 2.1A). The East Cape Eddy may create the disjunction that has been identified at the East Cape (Stevens and Hogg 2004, Veale and Lavery 2012, Martin 2011, Will et al. 2011).
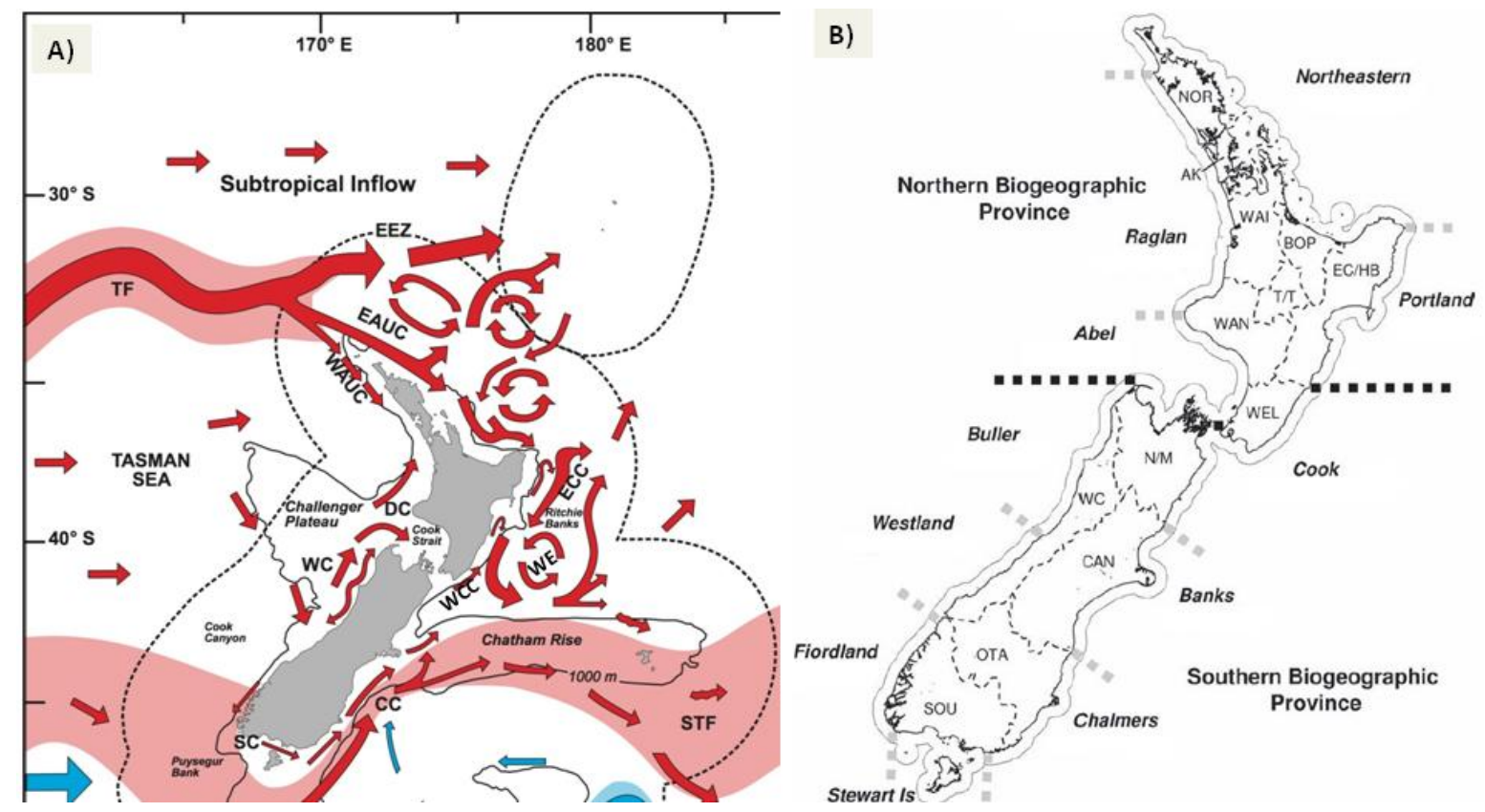

Figure 2.1 A) Map of New Zealand, with the exclusive economic zone (EEZ) in a dotted line, and surrounding surface currents. CC, Canterbury Current; DC, D'Urville Current; EAUC, East Auckland Current; ECC, East Cape Current; NCE, North Cape Eddy, SC, Southland Current; STF, Subtropical Front; WAUC, West Auckland Current; WC, Westland Current; WCC, Wairarapa Coastal Current; WE, Wairarapa Eddy. Image adapted from NIWA data. B) Biogeographic provinces (black dashed lines) and regions (grey dashed lines) identified for mainland New Zealand by Shears et al. (2008). Image from Shears et al. 2008.

Knowledge about biogeographic boundaries is useful for spatial planning and describing broad patterns in community structure (Figure 2.1B). The environmental forces influencing the distribution of species used to identify biogeographic regions are likely to influence genetic connectivity between populations as well. However, concordance between New Zealand's phylogeographic boundaries and the biogeographic regions is rare for most species (Ross et al. 2009). Concordance will be influenced by the type of molecular marker, sampling coverage, and the fact that the positions of the regional boundaries are only rough guides to community level changes. The ability to precisely define biogeographic boundaries of community structure requires fine scale sampling that has yet to be undertaken. The position of phylogeographic breaks will vary with life history traits, habitat preferences, and environmental conditions. However, the limited dispersal potential of direct developing species suggests fine scale sampling would identify genetic boundaries that could be used for comparison between multiple taxa. Such fine scale surveys have not, to my knowledge, been undertaken on the mainland of New Zealand. 
The direct-developing spotted whelk, Cominella maculosa, is an abundant scavenger of rocky intertidal habitats throughout New Zealand (Figure 1.3). A recent molecular survey of the North Island suggested discrete population structure, IBD pattern, and discordance with the biogeographic regions (Fleming et al. in prep). These findings are consistent with a species that is expected to disperse short distances by crawling along the shore. The study found three locations where genetic disjunctions occurred over a relatively small geographic scale $(<130 \mathrm{~km})$. All three disjunctions occurred at or near known biogeographic boundaries; one was located at the Portland/Northeastern boundary, one occurred south of the Portland/Cook boundary, and the third was located north of the Raglan/Abel boundary (Figure 2.1B). It is unclear whether the findings were an artefact of a small sample size bias along an IBD pattern of genetic structuring or if there were barriers to dispersal that have historically restricted gene flow. The aim of this study was to use large sample sizes and fine scale sampling to investigate the disjunction along the Wairarapa Coast, near the Portland/Cook biogeographic boundary, using DNA sequences from the mitochondrial cytochrome $c$ oxidase subunit 1 (CO1) gene. Observations of an IBD pattern or a barrier to dispersal will help to clarify the potential dispersal mechanisms of the species. During the course of investigating this Wairarapa Coast disjunction, opportunistic sampling was undertaken for addition to the North Island dataset (Fleming et al. in prep). The analysis of these new sites and a short summary of how they add to the Fleming et al. data set are discussed before the Wairarapa disjunction is presented.

\subsection{Spotted Whelk Connectivity on the North Island}

\subsubsection{A Summary of the Current Situation}

Cominella maculosa sampled at 17 locations around the North Island and Nelson showed discrete population structure with an isolation by distance pattern (Table 2.1, Figure 2.2A). Despite this discrete structuring, shared haplotypes were found at high frequencies in the Wellington region (Hap 1), the Auckland and Bay of Plenty regions (Hap 6), and between the two East Coast populations (Hap 27) (Table 2.2). Insignificant pairwise differentiation occurred between at least two neighbouring populations in these regions and between three populations found across the Auckland and Bay of Plenty regions. However, grouping these populations into clusters was not supported under tests for hierarchical structure. 
Table 2.1 Sample sites and molecular diversity indices for Cominella maculosa at 22 locations on the North Island and Nelson. Broad northern and southern groupings are defined by the location of the LGM maximum sea surface isotherm of $15^{\circ} \mathrm{C}$ (Barrows and Juggins 2005). Horizontal lines identify the N-S boundary between East Coast populations and Taranaki populations. Five new sites were added to the 17 previously analyzed locations from Fleming et al. (in prep). These new sites are $\mathrm{WB}, \mathrm{NA}, \mathrm{PB}$, and $\mathrm{WhB}$.

\begin{tabular}{|c|c|c|c|c|c|c|c|c|}
\hline Site Code & Sampling Sites & $\begin{array}{l}\text { Position } \\
\text { (Latitude, Longitude) }\end{array}$ & $\mathbf{n}$ & $\mathbf{S}$ & $\mathbf{H}_{\mathrm{p}}$ & $\mathbf{H}_{\mathrm{n}}$ & $\boldsymbol{h}$ & $\pi$ \\
\hline AMB & Matheson Bay, Northland & $36^{\circ} 18^{\prime} \mathrm{S}, 174^{\circ} 48^{\prime} \mathrm{E}$ & 10 & 5 & 1 & 4 & $0.7778(0.091)$ & $0.0030(0.002)$ \\
\hline ASB & Snells Beach, Northland & $36^{\circ} 25^{\prime} \mathrm{S}, 174^{\circ} 44^{\prime} \mathrm{E}$ & 20 & 3 & 1 & 4 & $0.2842(0.128)$ & $0.0006(0.001)$ \\
\hline $\mathrm{ARB}$ & Red Beach, Northland & $36^{\circ} 35^{\prime} \mathrm{S}, 174^{\circ} 42^{\prime} \mathrm{E}$ & 23 & 4 & 2 & 4 & $0.3202(0.121)$ & $0.0007(0.001)$ \\
\hline $\mathrm{AAB}$ & Army Bay, Northland & $36^{\circ} 35^{\prime} \mathrm{S}, 174^{\circ} 48^{\prime} \mathrm{E}$ & 24 & 3 & 1 & 4 & $0.3696(0.117)$ & $0.0006(0.001)$ \\
\hline WB & Bowentown, Waihi Beach, Bay of Plenty & $37^{\circ} 28^{\prime} 2 \mathrm{~S}, 175^{\circ} 59^{\prime} 8 \mathrm{E}$ & 11 & 6 & 2 & 4 & $0.4909(0.175)$ & $0.0024(0.002)$ \\
\hline BMM & Mt Maunganui, Bay of Plenty & $37^{\circ} 37^{\prime} \mathrm{S}, 176^{\circ} 10^{\prime} \mathrm{E}$ & 10 & 5 & 3 & 5 & $0.7556(0.130)$ & $0.0030(0.002)$ \\
\hline BMA & Maketu, Bay of Plenty & $37^{\circ} 44^{\prime} \mathrm{S}, 176^{\circ} 27^{\prime} \mathrm{E}$ & 26 & 5 & 2 & 6 & $0.7169(0.078)$ & $0.0015(0.001)$ \\
\hline BOM & Omaio, Bay of Plenty & $37^{\circ} 48^{\prime} \mathrm{S}, 177^{\circ} 37^{\prime} \mathrm{E}$ & 31 & 8 & 4 & 7 & $0.7742(0.056)$ & $0.0038(0.002)$ \\
\hline GTA & Te Aroroa, East Cape & $37^{\circ} 37^{\prime} \mathrm{S}, 178^{\circ} 23^{\prime} \mathrm{E}$ & 29 & 3 & 1 & 3 & $0.3941(0.094)$ & $0.0018(0.001)$ \\
\hline GTT & Tatopouri, Gisbourne & $38^{\circ} 39^{\prime} 7 \mathrm{~S}, 178^{\circ} 08^{\prime} \mathrm{E}$ & 29 & 4 & 0 & 2 & $0.0690(0.063)$ & $0.0005(0.001)$ \\
\hline MP & Mahia, Mahia Peninsula & $39^{\circ} 5^{\prime} 19 \mathrm{~S}, 177^{\circ} 55^{\prime} 4 \mathrm{E}$ & 25 & 8 & 1 & 4 & $0.3600(0.117)$ & $0.0023(0.002)$ \\
\hline NA & Port Ahuriri, Napier & $39^{\circ} 28^{\prime} 38 \mathrm{~S}, 176^{\circ} 53^{\prime} 46 \mathrm{E}$ & 24 & 1 & 1 & 2 & $0.0833(0.075)$ & $0.0001(0.000)$ \\
\hline PB & Pourere Beach, Hawke's Bay & $40^{\circ} 7^{\prime} 9 \mathrm{~S}, 176^{\circ} 52^{\prime} 29 \mathrm{E}$ & 24 & 4 & 0 & 2 & $0.0833(0.075)$ & $0.0005(0.001)$ \\
\hline WhB & Whangaehu Beach, Hawke's Bay & $40^{\circ} 24^{\prime} 16 \mathrm{~S}, 176^{\circ} 38^{\prime} 11 \mathrm{E}$ & 23 & 9 & 2 & 4 & $0.6047(0.079)$ & $0.0063(0.004)$ \\
\hline WCS & Castlepoint, Wellington & $40^{\circ} 51^{\prime} \mathrm{S}, 176^{\circ} 14^{\prime} \mathrm{E}$ & 28 & 9 & 2 & 4 & $0.7169(0.042)$ & $0.0065(0.004)$ \\
\hline WCP & Cape Palliser, Wellington & $41^{\circ} 36^{\prime} \mathrm{S}, 175^{\circ} 17^{\prime} \mathrm{E}$ & 27 & 1 & 1 & 2 & $0.1425(0.086)$ & $0.0002(0.000)$ \\
\hline WPH & Point Howard, Wellington & $41^{\circ} 15^{\prime} \mathrm{S}, 174^{\circ} 54^{\prime} \mathrm{E}$ & 21 & 0 & 0 & 1 & $0.0000(0.000)$ & $0.0000(0.000)$ \\
\hline WMP & Moa Point, Wellington & $41^{\circ} 20^{\prime} \mathrm{S}, 174^{\circ} 48^{\prime} \mathrm{E}$ & 19 & 1 & 1 & 2 & $0.1988(0.112)$ & $0.0003(0.000)$ \\
\hline WMA & Makara, Wellington & $41^{\circ} 13^{\prime} \mathrm{S}, 174^{\circ} 42^{\prime} \mathrm{E}$ & 20 & 0 & 0 & 1 & $0.0000(0.000)$ & $0.0000(0.000)$ \\
\hline NEL & Nelson & $41^{\circ} 16^{\prime} \mathrm{S}, 173^{\circ} 15^{\prime} \mathrm{E}$ & 26 & 8 & 4 & 6 & $0.6092(0.102)$ & $0.0031(0.002)$ \\
\hline TNP & New Plymouth & $39^{\circ} 03^{\prime} \mathrm{S}, 174^{\circ} 3^{\prime} \mathrm{E}$ & 31 & 1 & 1 & 2 & $0.2796(0.090)$ & $0.0005(0.001)$ \\
\hline \multirow[t]{4}{*}{ TMA } & Marokopa, Waitomo & $38^{\circ} 19^{\prime} \mathrm{S}, 174^{\circ} 42^{\prime} \mathrm{E}$ & 31 & 0 & 1 & 1 & $0.0000(0.000)$ & $0.0000(0.000)$ \\
\hline & Overall & & 512 & 41 & 31 & 41 & $0.8683(0.007)$ & $0.0060(0.003)$ \\
\hline & Northern Sites & AMB-MP,TMA & 269 & 30 & 19 & 28 & $0.8428(0.014)$ & $0.0041(0.002)$ \\
\hline & Southern Sites & NA-TNP & 243 & 21 & 12 & 16 & $0.6587(0.025)$ & $0.0055(0.003)$ \\
\hline
\end{tabular}

$n$, sample size; $S$, segregating sites; $H_{p}$, number of private haplotypes; $H_{n}$, number of haplotypes; $h$, haplotype diversity; $\pi$, nucleotide diversity 


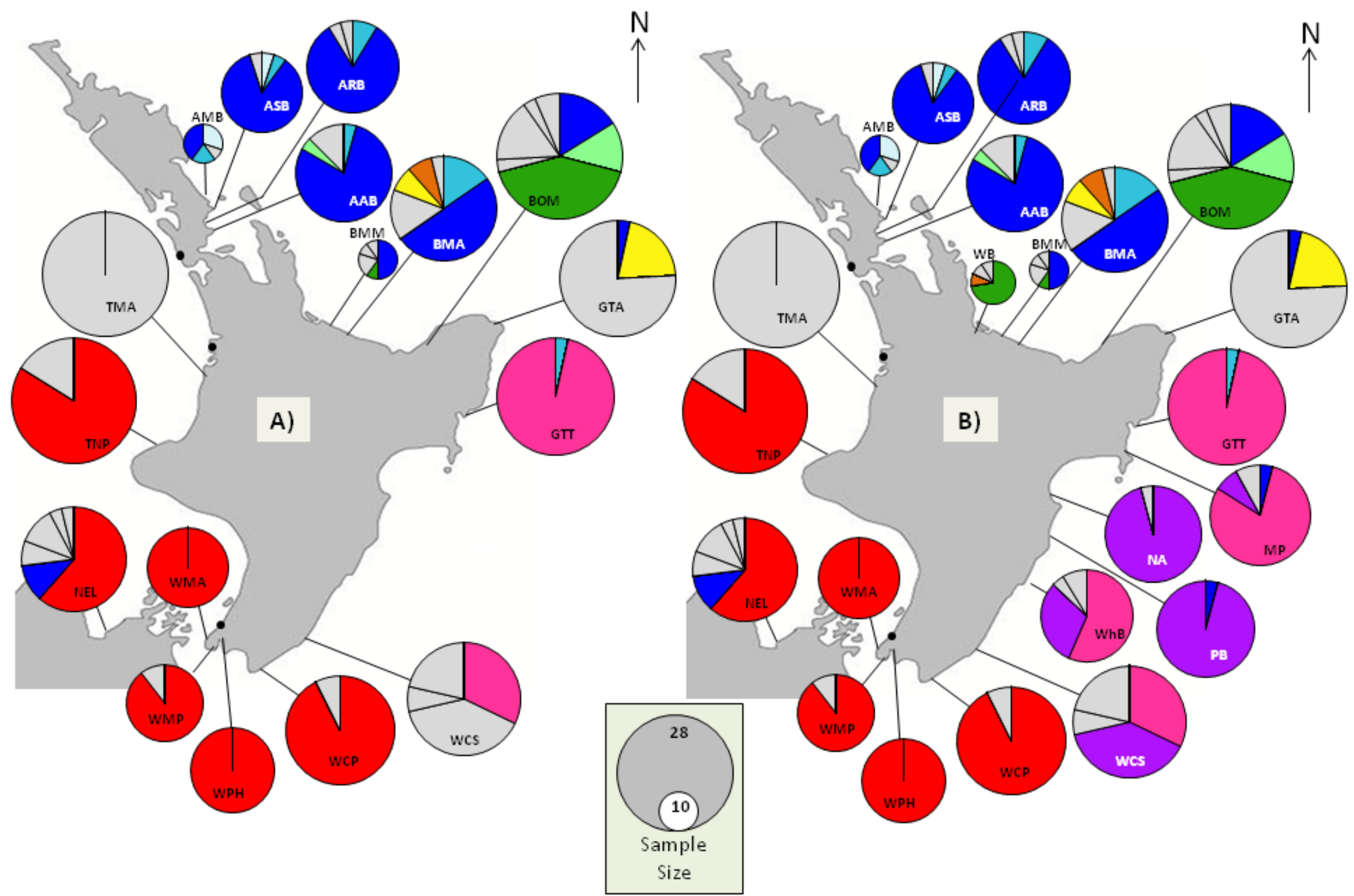

Figure 2.2 Haplotype distribution of a 610bp CO1 fragment for Cominella maculosa. Black dots represent locations where whelks were absent. Site codes are described in Table 2.1, sample sizes are indicated by circle size. Each colour represents a unique haplotype sequence shared with at least one other location. Grey colours are private haplotypes; unique haplotypes found only at that one location. A) Haplotype distributions for original 17 locations. B) Haplotype distributions with new site locations added: WB, MP, NA, PB, and WhB. 
Table 2.2 Cominella maculosa haplotypes for a 610 bp CO1 fragment at North Island and Nelson locations. Private haplotypes are in bold. Site codes and locations are described in Table 2.1. Sites have been separated by broad regional categories that are used in text. GTA is the only East Cape location and NEL is the only South Island location, hence they lack regional titles. Five new locations were added to 17 previously analyzed locations by Fleming et al. (in prep). New locations are WB, MP, NA, $\mathrm{PB}$, and WhB.

\begin{tabular}{|c|c|c|c|c|c|c|c|c|c|c|c|c|c|c|c|c|c|c|c|c|c|c|}
\hline & \multicolumn{4}{|c|}{ Auckland Region } & \multicolumn{4}{|c|}{ Bay of Plenty Region } & \multirow[b]{2}{*}{ GTA } & \multicolumn{6}{|c|}{ East Coast Region } & \multicolumn{4}{|c|}{ Wellington Region } & \multirow[b]{2}{*}{ NEL } & \multicolumn{2}{|c|}{ Taranaki } \\
\hline & AMB & ASB & ARB & $A A B$ & WB & BMM & BMA & Вом & & GT & MP & NA & PB & WhB & wCS & WCP & WPH & WMP & WMA & & TNP & TMA \\
\hline Hap_1 & 0 & 0 & 0 & 0 & 0 & 0 & 0 & 0 & 0 & 0 & 0 & 0 & 0 & 0 & 0 & 25 & 21 & 17 & 20 & 16 & 26 & 0 \\
\hline Hap_2 & 0 & 0 & 0 & 0 & 0 & 0 & 0 & 0 & 0 & 0 & 0 & 0 & 0 & 0 & 0 & 0 & 0 & 2 & 0 & 0 & 0 & 0 \\
\hline Hap_3 & 3 & 1 & 0 & 0 & 0 & 0 & 0 & 0 & 0 & 0 & 0 & 0 & 0 & 0 & 0 & 0 & 0 & 0 & 0 & 0 & 0 & 0 \\
\hline Hap_4 & 1 & 0 & 0 & 0 & 0 & 0 & 0 & 0 & 0 & 0 & 0 & 0 & 0 & 0 & 0 & 0 & 0 & 0 & 0 & 0 & 0 & 0 \\
\hline Hap_5 & 2 & 1 & 2 & 1 & 0 & 0 & 4 & 0 & 0 & 1 & 0 & 0 & 0 & 0 & 0 & 0 & 0 & 0 & 0 & 0 & 0 & 0 \\
\hline Hap_6 & 4 & 17 & 19 & 19 & 0 & 5 & 13 & 5 & 1 & 0 & 1 & 0 & 1 & 0 & 0 & 0 & 0 & 0 & 0 & 3 & 0 & 0 \\
\hline Hap_7 & 0 & 0 & 0 & 1 & 0 & 0 & 0 & 4 & 0 & 0 & 0 & 0 & 0 & 0 & 0 & 0 & 0 & 0 & 0 & 0 & 0 & 0 \\
\hline Hap_8 & 0 & 0 & 0 & 3 & 0 & 0 & 0 & 0 & 0 & 0 & 0 & 0 & 0 & 0 & 0 & 0 & 0 & 0 & 0 & 0 & 0 & 0 \\
\hline Hap_9 & 0 & 0 & 1 & 0 & 0 & 0 & 0 & 0 & 0 & 0 & 0 & 0 & 0 & 0 & 0 & 0 & 0 & 0 & 0 & 0 & 0 & 0 \\
\hline Hap_10 & 0 & 0 & 1 & 0 & 0 & 0 & 0 & 0 & 0 & 0 & 0 & 0 & 0 & 0 & 0 & 0 & 0 & 0 & 0 & 0 & 0 & 0 \\
\hline Hap_11 & 0 & 1 & 0 & 0 & 0 & 0 & 0 & 0 & 0 & 0 & 0 & 0 & 0 & 0 & 0 & 0 & 0 & 0 & 0 & 0 & 0 & 0 \\
\hline Hap_12 & 0 & 0 & 0 & 0 & 0 & 0 & 0 & 0 & 0 & 0 & 0 & 0 & 0 & 0 & 0 & 0 & 0 & 0 & 0 & 0 & 5 & 0 \\
\hline Hap_13 & 0 & 0 & 0 & 0 & 0 & 0 & 0 & 0 & 0 & 0 & 0 & 0 & 0 & 0 & 0 & 0 & 0 & 0 & 0 & 0 & 0 & 31 \\
\hline Hap_14 & 0 & 0 & 0 & 0 & 8 & 1 & 0 & 13 & 0 & 0 & 0 & 0 & 0 & 0 & 0 & 0 & 0 & 0 & 0 & 0 & 0 & 0 \\
\hline Hap_15 & 0 & 0 & 0 & 0 & 0 & 2 & 0 & 0 & 0 & 0 & 0 & 0 & 0 & 0 & 0 & 0 & 0 & 0 & 0 & 0 & 0 & 0 \\
\hline Hap_16 & 0 & 0 & 0 & 0 & 0 & 1 & 0 & 0 & 0 & 0 & 0 & 0 & 0 & 0 & 0 & 0 & 0 & 0 & 0 & 0 & 0 & 0 \\
\hline Hap_17 & 0 & 0 & 0 & 0 & 0 & 1 & 0 & 0 & 0 & 0 & 0 & 0 & 0 & 0 & 0 & 0 & 0 & 0 & 0 & 0 & 0 & 0 \\
\hline Hap_18 & 0 & 0 & 0 & 0 & 0 & 0 & 4 & 0 & 0 & 0 & 0 & 0 & 0 & 0 & 0 & 0 & 0 & 0 & 0 & 0 & 0 & 0 \\
\hline Hap_19 & 0 & 0 & 0 & 0 & 0 & 0 & 2 & 0 & 6 & 0 & 0 & 0 & 0 & 0 & 0 & 0 & 0 & 0 & 0 & 0 & 0 & 0 \\
\hline Hap_20 & 0 & 0 & 0 & 0 & 1 & 0 & 2 & 0 & 0 & 0 & 0 & 0 & 0 & 0 & 0 & 0 & 0 & 0 & 0 & 0 & 0 & 0 \\
\hline Hap_21 & 0 & 0 & 0 & 0 & 0 & 0 & 1 & 0 & 0 & 0 & 0 & 0 & 0 & 0 & 0 & 0 & 0 & 0 & 0 & 0 & 0 & 0 \\
\hline Hap_22 & 0 & 0 & 0 & 0 & 0 & 0 & 0 & 1 & 0 & 0 & 0 & 0 & 0 & 0 & 0 & 0 & 0 & 0 & 0 & 0 & 0 & 0 \\
\hline Hap_23 & 0 & 0 & 0 & 0 & 0 & 0 & 0 & 5 & 0 & 0 & 0 & 0 & 0 & 0 & 0 & 0 & 0 & 0 & 0 & 0 & 0 & 0 \\
\hline Hap_24 & 0 & 0 & 0 & 0 & 0 & 0 & 0 & 1 & 0 & 0 & 0 & 0 & 0 & 0 & 0 & 0 & 0 & 0 & 0 & 0 & 0 & 0 \\
\hline Hap_25 & 0 & 0 & 0 & 0 & 0 & 0 & 0 & 2 & 0 & 0 & 0 & 0 & 0 & 0 & 0 & 0 & 0 & 0 & 0 & 0 & 0 & 0 \\
\hline Hap_26 & 0 & 0 & 0 & 0 & 0 & 0 & 0 & 0 & 22 & 0 & 0 & 0 & 0 & 0 & 0 & 0 & 0 & 0 & 0 & 0 & 0 & 0 \\
\hline Hap_27 & 0 & 0 & 0 & 0 & 0 & 0 & 0 & 0 & 0 & 28 & 20 & 0 & 0 & 13 & 9 & 0 & 0 & 0 & 0 & 0 & 0 & 0 \\
\hline Hap_28 & 0 & 0 & 0 & 0 & 0 & 0 & 0 & 0 & 0 & 0 & 2 & 23 & 23 & 7 & 11 & 0 & 0 & 0 & 0 & 0 & 0 & 0 \\
\hline Hap_29 & 0 & 0 & 0 & 0 & 0 & 0 & 0 & 0 & 0 & 0 & 0 & 0 & 0 & 0 & 2 & 0 & 0 & 0 & 0 & 0 & 0 & 0 \\
\hline Hap_30 & 0 & 0 & 0 & 0 & 0 & 0 & 0 & 0 & 0 & 0 & 0 & 0 & 0 & 0 & 6 & 0 & 0 & 0 & 0 & 0 & 0 & 0 \\
\hline Hap_31 & 0 & 0 & 0 & 0 & 0 & 0 & 0 & 0 & 0 & 0 & 0 & 0 & 0 & 0 & 0 & 0 & 0 & 0 & 0 & 2 & 0 & 0 \\
\hline Hap_32 & 0 & 0 & 0 & 0 & 0 & 0 & 0 & 0 & 0 & 0 & 0 & 0 & 0 & 0 & 0 & 0 & 0 & 0 & 0 & 3 & 0 & 0 \\
\hline Hap_33 & 0 & 0 & 0 & 0 & 0 & 0 & 0 & 0 & 0 & 0 & 0 & 0 & 0 & 0 & 0 & 0 & 0 & 0 & 0 & 1 & 0 & 0 \\
\hline Hap_34 & 0 & 0 & 0 & 0 & 0 & 0 & 0 & 0 & 0 & 0 & 0 & 0 & 0 & 0 & 0 & 0 & 0 & 0 & 0 & 1 & 0 & 0 \\
\hline Hap_35 & 0 & 0 & 0 & 0 & 0 & 0 & 0 & 0 & 0 & 0 & 0 & 0 & 0 & 0 & 0 & 2 & 0 & 0 & 0 & 0 & 0 & 0 \\
\hline Hap_36 & 0 & 0 & 0 & 0 & 0 & 0 & 0 & 0 & 0 & 0 & 2 & 0 & 0 & 0 & 0 & 0 & 0 & 0 & 0 & 0 & 0 & 0 \\
\hline Hap_37 & 0 & 0 & 0 & 0 & 0 & 0 & 0 & 0 & 0 & 0 & 0 & 1 & 0 & 0 & 0 & 0 & 0 & 0 & 0 & 0 & 0 & 0 \\
\hline Hap_38 & 0 & 0 & 0 & 0 & 1 & 0 & 0 & 0 & 0 & 0 & 0 & 0 & 0 & 0 & 0 & 0 & 0 & 0 & 0 & 0 & 0 & 0 \\
\hline Hap_39 & 0 & 0 & 0 & 0 & 1 & 0 & 0 & 0 & 0 & 0 & 0 & 0 & 0 & 0 & 0 & 0 & 0 & 0 & 0 & 0 & 0 & 0 \\
\hline Hap_40 & 0 & 0 & 0 & 0 & 0 & 0 & 0 & 0 & 0 & 0 & 0 & 0 & 0 & 1 & 0 & 0 & 0 & 0 & 0 & 0 & 0 & 0 \\
\hline Hap_41 & 0 & 0 & 0 & 0 & 0 & 0 & 0 & 0 & 0 & 0 & 0 & 0 & 0 & 2 & 0 & 0 & 0 & 0 & 0 & 0 & 0 & 0 \\
\hline
\end{tabular}




\subsubsection{Methods}

\subsubsection{Sampling and DNA extraction}

Cominella maculosa were collected at five new locations and added to the existing dataset (Table 2.1). New locations were: Bowentown at Waihi Beach (WB) in the Bay of Plenty, Mahia on the Mahia Penisula (MP), Port Ahuriri at Napier (NA), Pourere Beach (PB), and Whangaehu Beach (WhB). Samples were collected between November 2014 and November 2015 by searching tidepools at low tide, often after baiting pools with crushed limpets. Specimens were preserved whole in $80 \%$ ethanol. Foot and operculum tissue was removed and preserved in $95 \%$ ethanol by either pulling the whole whelk from the shell or by crushing the shell. Intact shells from each location were deposited with the Museum of New Zealand Te Papa Tongarewa and assigned a registration number (MP, M.110143; NA, M.127597; and PB, M.162486).

Foot tissue was excised and digested for 2 hours at $60^{\circ} \mathrm{C}$ in $600 \mu \mathrm{L}$ extraction buffer ( $12 \mathrm{mM}$ Tris-HCL pH 8.0, $47.5 \mathrm{mM} \mathrm{NaCl}$, 9.5 mM EDTA, 0.19\% SDS, $0.5 \mathrm{mg}$ proteinase-K). DNA was recovered through the following modified phenol-chloroform technique. After digestion, samples were centrifuged and the supernatant removed and rocked for 10 minutes with $600 \mu \mathrm{L}$ of phenol:chloroform:isoamyl alcohol (25:24:1). Samples were then centrifuged for 5 minutes and the dense phenol layer was removed and discarded appropriately. The sample was again mixed with $600 \mu \mathrm{L}$ of phenol:chloroform:isoamyl alcohol (25:24:1), rocked for 5 minutes, centrifuged for 5 minutes, and the phenol layer removed. The sample was then mixed with $600 \mu \mathrm{L}$ chloroform:isoamyl alcohol (24:1), rocked for 10 minutes, centrifuged for 5 minutes, and the bottom layer removed. Chilled $99.9 \%$ ethanol (2.5\% volume of supernatant) and $3 \mathrm{M}$ sodium acetate ( $10 \%$ volume of supernatant + ethanol) was added to the final supernatant. Samples were placed at $-20^{\circ} \mathrm{C}$ for 30 minutes or overnight before being centrifuged for 30 minutes at $4^{\circ} \mathrm{C}$. The ethanol solution was removed and $1 \mathrm{~mL}$ of $70 \%$ chilled ethanol was added before being centrifuged for 10 minutes at $4^{\circ} \mathrm{C}$. Ethanol was removed and the DNA was dried in a vacuum centrifuge (Eppendorf Concentrator 5301) for 5-10 minutes. DNA was suspended in 30-70 $\mu \mathrm{L}$ of TE buffer (10 mM Tris-HCl pH 8.0, 1 mM EDTA). DNA concentration and quality was determined with a Nanodrop spectrophotometer (Thermo Fisher Scientific).

\subsubsection{PCR sequencing and alignment}

The mitochondrial CO1 region was amplified by PCR using the "universal bar-coding" primers LCO1490 (5'-ggtcaacaaatcataaagatattgg-3') and HCO2198 (5'-taaacttcagggtgaccaaaaaatca-3') (Folmer et al., 1994). The PCR was conducted in $25 \mu \mathrm{L}$ volumes containing $1 X$ Bioline PCR buffer (670 mM Tris- $\mathrm{HCl}$, $160 \mathrm{mM}\left(\mathrm{NH}_{4}\right)_{2} \mathrm{SO}_{4}, 0.1 \%$ stabilizer), $3.0 \mathrm{mM} \mathrm{MgCl}, 0.6 \mathrm{mg} / \mathrm{mL}$ bovine serum albumin, 0.05 units Taq DNA polymerase (Bioline), $0.4 \mathrm{mM}$ of each dNTP, $0.1 \mu \mathrm{M}$ of each primer, and $120 \mathrm{ng} / \mu \mathrm{L}$ of template 
DNA. Thermocycling was carried out on a Biometra TProfessional Thermocycler (Göttingen, Germany) under the following conditions: 5 minutes at $95^{\circ} \mathrm{C}, 40$ cycles of 35 seconds at $95^{\circ} \mathrm{C}, 35$ seconds at $50^{\circ} \mathrm{C}$, 45 seconds at $72^{\circ} \mathrm{C}$, followed by a final 10 minute extension at $74^{\circ} \mathrm{C}$. PCR products were cleaned with ExoSAP-It (Amersham Parmacia Biotech) and DNA sequences determined using 3730xI DNA Analyzer (Applied Biosystems) at the Macrogen sequencing service (Macrogen Inc., Seoul, Korea). Partial sequences of 710-bp were quality checked and edited by eye before being trimmed to 610-bp using Geneious 8.1.6 (http://www.geneious.com, Kearse et al. 2012). Previously sequenced samples (Fleming et al. in prep) were added and all sequences were aligned using Geneious alignment algorithm under default settings.

\subsubsection{Statistical analyses}

All statistical analyses were performed using updated software versions, but similar settings as those used previously by Fleming et al. (in prep). Haplotypes were identified using DnaSP 5.10.01 (Librado and Rozas 2009). Genetic diversity was determined using Arlequein 3.5.2.2 (Excoffier and Lischer 2010). Measures of diversity included segregating sites $(S)$, number of haplotypes $\left(H_{n}\right)$, haplotype diversity $(h)$, and nucleotide diversity $(\pi)$. To determine if sample size was adequate for capturing haplotype diversity, a rarefaction curve was produced using Analytic Rarefaction v1.3 (Holland 2003, http://strata.uga.edu/software/index.html). A flattening trend in a rarefaction curve would indicate sufficient sample sizes had been reached and increased sampling would not lead to the discovery of more haplotypes.

Tests to determine whether the data conformed to the neutral model of evolution were conducted in Arlequin 3.5.2.2 (Excoffier and Lisher 2010) with 10,000 permutations. Tajima's $D$ (Tajima 1989) and Fu's $F_{S}$ (Fu and Li 1993) were used to detect selection and hitchhiking events, but both statistics are sensitive to demographic changes (Pálsson et al. 2014). If DNA sequence neutrality is assumed, then significant test statistics are indications of recent population expansions or contractions (Ramos-Onsins and Rozas 2002). Due to the way Fu's $F_{S}$ statistic is performed, $\mathrm{p}$-values are significant at a value below 0.02 (Fu 1997, Excoffier and Lischer 2015).

Previously, Haploviewer was used to create haplotype networks for the North Island. However, this program bases networks on pre-defined trees. Since trees only allow bifurcating relationships, they do not adequately reflect the multiple relationships that could explain haplotype connections. Therefore, PopART (http://popart.otago.ac.nz) was used to create a minimum spanning haplotype network (Bandelt et al. 1999) that allows for cyclical haplotype relationships. To simplify visual assessment for regional patterns, the colour scheme for the new haplotype network was also updated. 
AMOVA was used to partition total molecular variance into three hierarchical components with an associated fixation index (Excoffier et al. 1992). These indices describe variation within all populations $\left(\phi_{S T}\right)$, between populations within a predefined group $\left(\phi_{\mathrm{SC}}\right)$, and between all predefined groups $\left(\phi_{\mathrm{CT}}\right)$ (Excoffier et al. 1992). The best group structure is determined by maximizing the between group variation (i.e. largest significant $\phi_{C T}$ ). While AMOVA is useful in testing hypothesis of population structure (such as northern-southern differentiation), it requires a priori assignment to groups. A priori bias can be removed by conducting spatial analysis of variance (SAMOVA) which clusters populations into a predefined number of groups with the aim of maintaining geographic homogeneity while maximizing between group variation (Dupanloup et al. 2002). The optimum number of groups is determined by identifying the largest significant $\phi_{C T}$ from iterative analysis using 2 through $\mathrm{N}-1$ groups, where $\mathrm{N}=$ the total number of populations.

Population clustering was tested by AMOVA in Arlequin 3.5.2.2 (Excoffier and Lisher 2010) using conventional haplotype frequency analysis with 10,000 permutations. Five a priori groupings were tested with AMOVA including 12 regional groups based on haplotype sharing and $\phi_{S T}$ results, five groups based on biogeographic regions (Shears et al. 2008), a northern and southern (N-S) division based on LGM $15^{\circ} \mathrm{C}$ isotherm (Barrows and Juggins, 2005), a N-S division based on breaks at the East Cape and Cape Reinga, and a N-S division with only Cook Strait populations forming the southern group. Iterative runs of SAMOVA using assignment into 2 through 21 geographically homogenous groups were conducted with SAMOVA 2.0 (Dupanlaup et al. 2002). The grouping that produced the largest significant $\phi_{C T}$ statistic was then subjected to AMOVA in Arlequin 3.5.2.2 (Excoffier and Lisher 2010) to ensure fixation index values were comparable across programs.

To test for an IBD pattern, a Mantel test was performed in Arlequin 3.5.2.2 using 10000 permutations (Mantel 1967, Excoffier and Lisher 2010). Mantel tests use regression analysis to detect if nearby populations are more similar than distant populations (Smouse et al. 1986). Previously, Fleming et al. (in prep) used $\phi_{\text {ST }}$ values for the measure of differentiation and natural log kilometres for the measure of distance. This method does appear in the literature (Pálsson et al. 2014), but it appears to be less common than using $\phi_{\mathrm{ST}}$ and untransformed kilometre distances (Marko 2004, Buchanan and Zuccarello 2012, Keeney et al.2013, Crandall et al. 2014, Rabone et al. 2015). To complicate parameter selection, many studies compare Slatkin's linearized genetic differentiation $\left[\phi_{\mathrm{ST}} /\left(1-\phi_{\mathrm{ST}}\right)\right]$ with both transformed kilometres (Reisser et al. 2014, Hernández et al. 2015) and untransformed kilometres (Waters et al. 2005, Keeney et al. 2009). Rousset (1997) suggests using Slatkin's linearized differentiation with untransformed distances when a species inhabits a one-dimensional habitat and log transformed distances when a species inhabits a two-dimensional habitat. Habitats are considered one-dimensional when the sampling distance between populations is greater than width of the habitat (Rousset 1997). 
Conversely, two-dimensional habitats are wider than the distance between sampled populations (Rousset 1997). In order to determine if Mantel settings influence IBD detection, all four parameter choices were used. Between site distances were determined using straight line measurements through water with Google Earth v7.1.5 (Google Inc.).

\subsubsection{The Updated Situation: Results and Brief Discussion}

The new locations increased the sample size from 404 to 512 individuals and produced better resolution along the East Coast region (Table 2.1, Figure 2.2B). The rarefaction curve shows a mild trend towards flattening (Figure 2.3) indicating the data set has a decent sample size, but increased sampling would likely discover more diversity which could help explain connectivity patterns. Overall, indices increased slightly for both haplotype diversity (from 0.8415 to 0.8683 ) and nucleotide diversity (from 0.0053 to 0.0060 ). Diversity indices at WB, MP and WhB did not differ from neighbouring diversity measures (Table 2.1). However, NA and PB had much lower haplotype diversity (0.08) compared to northern and southern neighbours ( 0.36 at MP and 0.60 at $\mathrm{WhB}$, respectively). A similar reduction in haplotype diversity occurs at GTT (0.06), where neighbouring diversity ranges from 0.39 to 0.36 (Table 2.1). The only other locations where lower haplotype diversity was observed $(h=0.00)$ was at two Wellington populations (WPH and WMA) and a Taranaki population (TMA). The southern locations, defined by the LGM isotherm, contain lower haplotype diversity than northern sites (0.66 vs 0.84). Interestingly, the southern group contains slightly more nucleotide diversity ( 0.0055 vs 0.0041$)$. While the new locations only minutely increased the northern haplotype diversity ( 0.83 to 0.84 ), the new sites greatly increased southern haplotype diversity (from 0.47 to 0.66 ). The additional sites raised nucleotide diversity for both northern ( 0.0037 to 0.0041 ) and southern groupings ( 0.0034 to 0.0055$)$.

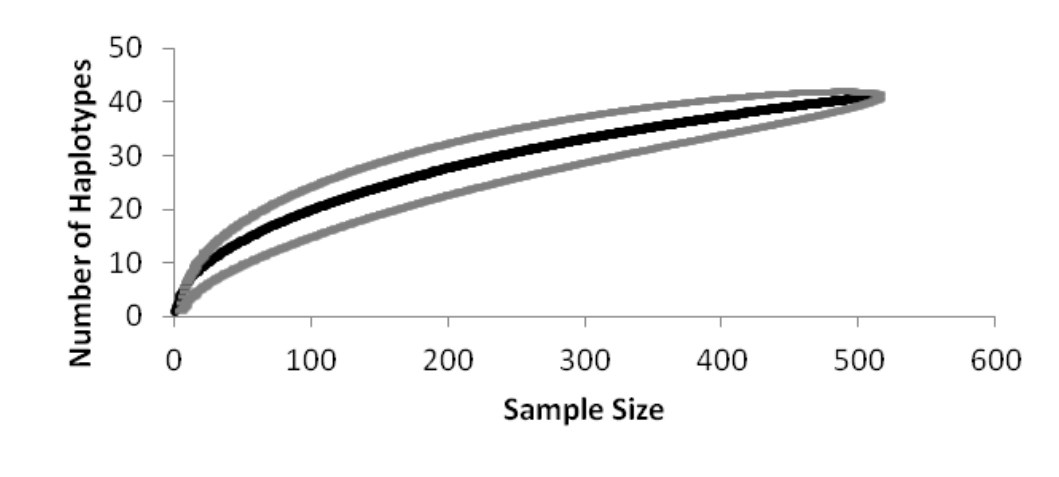

Figure 2.3 Rarefaction curve for a 610bp fragment of CO1 haplotypes from Cominella maculosa sampled in the North Island and Nelson. The black line represents the expected number of haplotypes found for a randomly selected sample size taken from the data. The grey lines represent upper and lower $95 \%$ confidence intervals. Rarefaction was conducted with Analytic Rarefaction v1.3 (Holland 2003, http://strata.uga.edu/software/index.html). 
New locations produced five new segregating sites and six new private haplotypes, with only PB not containing a private haplotype (Table 2.2). A previously private haplotype with a high frequency at WCS became shared with all four East Coast sites and dominant in three (Hap 28, Figure 2.2). The haplotype shared between GTT and WCS (Hap 27) was found in only two of the four new sites (Table 2.2). Surprisingly, both MP and PB contained a small proportion of the dominant Auckland haplotype (Hap 6). The presence of this Auckland haplotype in Nelson is currently being considered as a human mediated translocation by Fleming et al. (in prep). The low frequency occurrence at MP and PB could also reflect human mediated movement. However, both of these locations are fairly remote with only small settlements, unlike Nelson with a busy port and larger populations. It could be possible that Hap 6 is a relic of slow migration around the coast. If this is the case, it could indicate Auckland or Northland as the origin of $C$. maculosa divergence from $C$. adspersa, which is estimated to have occurred 0.4-2.6 million years ago (Donald et al. 2015).

A comparison between previous and updated haplotype networks is difficult, due to the use of different programs and colour schemes (Figure 2. 4). The updated haplotype network has several cyclical connections with multiple mutations separating several of the haplotypes. While the previous dataset indicated two high frequency haplotypes, the new dataset suggests four high frequency haplotypes found in three regions. The dominant Auckland haplotype (Hap 6) shows the starburst pattern expected when an abundant species experiences recent range expansion (Avise 2000). Its central position in the network supports the possibility that the Auckland region could be the origin of divergence. An Auckland origin is also supported by the fact that all dominant regional haplotypes (Hap 1, 27 and 28) are more similar to Hap 6 than to each other. This also suggests that the two highly divergent East Coast haplotypes (Hap 27 and 28) originated from multiple founder events (Figure 2. 4B). Intermediate haplotypes are missing between Hap 6 and both East Coast haplotypes (Hap 27 and 28), but they are present between Hap 6 and the Wellington haplotype (Hap 1) at BMA, WB, and NEL (Figure 2. $4 \mathrm{~B})$. 
A)

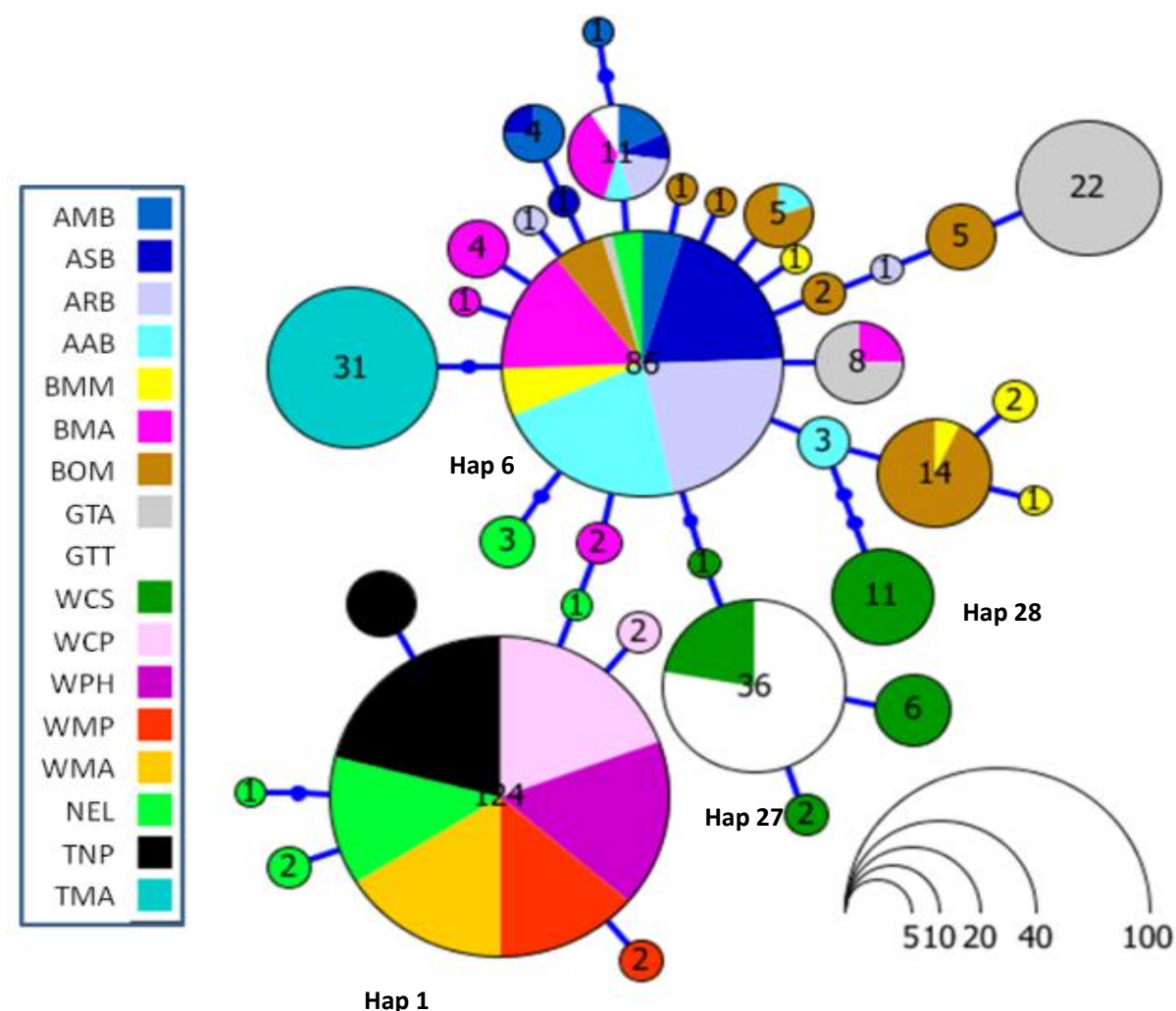

Hap 1

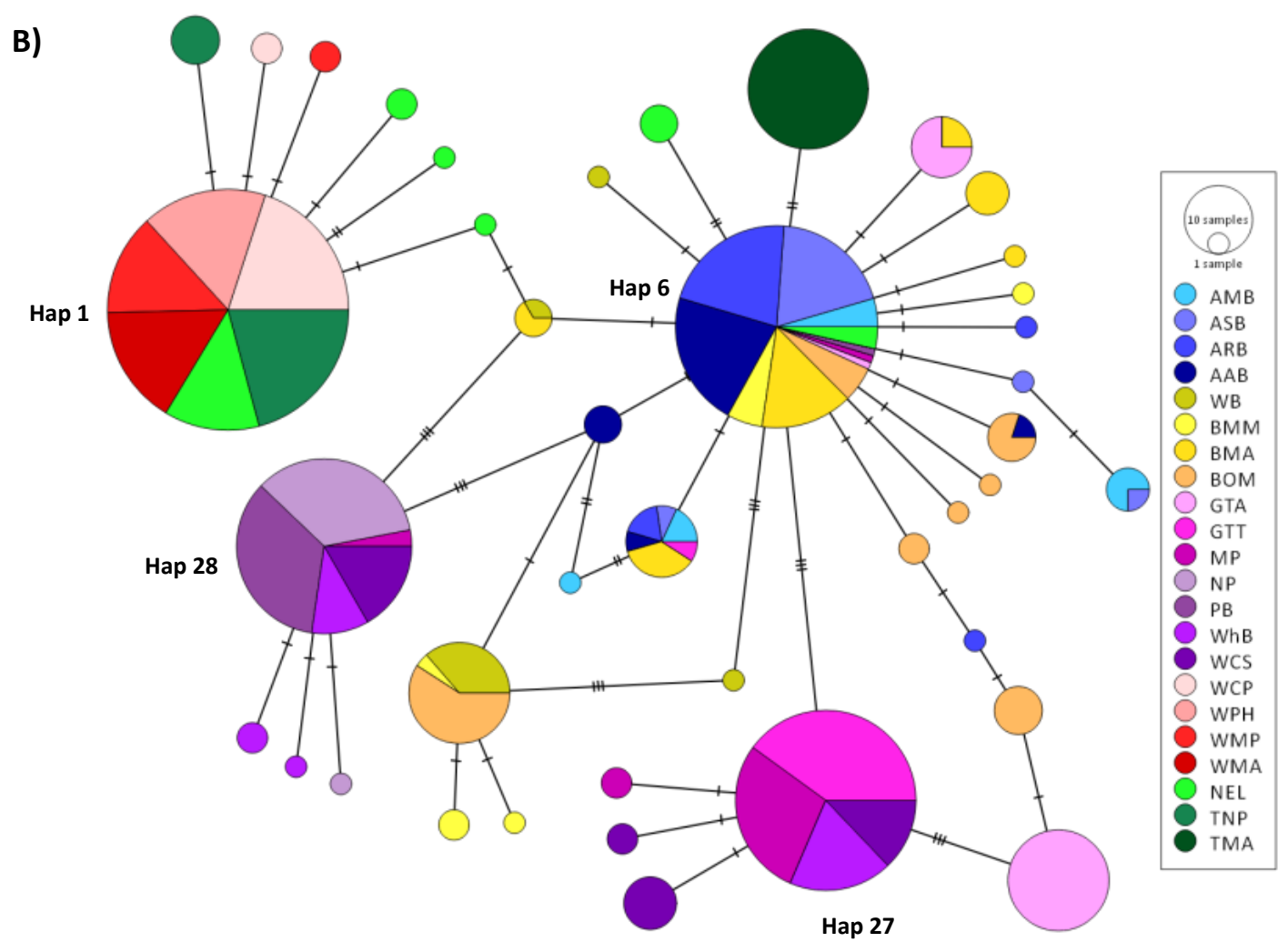

Figure 2. 4 Haplotype network for a 610bp fragment of $\mathrm{CO} 1$ gene from Cominella maculosa sampled in the North Island and Nelson. Circles represent haplotypes, with the colours representing number of samples containing the haplotype at each site. See Table 2.1 for site code information. The four regionally dominant haplotypes are labelled. A) The original network for 17 sample locations. This network was created in Haploviewer from a maximum likelihood tree created using a K80 model of nucleotide substitution. Numbers in the circles represent the total number of samples for each haplotype. Lines represent one mutation step, dots represent theoretical haplotypes. B) Minimum spanning network created in PopART using expanded dataset from 22 locations. Hash marks represent mutational changes between haplotypes. 
Neutrality tests were insignificant for Tajima's $D$ and Fu's $F_{S}$ for all populations except PB (Table 2.3). The Tajima's $D$ statistic was negative and significant for $\mathrm{PB}$, indicating either a population expansion or the process of selection is violating the assumption of neutrality. Significant Tajima's $D$ statistics are uncommon in the North Island, with only ARB and GTT producing negative values.

Pairwise comparison revealed significant differentiation between the new sites and the majority of all other populations (Table 2.4). Insignificant differentiation, implying connectivity, was found between WB \& BOM, NA \& PB, and WhB \& WCS. Interestingly, WB is significantly differentiated from its nearest neighbours of $A A B$ and $B M M$. However, the sample size at WB is quite small $(n=11)$ and should be interpreted with some caution. Contrary to previous findings, grouping populations by biogeographic regions was better supported than grouping populations by the LGM isotherm (Table 2.5).

Biogeographic grouping was weaker than the best N-S division, which grouped the Cook Strait populations together (Table 2.5). However, using the twelve groups based on haplotype distribution was more strongly supported than all other a priori groupings (Table 2.5). Maximal differentiation was further increased when populations were clustered into 14 groupings identified by SAMOVA (Table 2.5). 
Table 2.3 Neutrality statistics and corresponding p-values for a $610 \mathrm{bp}$ fragment of the CO1 gene for Cominella maculosa sampled throughout the North Island and Nelson. Significant results are in bold ( $\mathrm{p}<0.05$ for Tajima's $D$ and $\mathrm{p}<0.02$ for Fu's $F_{s}$ ). See Table 2.1 for site code information. Northern and southern groupings, noted by horizontal lines between populations, are based on LGM isotherm position (Barrows and Juggins 2005). Five new locations were added to 17 previously analyzed locations by Fleming et al. (in prep). New locations are WB, MP, NA, PB, and WhB.

\begin{tabular}{|c|c|c|c|c|}
\hline Sampling sites & Tajima's $D$ & $p$ & Fu's $F_{s}$ & $p$ \\
\hline AMB & 0.0739 & 0.5686 & 0.36099 & 0.5608 \\
\hline ASB & -1.44071 & 0.0572 & -2.13527 & 0.0064 \\
\hline ARB & -1.67904 & 0.0262 & -1.79546 & 0.035 \\
\hline $\mathrm{AAB}$ & -1.27878 & 0.0778 & -1.93644 & 0.029 \\
\hline WB & -1.07757 & 0.1764 & 0.1143 & 0.4966 \\
\hline BMM & 0.12431 & 0.6042 & -0.81501 & 0.2372 \\
\hline BMA & -0.8574 & 0.2272 & -2.12402 & 0.0542 \\
\hline BOM & 0.43008 & 0.7016 & 0.03233 & 0.5368 \\
\hline GTA & 1.04084 & 0.8564 & 1.83817 & 0.853 \\
\hline GTT & -1.88946 & 0.0064 & 0.58716 & 0.3944 \\
\hline MP & -1.03706 & 0.1672 & 1.13217 & 0.7458 \\
\hline NA & -1.15933 & 0.1348 & -1.02785 & 0.0708 \\
\hline PB & -1.88381 & 0.0056 & 0.79536 & 0.472 \\
\hline WhB & 1.91762 & 0.9826 & 4.68797 & 0.9632 \\
\hline WCS & 2.23481 & 0.988 & 5.45083 & 0.9786 \\
\hline WCP & -0.72804 & 0.2074 & -0.34896 & 0.177 \\
\hline WPH & 0 & 1 & 0 & N.A. \\
\hline WMP & -0.56216 & 0.2432 & -0.05451 & 0.225 \\
\hline WMA & 0 & 1 & 0 & N.A. \\
\hline NEL & -0.33385 & 0.4002 & -0.01893 & 0.5212 \\
\hline TNP & 0.18025 & 0.7436 & 0.63659 & 0.437 \\
\hline TMA & 0 & 1 & 0 & N.A. \\
\hline OVERALL & -1.04484 & 0.1366 & -14.9899 & 0.0078 \\
\hline Northern & -1.33911 & 0.0648 & -12.026 & 0.0036 \\
\hline Southern & -0.07355 & 0.551 & -0.31342 & 0.5292 \\
\hline \multicolumn{5}{|l|}{ AMOVA groupings: } \\
\hline$(\mathrm{ASB}, \mathrm{ARB}, \mathrm{AAB})$ & -1.95653 & 0.004 & -6.82428 & $<0.0001$ \\
\hline (GTT,MP) & -1.61445 & 0.0334 & -0.58834 & 0.3568 \\
\hline (NA,PB) & -1.99239 & 0.0018 & -1.31501 & 0.1288 \\
\hline $\begin{array}{l}\text { (WCP,WPH,WMP, } \\
\text { WMA,TNP) }\end{array}$ & -1.28005 & 0.0664 & -3.20572 & 0.012 \\
\hline
\end{tabular}


Table 2.4 Pairwise comparison from a 610bp fragment of the COI gene for Cominella maculosa sampled around the North Island and Nelson. Pairwise ФST values are below the diagonal, pvalues are above the diagonal (see foot note for interpretation). Site codes and locations are described in Table 2.1. The Five new locations added to 17 previously analyzed locations are WB, $\mathrm{MP}, \mathrm{NA}, \mathrm{PB}$, and $\mathrm{WhB}$.

\begin{tabular}{|c|c|c|c|c|c|c|c|c|c|c|c|c|c|c|c|c|c|c|c|c|c|c|}
\hline & AMB & ASB & ARB & AAB & WB & BMM & BMA & $\mathrm{BOM}$ & GTA & GTT & MP & NA & PB & WhB & WCS & WCP & WPH & WMP & WMA & NEL & TNP & TMA \\
\hline AMB & & $*$ & *** & $* *$ & *** & NS & NS & ** & $* * *$ & $* * *$ & $* * *$ & $* * *$ & $* * *$ & $* * *$ & $* * *$ & $* * *$ & $* * *$ & $* * *$ & $* * *$ & $* * *$ & $* * *$ & $* * *$ \\
\hline $\mathrm{ASB}$ & 0.209 & & NS & NS & **** & * & * & **** & *** & **** & **** & **** & $* * *$ & $* * *$ & **** & $* * *$ & $* * *$ & $* * *$ & $* * *$ & $* * *$ & $* * *$ & **** \\
\hline ARB & 0.205 & -0.030 & & NS & **** & $*$ & $*$ & $* * *$ & $* * *$ & $* * *$ & $* * *$ & $* * *$ & $* * *$ & $* * *$ & $* * *$ & $* * *$ & $* * *$ & $* * *$ & $* * *$ & $* * *$ & $* * *$ & $* * *$ \\
\hline$\overline{\mathrm{AAB}}$ & 0.190 & -0.007 & -0.007 & & $* * *$ & * & $*$ & $* * *$ & $* * *$ & $* * *$ & $* * *$ & $* * *$ & $* * *$ & $* * *$ & $* * *$ & **** & **** & $* * *$ & $* * *$ & **** & $* * *$ & $* * *$ \\
\hline WB & 0.369 & 0.634 & 0.616 & 0.585 & & ** & **** & NS & **** & $* * *$ & **** & $* * *$ & $* * *$ & $* * *$ & $* * *$ & $* * *$ & $* * *$ & $* * *$ & $* * *$ & $* * *$ & $* * *$ & **** \\
\hline BMM & 0.042 & 0.134 & 0.122 & 0.100 & 0.331 & & NS & $*$ & $* * *$ & $* * *$ & $* * *$ & $* * *$ & $* * *$ & $* * *$ & $* * *$ & $* * *$ & $* * *$ & $* * *$ & $* * *$ & $* * *$ & $* * *$ & $* * *$ \\
\hline BMA & 0.031 & 0.108 & 0.092 & 0.089 & 0.370 & 0.020 & & $* * *$ & $* * *$ & $* * *$ & $* * *$ & $* * *$ & $* * *$ & $* * *$ & $* * *$ & $* * *$ & $* * *$ & $* * *$ & $* * *$ & $* * *$ & $* * *$ & $* * *$ \\
\hline $\mathrm{BOM}$ & 0.171 & 0.360 & 0.353 & 0.329 & 0.071 & 0.127 & 0.188 & & $* * *$ & $* * *$ & $* * *$ & $* * *$ & $* * *$ & $* * *$ & $* * *$ & $* * *$ & $* * *$ & $* * *$ & $* * *$ & $* * *$ & $* * *$ & $* * *$ \\
\hline GTA & 0.459 & 0.643 & 0.629 & 0.607 & 0.572 & 0.466 & 0.430 & 0.410 & & $* * *$ & $* * *$ & $* * *$ & $* * *$ & $* * *$ & $* * *$ & $* * *$ & $* * *$ & $* * *$ & $* * *$ & $* * *$ & $* * *$ & $* * *$ \\
\hline GTT & 0.711 & 0.841 & 0.817 & 0.792 & 0.803 & 0.721 & 0.617 & 0.571 & 0.768 & & $*$ & $* * *$ & $* * *$ & $* * *$ & **** & $* * *$ & $* * *$ & $* * *$ & $* * *$ & $* * *$ & $* * *$ & $* * *$ \\
\hline MP & 0.475 & 0.663 & 0.648 & 0.623 & 0.592 & 0.481 & 0.449 & 0.419 & 0.622 & 0.064 & & $* * *$ & $* * *$ & * & **** & **** & $* * *$ & $* * *$ & $* * *$ & $* * *$ & **** & $* * *$ \\
\hline NA & 0.679 & 0.824 & 0.800 & 0.774 & 0.778 & 0.688 & 0.592 & 0.545 & 0.750 & 0.925 & 0.757 & & NS & $* * *$ & $* * *$ & $* * *$ & $* * *$ & $* * *$ & $* * *$ & $* * *$ & $* * *$ & $* * *$ \\
\hline PB & 0.673 & 0.818 & 0.793 & 0.766 & 0.778 & 0.680 & 0.583 & 0.542 & 0.749 & 0.925 & 0.757 & -0.021 & & $* * *$ & $* * *$ & $* * *$ & $* * *$ & $* * *$ & $* * *$ & $* * *$ & **** & **** \\
\hline $\mathrm{WhB}$ & 0.324 & $\begin{array}{l}0.549 \\
\end{array}$ & 0.538 & 0.514 & 0.441 & 0.333 & 0.338 & 0.306 & 0.507 & 0.282 & 0.080 & 0.519 & 0.519 & & NS & $* * *$ & $* * *$ & $* * *$ & $* * *$ & $* * *$ & $* * *$ & $* * *$ \\
\hline WCS & 0.258 & 0.480 & 0.471 & 0.450 & 0.373 & 0.267 & 0.283 & 0.254 & 0.446 & 0.434 & 0.239 & 0.342 & 0.342 & 0.053 & & $* * *$ & $* * *$ & $* * *$ & $* * *$ & $* * *$ & *** & **** \\
\hline WCP & 0.647 & 0.796 & 0.775 & 0.749 & 0.743 & 0.655 & 0.574 & 0.529 & 0.728 & 0.896 & 0.752 & 0.885 & 0.885 & 0.639 & 0.567 & & NS & NS & NS & ** & NS & **** \\
\hline WPH & 0.724 & 0.861 & 0.833 & 0.805 & 0.824 & 0.733 & 0.616 & 0.566 & 0.777 & 0.960 & 0.807 & 0.956 & 0.956 & 0.687 & 0.607 & 0.025 & & NS & NS & ** & NS & $* * *$ \\
\hline WMP & 0.573 & 0.758 & 0.736 & 0.708 & 0.686 & 0.583 & 0.518 & 0.476 & 0.688 & 0.879 & 0.712 & 0.865 & 0.865 & 0.586 & 0.513 & 0.008 & 0.063 & & NS & $*$ & NS & $* * *$ \\
\hline WMA & 0.716 & 0.858 & 0.830 & 0.801 & 0.819 & 0.725 & 0.610 & 0.561 & 0.773 & 0.959 & 0.803 & 0.955 & 0.955 & 0.682 & 0.602 & 0.023 & 0.000 & 0.059 & & ** & NS & $* * *$ \\
\hline NEL & 0.289 & 0.492 & 0.481 & 0.459 & 0.437 & 0.290 & 0.296 & 0.293 & 0.500 & 0.672 & 0.512 & 0.646 & 0.645 & 0.393 & 0.336 & 0.128 & 0.186 & 0.088 & 0.181 & & $*$ & $* * *$ \\
\hline TNP & 0.553 & 0.719 & 0.702 & 0.680 & 0.651 & 0.562 & 0.513 & 0.473 & 0.665 & 0.823 & 0.683 & 0.808 & 0.808 & 0.573 & 0.508 & 0.053 & 0.103 & 0.037 & 0.100 & 0.086 & & $* * *$ \\
\hline TMA & 0.780 & 0.886 & 0.861 & 0.836 & 0.862 & 0.788 & 0.664 & 0.613 & 0.809 & 0.967 & 0.837 & 0.964 & 0.964 & 0.733 & 0.654 & 0.934 & 1.000 & 0.924 & 1.000 & 0.716 & 0.860 & \\
\hline
\end{tabular}

NS, non-significant; * $\mathrm{p}<0.05 ; * * \mathrm{p}<0.01 ; * * * \mathrm{p}<0.001$ 
Table 2.5 Analysis of Molecular Variance and Spatial Analysis of Molecular Variance for population structure in C. maculosa using 610bp fragment of the COI gene. Site codes can be found in Table 2.1. A) Analysis performed with original 17 locations. B) Analysis performed on expanded dataset of 22 locations.

A)

\begin{tabular}{|c|c|c|c|c|}
\hline $\begin{array}{l}\text { No. of } \\
\text { groups }\end{array}$ & Source of Variation & $\Phi_{\mathrm{sc}}$ & $\Phi_{\text {ST }}$ & $\Phi_{\text {ст }}$ \\
\hline \multicolumn{5}{|c|}{ AMOVA a priori } \\
\hline 8 & $\begin{array}{l}\text { (AMB) (ASB-BMA) (BOM) (GTA) } \\
(\text { GTT) (WCS) (WCP-TNP) (TMA) }\end{array}$ & $0.07065^{* * * *}$ & $0.62727 * * * *$ & $0.59893 * * * *$ \\
\hline \multicolumn{5}{|c|}{ SAMOVA } \\
\hline 16 & $\begin{array}{l}\text { (AMB) (ASB) (ARB) (AAB) (BMM) } \\
\text { (BMA) (BOM) (GTA) (GTT) (WCS) } \\
\text { (WCP) (WPH, WMA) (WMP) (NEL) } \\
\text { (TNP) (TMA) }\end{array}$ & $-0.05131 * * * *$ & $0.72388 * * * *$ & $0.73735^{*}$ \\
\hline 13 & $\begin{array}{l}\text { (AMB) (ASB-AAB,BMA) (BMM) } \\
\text { (BOM) (GTA) (GTT) (WCS) (WCP) } \\
\text { (WPH, WMA) (WMP) (NEL) (TNP) } \\
\text { (TMA) }\end{array}$ & $-0.00874 * * * *$ & $0.73176 * * * *$ & $0.73405^{* * * *}$ \\
\hline \multicolumn{5}{|c|}{ AMOVA Biogeographic regions proposed by Shears et al. (2008) } \\
\hline 5 & $\begin{array}{l}\text { (ASB-GTA) (GTT-GTA) (WCS- } \\
\text { WMA) (NEL) (TNP,TMA) }\end{array}$ & $0.47688 * * * *$ & $0.60750 * * * *$ & $0.24970 * *$ \\
\hline \multicolumn{5}{|c|}{$\begin{array}{l}\text { AMOVA Biogeographic regions inferred from estimated } 15^{\circ} \mathrm{C} \text { SST isotherm in LGM by } \\
\text { Barrows and Juggins (2005) }\end{array}$} \\
\hline 2 & (ASB-GTT,TMA) (WCS-TNP) & $0.49728 * * * *$ & $0.64427 * * * *$ & $0.29239 * *$ \\
\hline
\end{tabular}

B)

\begin{tabular}{|c|c|c|c|c|}
\hline $\begin{array}{l}\text { No. of } \\
\text { groups }\end{array}$ & Source of Variation & $\Phi_{\mathrm{sc}}$ & $\Phi_{\mathrm{ST}}$ & $\Phi_{\text {ст }}$ \\
\hline \multicolumn{5}{|c|}{ AMOVA regional } \\
\hline 12 & $\begin{array}{l}\text { (AMB) (ASB-AAB) (WB) (BMM) } \\
\text { (BMA) (BOM) (GTA) (GTT,MP) } \\
\text { (NA,PB) (WhB,WCS) (WCP-TNP) } \\
\text { (TMA) }\end{array}$ & $0.03955^{* *}$ & $0.63556 * * * *$ & $0.62055 * * * *$ \\
\hline \multicolumn{5}{|c|}{ SAMOVA } \\
\hline 14 & $\begin{array}{l}\text { (AMB) (ASB-AAB) (WB) (BMM) } \\
\text { (BMA) (BOM) (GTA) (GTT,MP) } \\
\text { (NA,PB) (WhB) (WCS) (WCP- } \\
\text { WMA,TNP) (NEL) (TMA) }\end{array}$ & -0.00506 & $0.62866 * * * *$ & $0.63053 * * * *$ \\
\hline \multicolumn{5}{|c|}{ AMOVA Biogeographic regions proposed by Shears et al. (2008) } \\
\hline 5 & $\begin{array}{l}\text { (ASB-GTA) (GTT-WhB) (WCS-WMA) } \\
\text { (NEL) (TNP,TMA) }\end{array}$ & $0.51045 * * * *$ & $0.63368 * * * *$ & $0.25172 * *$ \\
\hline \multicolumn{5}{|c|}{ AMOVA North/South at LGM $15^{\circ} \mathrm{C}$ SST isotherm (Barrows and Juggins 2005) } \\
\hline 2 & (ASB-GTT,TMA) (WCS-TNP) & $0.56562 * * * *$ & $0.64686 * * * *$ & $0.18703 * *$ \\
\hline \multicolumn{5}{|c|}{ AMOVA North/South at East Cape \&Northland } \\
\hline 2 & (AMB-GTA) (GTT-TMA) & $0.56915 * * * *$ & $0.64982 * * * *$ & $0.18723 * *$ \\
\hline \multicolumn{5}{|c|}{ AMOVA North/South at Cook Strait } \\
\hline 2 & (AMB-WCS, TNP,TMA) (WCP-NEL) & $0.55395 * * * *$ & $0.68517 * * * *$ & $0.29417 * *$ \\
\hline
\end{tabular}


Mantel tests were significant for an IBD pattern when using $\phi_{\text {Sт }}$ and both untransformed $\left(r^{2}=0.423, p<\right.$ $0.0001)$ and natural log transformed distances $\left(r^{2}=0.531, p<0.0001\right)$. However, insignificant results were obtained when tested with Slatkin's linearized differentiation against both untransformed geographic distance $\left(r^{2}=-0.034, p=0.6690\right)$ and natural log transformed distances $\left(r^{2}=0.004, p=\right.$ 0.5531). In a recent review of Mantel tests using $F_{S T}$ and Km, Diniz-Filho et al. (2013) suggests that a significant result indicates structure of genetic variability through space. This structuring could be due to IBD or other processes (e.g. postglacial recolonization) that create population clusters (Meirmans 2012). Diniz-Filho et al. (2013) then present Rousset's (1997) work showing that Slatkin's linearized Fst produces a linear relationship with distance when an IBD pattern is present. An insignificant result using Rousset's (1997) methods can be interpreted as an absence of IBD or as an indication that the parameter estimation process is flawed. Therefore, comparing the results of both $\phi_{\mathrm{ST}}$ and Slatkin's linearized Mantel tests can be informative.

For North Island Cominella maculosa, a significant $\phi_{S T}$ Mantel test suggests that the North Island populations are structured, but an insignificant Mantel test using Rousset's (1997) methods suggests the structuring is not due to IBD processes or that the parameter estimates are incorrect. A lack of IBD indicates that the 14 population groups identified by SAMOVA, mostly comprised of single populations, should not be viewed as engaging in gene flow with only nearest neighbours. The insignificant pairwise comparison between non-neighbours WB and BOM highlights this point. This result could indicate dispersal by means other than crawling is occurring. Conversely, an IBD pattern may be masked if using through water straight line distances between populations is inappropriate. If whelks disperse by crawling along the shore, then the distance between populations should be measured along the coast.

\subsection{Fine Scale Connectivity along the Wairarapa Coast}

One of the interesting features of the North Island survey of Cominella maculosa was the identification of several genetic disjunctions between populations situated in close geographic proximity $(<130 \mathrm{~km})$. These disjunctions can be seen between GTA \& BOM, GTA \& GTT, WCS \& WCP, and TNP \& TMA (Figure 2.2). Considering the prevalence of regional haplotypes over large distances, the absence of shared haplotypes over such small distances is surprising. Two of these disjunctions occur on the east and west of the East Cape population of GTA, where genetic disjunctions have previously been reported (Stevens and Hogg 2004, Veale and Lavery 2102, Martin 2011). A second disjunction occurs between Taranaki populations that are separated by continuous uninhabitable soft sediment that could pose a barrier to crawling dispersal. The unstable composition of the Canterbury Bight has been identified as a barrier to dispersal for a direct developing chiton, Sypharochiton pelliserpentis (Nikula et al. 2011). The last disjunction occurs between WCS and WCP on the Wairarapa Coast. With few roads and steep 
coastal cliffs, this rugged and exposed area of the North Island is difficult to access. As such, sites south of Castlepoint are rarely included in genetic surveys. Examining the genetic patterns occurring at locations between the observed disjunctions can give insight into dispersal mechanisms and barriers to dispersal for the coastal whelk. As the Wairarapa Coast was the nearest area of interest to researchers at Victoria University of Wellington, this area was chosen for fine scale genetic analysis.

\subsubsection{Methods}

\subsubsection{Sampling, DNA extraction, and PCR Sequencing}

Cominella maculosa were collected in 2015 from tide pools baited with frozen mussels at low tide. Whelks larger than ten $\mathrm{mm}$ were collected over a two hour period. Freshly collected whelks were either placed directly in $80 \%$ ethanol or transported in sea water and frozen before processing. A total of 250 new specimens were collected at five locations between Castlepoint and Cape Palliser. From north to south, these sites included Riversdale (RI), Flat Point (FP), Honeycomb Rock (HR), Glendhu (GL), and Tora (TO). The original Castlepoint dataset (WCS) was increased by obtaining 19 preserved specimens from a 2014 collection. In order to differentiate this larger sample size from the smaller sample size analyzed in the North Island dataset, this location will be coded as CA from here on out. No changes were made to the Cape Palliser dataset (WCP).

Foot and operculum tissue was removed and preserved in $95 \%$ ethanol by either pulling the whole whelk from the shell or by crushing the shell. Intact shells were deposited with the Museum of New Zealand Te Papa Tongarewa (RI, M.120366; FP, M.081982; HR, M.129383; and for three GL subsites. M.103412, M.129331, M.167160). DNA was recovered from foot tissue using the protocol outlined in Section 2.3.2.1. PCR sequencing and alignment was conducted following the protocol outlined in Section 2.3.2.2.

\subsubsection{Statistical analyses}

Haplotypes were identified using DnaSP 5.10.01 (Librado and Rozas 2009). Genetic diversity was determined using Arlequein 3.5.2.2 (Excoffier and Lisher 2010). Measures of diversity included the number of segregating sites (S), transitions (Ts), transversions (Tv), nucleotide difference ( $k$ ), number of haplotypes $\left(H_{n}\right)$, haplotype diversity $(h)$, nucleotide diversity $(\pi)$, and nucleic acid composition. Historic demographic changes were tested in Arlequin 3.5.2.2 using Tajima's D statistic (Tajima 1989) and Fu's $F_{S}$ statistic (Fu 1997). Pairwise genetic divergence was estimated in Arlequin 3.5.2.2 (Excoffier and Lischer 2010) using 10,000 permutations and haplotype frequency to calculate the fixation index $\phi_{\text {ST. }}$. Sample size adequacy was assessed using a rarefaction curve produced with Analytic Rarefaction v1.3 (Holland 
2003). Haplotype relationships were visualized with a minimum spanning haplotype network (Bandelt et al. 1999) created in PopART (http://popart.otago.ac.nz).

Insight into historic demographic processes can be gained by comparing haplotype diversity $(h)$ with average sequence divergence $(\pi \%)$. Grant and Bowen (1998) identified four categories to describe combinations of high and low diversity indices. Haplotype diversity is considered low at less than 0.5 , while nucleotide diversity is low at $0.5 \%$ (Grant and Bowen 1998). Cominella maculosa diversity indices were plotted on a haplotype vs nucleotide diversity graph for individual populations and pooled locations. To compare C. maculosa with other New Zealand species and other direct developing species, the graph was populated with diversity indices found in peer-reviewed literature. Reported diversity indices were multiplied by 100 to produce the required $\pi \%$ value.

Differentiation between populations was estimated in Arlequin 3.5.2.2 (Excoffier and Lisher 2010) using haplotype frequency to calculate the fixation index, $\phi_{S T}$, and significance was tested with 10,000 permutations. Three $a$ priori groupings were tested with AMOVA in Arlequin 5.2.2.2 (Excoffier and Lisher 2010) using 10,000 permutations of haplotype frequency data. The first two groups tested for a break between northern and southern locations. The first scenario included HR in the northern group and the second scenario included HR in the southern group. The third grouping tested the hypothesis that two or more neighbour populations formed distinct groups. This third scenario combined CA with $\mathrm{RI}$, FP with HR, and the three southern together (GL, TO, WCP).

Iterative runs of SAMOVA were performed for two through six groups using SAMOVA 2.0 (Dupanloup et al. 2002). The SAMOVA grouping was determined by identifying the largest significant $\phi_{C T}$ statistic. To compare the SAMOVA groups to a priori groups, the best SAMOVA grouping was analysed by AMOVA in Arlequin 3.5.2.2 (Excoffier and Lisher 2010). Mantel tests were first performed with $\phi_{\mathrm{ST}}$ and untransformed distance $(\mathrm{Km})$ to test for population structure. Mantel tests were then performed under the one-dimensional model of habitat (Rousset 1997) using Slatkin's linearized genetic differentiation and untransformed distance to test for IBD. Mantel tests were performed in Arlequin 3.5.2.2 with 10000 permutations (Excoffier and Lisher 2010). Distances between populations were determined in Google Earth v7.1.5 (Google Inc.) with shortest distance through water. Due to the linear nature of the Wairarapa Coast, shortest distance through water is also equal to the shortest coastal distance.

\subsubsection{Results}

A total of 324 whelks were sequenced from seven locations along $125 \mathrm{~km}$ of Wairarapa coastline (Figure 2.5, Table 2.6). Ten haplotypes were identified with 16 segregating sites, $81 \%$ of which were transition type changes (Table 2.6). Five of the seven locations contained at least one private 
haplotype, with the central locations of HR and FP exhibiting no privatization (Table 2.7). Overall haplotype diversity was 0.61 , with CA and RI having the highest population level diversity $(0.68$ and 0.53 , respectively). All other populations had much lower haplotype diversity, ranging from 0.06 to 0.26 (Table 2.6). Nucleotide diversity within populations showed the same pattern, with overall diversity being similar to the highest population level values (CA and RI, Table 2.6). Even these "high" values are quite low (0.005), but the other populations were even lower ( 0.0001 for TO). The average number of nucleotide differences ranged from 3.19 for the most diverse population (CA) and 0.06 for the least diverse population (TO, Table 2.6). None of the populations deviated significantly from neutrality under Fu's $F_{s}$ or Tajima's $D$ (Table 2.6). Since Fu's $F_{s}$ is only significant at $p<0.02$, the $p=$ 0.025 value at $\mathrm{RI}$ is insignificant (Fu 1997, Excoffier and Lischer 2015).

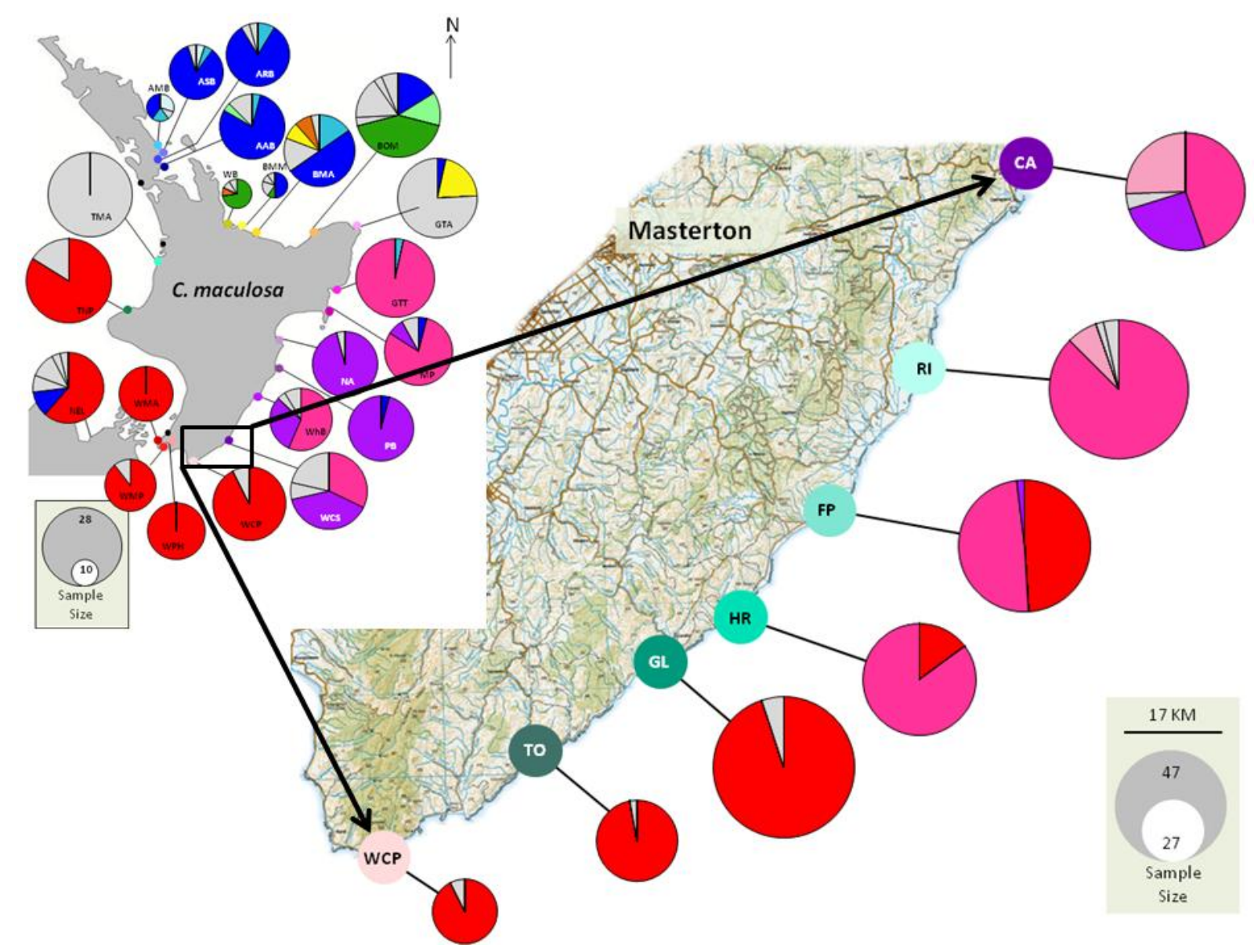

Figure 2.5 Distribution of $\mathrm{CO} 1$ haplotypes for Cominella maculosa. Inset is the North Island distribution found in Figure 2.2B. Expanded is the Wairarapa Coast distribution. Site code information is found in Table 2.1 for the inset and Table 2.6 for the Wairarapa. Sample sizes at each location are indicated by sample size. Note the discrepancy in scale between inset and expanded views. WCS (inset) is the same location as CA (Wairarapa), but CA sample size has been increased. WCP location and sample size is the same along the Wairarapa and inset. 
Table 2.6 Sample information, genetic diversity indices, and neutrality tests for Cominella maculosa sampled along the Wairarapa Coast of the North Island of New Zealand. Analysis are based on $610 \mathrm{bp}$ sequences from the $\mathrm{CO} 1$ gene.

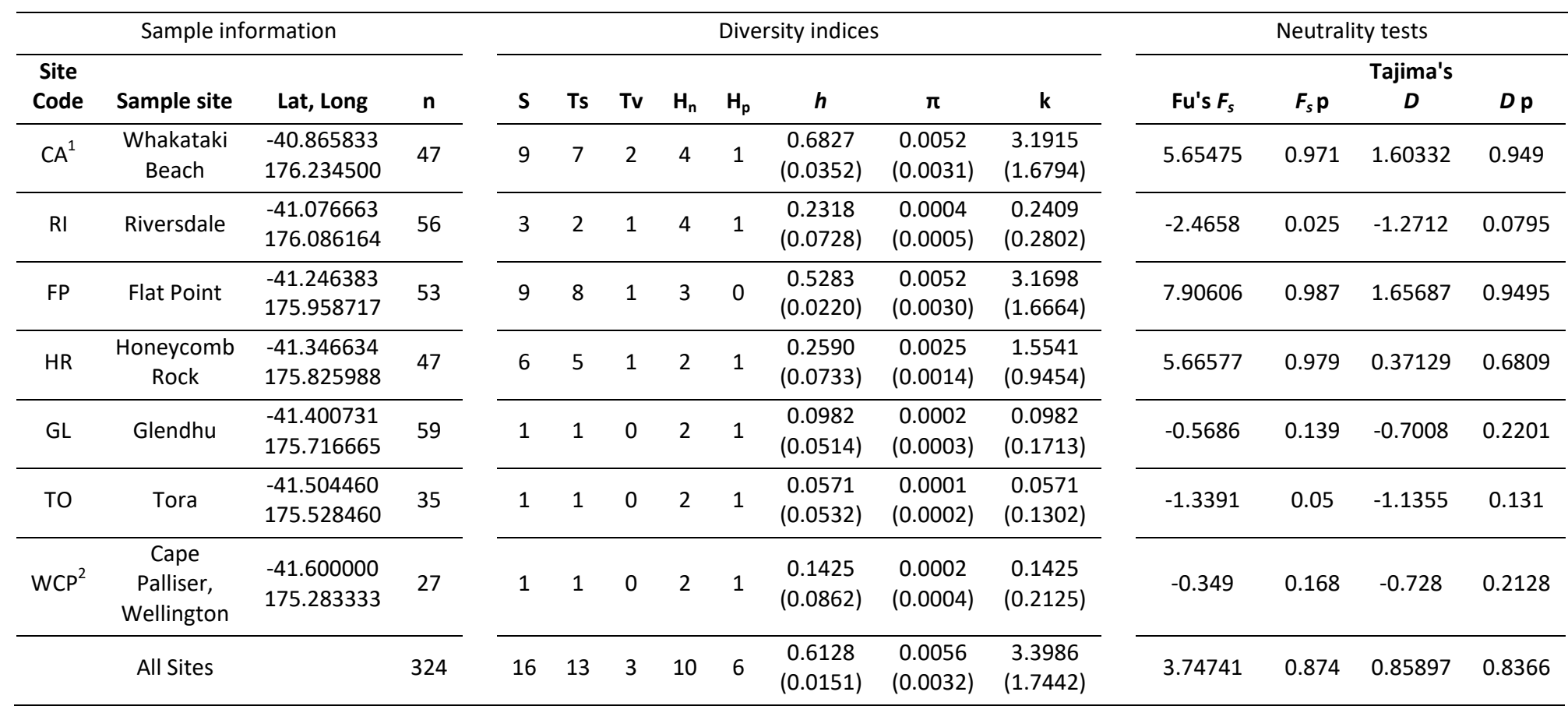

$\mathrm{n}$, sample size; $\mathrm{S}$, segregating sites; Ts, transitions; Tv, transversions; $\mathrm{H}_{\mathrm{n}}$, nuber of haplotypes; $\mathrm{H}_{\mathrm{p}}$, number of private haplotypes; $h$, haplotype diversity; $\pi$, nucelotide diversity; $\mathrm{k}$, nucleotide differences

${ }^{1}$ Same location as WCS in section 2.3. The code has been changed to reflect the larger sample size.

${ }^{2}$ Exact same sample set used in Section 2.3. Therefore, the code has not been changed 
Table 2.7 Haplotype counts from a 610 bp CO1 fragment for Cominella maculosa sampled along the Wairarapa Coast of the North Island. Private haplotypes are in bold with an asterisk at the count value. Site codes are described in Table 2.6. Haplotype numbers correlate to numbers used in North Island sampling (Table 2.2) with new haplotypes starting with Hap 42.

\begin{tabular}{c|ccccccc}
\hline & CA & RI & FP & HR & GL & TO & WCP \\
\hline Hap 1 & 0 & 0 & 26 & 7 & 56 & 34 & 25 \\
Hap 27 & 21 & 49 & 26 & 40 & 0 & 0 & 0 \\
Hap 28 & 12 & 0 & 1 & 0 & 0 & 0 & 0 \\
Hap 29 & $\mathbf{2}^{*}$ & 0 & 0 & 0 & 0 & 0 & 0 \\
Hap 30 & 12 & 4 & 0 & 0 & 0 & 0 & 0 \\
Hap 35 & 0 & 0 & 0 & 0 & 0 & 0 & $\mathbf{2}^{*}$ \\
Hap 42 & 0 & 0 & 0 & 0 & $\mathbf{3}^{*}$ & 0 & 0 \\
Hap 43 & 0 & $\mathbf{1 *}$ & 0 & 0 & 0 & 0 & 0 \\
Hap 44 & 0 & $\mathbf{2}^{*}$ & 0 & 0 & 0 & 0 & 0 \\
Hap 45 & 0 & 0 & 0 & 0 & 0 & $\mathbf{1 *}$ & 0 \\
\hline
\end{tabular}

The flattening trend of the rarefaction curve indicates sufficient sampling was achieved to capture diversity (Figure 2.6). The overall high haplotype diversity and low nucleotide diversity placed the Wairarapa into category four of demographic generalizations (Figure 2.7A). These populations are often large and stable or have undergone secondary contact and contain several highly divergent haplotypes (Grant and Bowen 1998). As the haplotype network shows (Figure 2.8A), highly divergent haplotypes are indeed present along the Wairarapa. When individual populations are plotted, it is evident that the overall Wairarapa position in category four is due to high haplotype diversity at CA and borderline high diversity at FP (Figure 2.7A). The nucleotide diversity in CA and FP is insufficient to move out of category two, a group which indicates rapid expansion after an ancient bottleneck or maintenance of consistently low effective population size (Grant and Bowen 1998). All other populations have low haplotype diversity and low nucleotide diversity, placing them firmly in category one (Figure 2.7A). Category one populations may have undergone recent bottlenecks or been founded by a recent recolonization event (Grant and Bowen 1998). The southern and northern groups from Fleming et al. (in prep) fall into the expanding population signature of category two while the overall North Island population falls into category four with stable populations or secondary contact. None of the C. maculosa diversity indices are outliers when compared to global direct developers (Figure 2.7B).

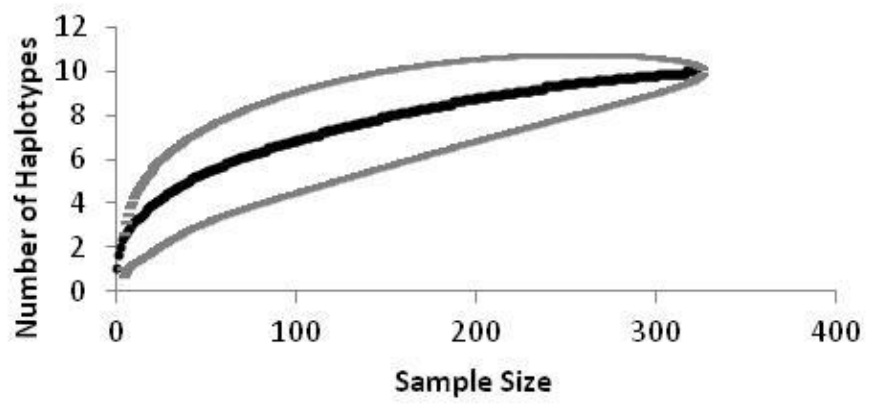

Figure 2.6 Rarefaction curve for CO1 haplotypes sampled along the Wairarapa of the North Island. The black line represents the expected number of haplotypes found for a randomly selected sample size taken from the data. The grey lines represent upper and lower 95\% confidence intervals. Rarefaction was conducted with Analytic Rarefaction v1.3 (Holland 2003, http://strata.uga.edu/software). 

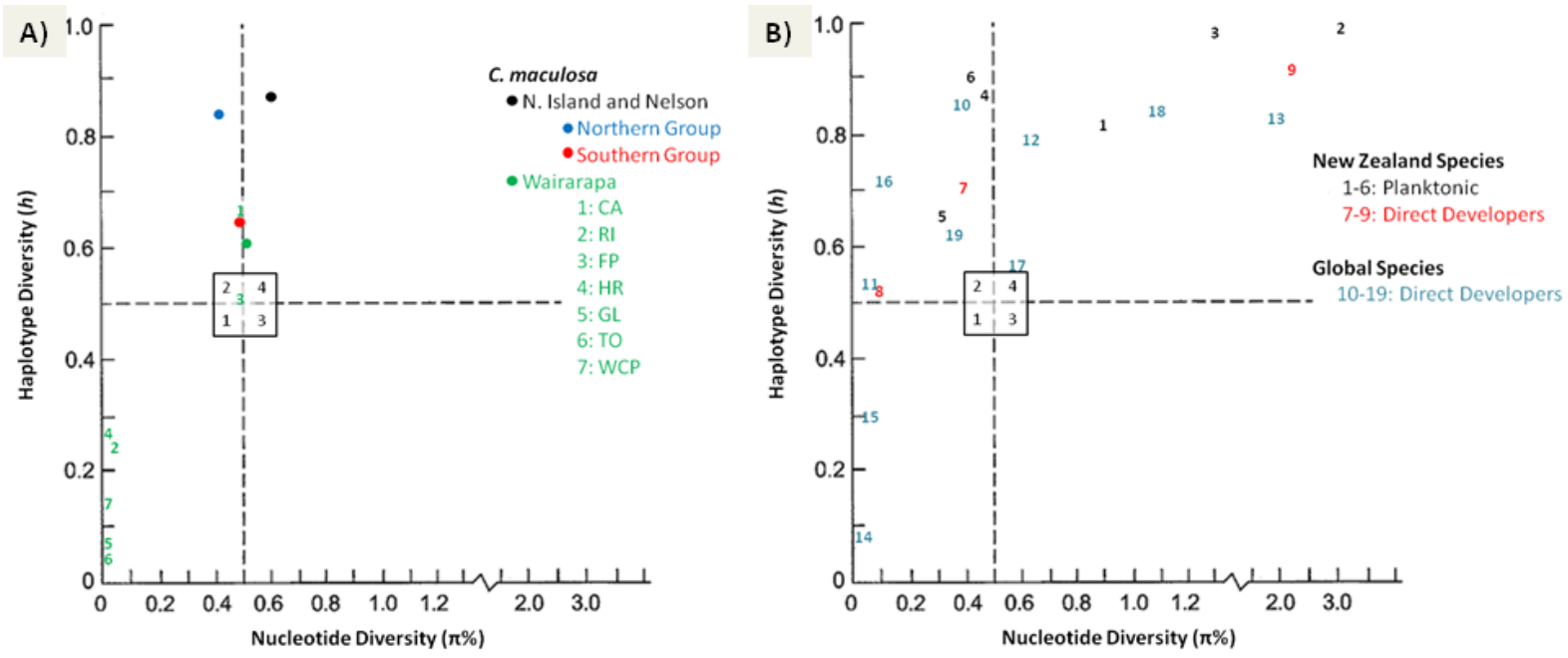

Figure 2.7 Haplotype diversity versus percentage nucleotide difference plots. A) Cominella maculosa groups reported in this study and B) other New Zealand species and direct developing species found globally. The numbers 1 through 4 in the central square indicate the four categories identified by Grant and Bowen (1998). The information for points plotted in B can be found in Table 2.8 .

Table 2.8 Reference information for points plotted in Figure2.7B, including the species and molecular marker for each study.

\begin{tabular}{|c|c|c|c|c|c|c|}
\hline $\begin{array}{l}\text { Plot } \\
\text { code }\end{array}$ & Source & $\begin{array}{l}\text { Development } \\
\text { Mode }\end{array}$ & Organism & Species & Country & mtDNA Region \\
\hline 1 & Hickey et al. 2009 & Planktonic & Fish & Forsterygion lapillum & $\mathrm{NZ}$ & Control Region \\
\hline 2 & Hickey et al. 2009 & Planktonic & Fish & Grahamina gymnota & NZ & Control Region \\
\hline 3 & Wilcox 2015 & Planktonic & Fish & Notolabrus celidotus & $\mathrm{NZ}$ & Control Region \\
\hline 4 & Ross et al. 2012 & Planktonic & Bivalve & Austrovenus stutchburyi & NZ & $\mathrm{CO} 1$ \\
\hline 5 & Apte and Gardner 2002 & Planktonic & Bivalve & Perna canaliculus & $\mathrm{NZ}$ & ND4 \\
\hline 7 & Keeney et al. 2013 & Direct & Gastropod & Zeacumantus subcarinatus & NZ & $\mathrm{CO} 1$ \\
\hline 8 & Keeney et al. 2013 & Direct & Gastropod & Zeacumantus lutulentus & $\mathrm{NZ}$ & $\mathrm{CO} 1$ \\
\hline 9 & Cumming et al. 2014 & Direct & Gastropod & Onchidella spp. & NZ & $\mathrm{CO} 1$ \\
\hline 10 & Nikula et al. 2010 & Direct & Crustacean & Parawaldeckia kidderi & Subantarctic & $\mathrm{CO} 1$ \\
\hline 11 & Nikula et al. 2010 & Direct & Crustacean & Limnoria stephenseni & Subantarctic & $\mathrm{CO} 1$ \\
\hline 15 & Lee and Boulding 2009 & Direct & Gastropod & Littorina subrotundata & USA & Cyt B \\
\hline 16 & Kamel et al. 2014 & Direct & Gastropod & Solenosteira macrospira & USA & CO1+Cyt B \\
\hline 17 & Azuma et al. 2015 & Direct & Gastropod & Neptunea arthritica & Japan & $\mathrm{CO} 1$ \\
\hline 18 & Kojima et al. 2004 & Direct & Gastropod & Batillaria cumingi & Japan & $\mathrm{CO} 1$ \\
\hline 19 & Pálsson et al. 2014 & Direct & Gastropod & Buccinum undatum & N. Atlantic & CO1+16S RNA \\
\hline
\end{tabular}


The "dumbbell" shaped haplotype network suggested there where two isolated populations that have undergone recent population expansions (Figure 2.8A, Avise 2000). However, the haplotype network should not be considered in isolation from the North Island haplotype network (Figure 2.8B). The two northern haplotypes are actually the two dominant East Coast haplotypes (Hap 27 and 28) observed in Section 2.3. As discussed previously, these haplotypes are more similar to the Auckland haplotype (Hap 6) than they are to the Wellington haplotype (Hap 1).

A)

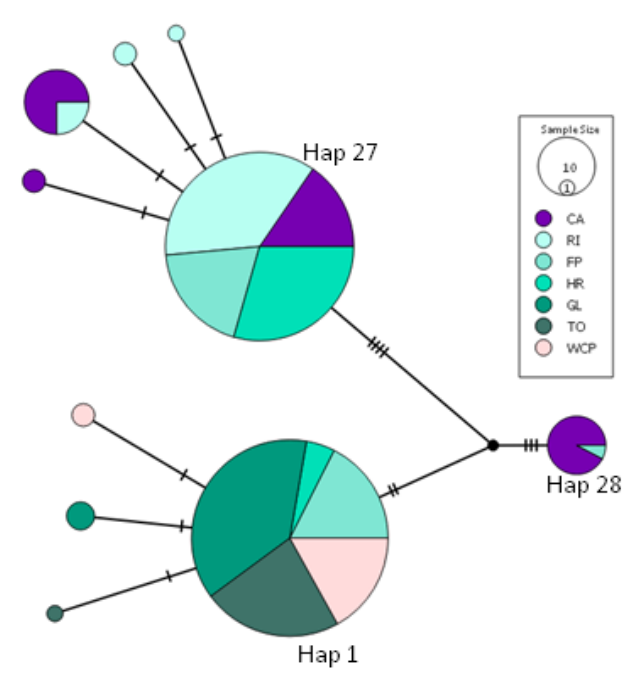

B)

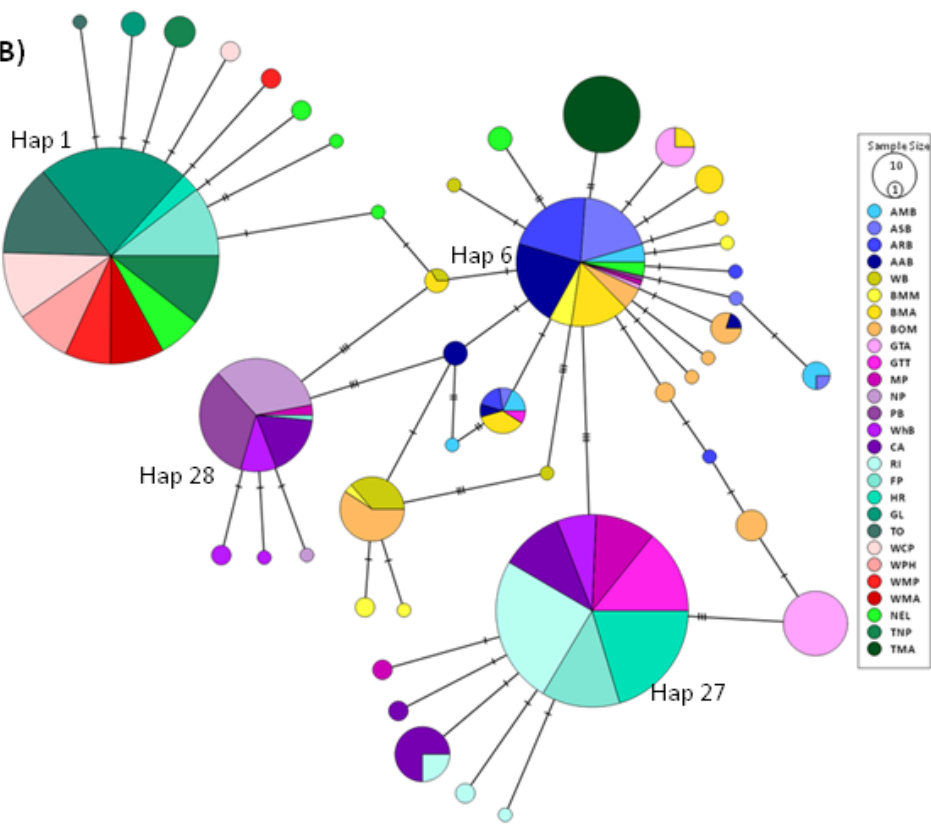

Figure 2.8 Minimum spanning network for CO1 haplotypes from Cominella maculosa. The size of each circle reflects the total number of samples detected for each haplotype, with colours reflecting how many individuals from each site contribute to the sample size. Hash marks represent one mutational change between haplotypes. Black dots represent theoretical haplotypes. A) Network for samples long the Wairarapa Coast of the North Island. See Table 2.6 for site code descriptions. B) Network for all North Island and Nelson samples discussed in this study. See Table 2.1 for site code descriptions, except CA is in Table 2.6.

Pairwise differentiation was significant between all populations except WCP, TO, and GL (Table 2.9). These three populations create a genetically similar southern grouping comprised of the dominant Wellington region haplotype (Hap 1). There is no evidence of a strong, impermeable barrier to dispersal that separates this southern haplotype from the northern sites (Figure 2.5). Rather, there appears to be a contact zone at HR and FP where the dominant southern and northern haplotypes merge (Figure 2.5). A priori groupings suggested a break between N-S groups at GL and HR, due to the higher AMOVA support of HR in the northern cluster (Table 2.10). Between-group variation became insignificant if HR was included in the southern cluster and the significant support for three groups, with a break between GL \& HR and between FP \& RI, was weaker than the N-S grouping (Table 2.10). The best SAMOVA clustering was created by four groups with the three southern populations remaining grouped, but the northern populations separated into CA, FP, and HR \& RI (Table 2.10). The settings used in SAMOVA should maintain geographic homogeneity; therefore it was surprising to find that the best clustering was to skip over FP and group HR with RI (Table 2.10). The relatively small spatial scale 
between sites could explain why the algorithm allowed this clustering. The four groups identified by SAMOVA were better supported than the a priori N-S grouping (Table 2.10). Mantel tests were insignificant for both $\phi S T(r 2=0.363, p=0.0627)$ and Slatkin's linearized differentiation $(r 2=0.18, p=$ 0.1797), indicating no population structure.

Table 2.9 Pairwise comparison ( $\phi_{S T}$ ) for Cominella maculosa sampled along the Wairarapa Cost of the North Island using 610 bp $\mathrm{CO} 1$ fragments. Site code descriptions can be found in Table 2.6.

\begin{tabular}{|c|c|c|c|c|c|c|c|}
\hline & CA & RI & FP & HR & GL & TO & WCP \\
\hline CA & & $* * *$ & $* * *$ & $* * *$ & $* * *$ & $* * *$ & $* * *$ \\
\hline RI & 0.23504 & & $* * *$ & * & $* * *$ & $* * *$ & $* * *$ \\
\hline FP & 0.22124 & 0.33674 & & $* * *$ & $* * *$ & $* * *$ & $* * *$ \\
\hline HR & 0.24023 & 0.03914 & 0.22315 & & $* * *$ & $* * *$ & $* * *$ \\
\hline GL & 0.63132 & 0.83649 & 0.42356 & 0.80073 & & NS & NS \\
\hline TO & 0.60096 & 0.8381 & 0.40042 & 0.80083 & 0.00072 & & NS \\
\hline WCP & 0.54459 & 0.7999 & 0.34103 & 0.75275 & 0.01136 & 0.01155 & \\
\hline
\end{tabular}

Table 2. 10 Analysis of molecular variance (AMOVA) and spatial analysis of molecular variance (SAMOVA) using 610bp fragment of the $\mathrm{COI}$ gene for $C$. maculosa sampled along the Wairarapa coast. Site codes can be found in Table 2.6.

\begin{tabular}{|c|c|c|c|c|c|c|c|}
\hline \multirow{2}{*}{$\begin{array}{l}\text { Number } \\
\text { of Groups }\end{array}$} & \multirow[b]{2}{*}{ Group Composition } & \multicolumn{2}{|c|}{ Among pops within groups } & \multicolumn{2}{|c|}{ Within pops } & \multicolumn{2}{|c|}{ Among groups } \\
\hline & & $\phi_{\mathrm{sc}}$ & $\%$ Variation & $\Phi_{\text {ST }}$ & $\%$ Variation & $\Phi_{\mathrm{CT}}$ & $\%$ Variation \\
\hline \multicolumn{8}{|c|}{ AMOVA in Arlequin 3.5.2.2 } \\
\hline 2 & WCP-GL, HR-CA & $0.22303 * * *$ & 33.37 & $0.66633^{* * *}$ & 9.58 & $0.57054^{*}$ & 57.05 \\
\hline 2 & WCP-FP, RI+CA & $0.45942 * * *$ & 38.57 & $0.61427^{* * *}$ & 32.78 & $0.28645^{\mathrm{NS}}$ & 28.65 \\
\hline 3 & WCP-GL, HR+FP, RI+CA & $0.19094 * * *$ & 39.9 & $0.60096 * * *$ & 9.42 & $0.50679 *$ & 50.68 \\
\hline SAMOVA & WCP-GL, HR+RI, FP, CA & $0.00262^{*}$ & 40.54 & $0.59457^{* * *}$ & 0.11 & $0.59351^{* *}$ & 59.35 \\
\hline \multicolumn{8}{|c|}{ SAMOVA in SAMOVA 2.0} \\
\hline 2 & WCP-GL, HR-CA & $0.26393 * * *$ & 23.77 & $0.76227^{* * *}$ & 8.52 & $0.67702^{*}$ & 67.7 \\
\hline 3 & WCP-GL, FP, HR+RI+CA & $0.10981 * * *$ & 27.8 & $0.72202^{* * *}$ & 3.43 & $0.68773 *$ & 68.77 \\
\hline 4 & WCP-GL, HR+RI, FP, CA & $0.02219 * * *$ & 30.34 & $0.69663 * * *$ & 0.69 & $0.68974 * *$ & 68.97 \\
\hline 5 & WCP-GL, HR, FP, RI, CA & $\mid-0.02241^{*}$ & 31.73 & $0.68272^{* * *}$ & -0.7 & |0.68967* & 68.97 \\
\hline 6 & WCP, TO+GL, HR, FP, RI, CA & $-0.02053^{\mathrm{NS}}$ & 33.09 & $0.66909 * * *$ & -0.67 & $0.67574 *$ & 67.57 \\
\hline
\end{tabular}

NS, non-significant; * $\mathbf{p}<0.05 ; * * p<0.01 ; * * * p<0.001$ 


\subsubsection{Discussion}

Spotted whelk populations sampled at seven locations along the Wairarapa Coast show an interesting pattern of high and low connectivity. The three southern populations (WCP, TO, GL) form a genetically connected group that is disconnected from the northern sites. This southern grouping is characterized by lower haplotype and nucleotide diversity, similar to the Wellington grouping in the North Island dataset. The strong support for this southern grouping through AMOVA and SAMOVA suggests a genetic break between GL and HR. This implies the presence of a semi-permeable dispersal barrier or the recent removal of a historically impermeable barrier. The presence of a mixture of northern and southern haplotypes in the middle populations (HR and FP) suggests there is a contact zone between the two areas. If crawling dispersal is slowly occurring from both northern and southern populations, then this blending pattern containing a high proportion of both haplotypes would be expected. Gene flow into these two middle populations is also supported by the lack of unique haplotypes, which are expected to accumulate in isolated populations. Between-group differentiation was maximised by dividing the northern cluster into three groups. However, the grouping of HR and RI is surprising, at it suggests the possibility that dispersal events bypass the FP population. Such coastal "leap frog" dispersal has been suggested for species that are able to raft on floating substrata (Figure 1.2, Thiel and Haye 2006). This type of dispersal could explain why an isolation-by-distance pattern, which relies on dispersal between nearest neighbours, was not detected (Thiel and Haye 2006). The lack of an IBD pattern could also be due to the small geographic scale. Patterns of IBD are most obvious at intermediate scales and when the distances between locations are 2-5 times greater than the dispersal distance of the species (Palumbi 2003). When the entire East Coast was used for a Mantel test, $\phi_{\text {ST }}$ regression indicated insignificant structure $\left(r^{2}=0.258, p=0.0568\right)$, but Slatkin's linearized differentiation significantly supported an IBD pattern $\left(r^{2}=0.383, p=0.0078\right)$.

The conflicting results of the Mantel test for the North Island dataset and the leapfrog grouping between RI and HR on the Wairarapa suggests an alternative dispersal mechanism may influence spotted whelk connectivity and distribution. While rafting dispersal has been supported for some New Zealand direct developing gastropods (Cumming et al.2014), these species are often highly associated with their algae raft. Spotted whelks are carnivorous scavengers that are associated with shallow rocky habitat rather than algae or wood, which would greatly reduce their rafting potential. However, the beach at the mouth of the Glendhu River is covered in a wide band of drift wood ( $>1 \mathrm{~m})$. It's possible that during communal egg laying some females attach eggs to a piece of drift wood. The northbound, nearshore Wairarapa Current could then move the wood north to HR or FP (Figure 2.1A). Since each capsule contains an average of 7 hatchlings (Carrasco and Phillips 2014) it would take only one or two random drifting events to transport a large quantity of dispersers northwards. The maternal 
inheritance of mtDNA and lack of variation from the Glendhu population would ensure that nearly every hatchling emerging from drifting capsules would contain the Wellington haplotype (Hap 1). Depending on survival and reproductive success, these random events could produce the high frequencies of southern haplotypes found at HR and FP. However, this scenario does not explain the connectivity between $\mathrm{HR}$ and RI, as no such accumulation of driftwood was observed at $\mathrm{HR}$. Egg capsule rafting may not be the only mechanism for dispersal by water. The communal egg laying behaviour often leads to females laying eggs on the shells of other females (Figure 1.3B). Since spotted whelks like to bury in gravel and hide under rocks, it's likely that the capsules would get dislodged before the 9 week developmental cycle was finished. While drifting of unattached C. maculosa egg capsules has not been confirmed, a clump of $C$. adpsersa capsules, which are morphologically very similar, was observed drifting at the Napier collection location.

Overall, genetic connectivity was low or absent in all northern Wairarapa sites but high enough to be panmictic between all southern sites (Table 2.9). Advantageous alleles can be spread with the migration of only 1 individual every 10 generations, which corresponds to a $\phi_{S T}<0.35$ (Lowe and Allendorf 2010). All of the northern sites exhibit differentiation below this threshold between each other, but northern and southern differentiation is much higher. Adaptive alleles would likely spread quickly within northern or southern groups, but not between the two groups and further supports the hypothesis of a historic barrier between the two groups. To gain a better understanding of the mechanisms operating along the Wairarapa coast, finer scale sampling at the other North Island disjunctions should be undertaken. If rafting events are a large contributor to dispersal, then exploring the rocky coastline between GTT \& GTA or GTA \& BOM could indicate the relative of importance of crawling versus rafting dispersal. Conversely, if coastal barriers restricting crawling dispersal are the primary mechanism creating structure, then the Taranaki populations may show a similar pattern. Unfortunately, there are unlikely to be populations between TMA and TNP from which to sample, due to the large expanse of soft sediment and absence of rocky habitat.

Assuming a neutral model of evolution (no selection or hitchhiking), insignificant neutrality tests indicate demographic stability for all populations. Plotting overall haplotype and nucleotide diversity suggested the Wairarapa coast is a large, stable population or has undergone secondary contact (Figure 2.7A). The highly divergent haplotypes found along the Wairarapa supports the interpretation that secondary contact has occurred. However, CA is the only population in which secondary contact is suggested, indicating that two highly divergent East Coast haplotypes are coming into secondary contact or that they have historically existed together after several founding events. When viewed in context of the North Island dataset, the Wairarapa sites show that Hap 27 occurs at high frequencies along the whole of the East Coast from GTT to HR. This haplotype is oddly missing in NA and PB, but 
this could be due to a small sample size and the high frequency of haplotype 28 . Haplotype 28 is also found over a large portion of the East Coast, including a single individual at FP.

The southern populations at both the North Island and Wairarapa scale exhibited a strong drop in genetic diversity. Reductions in diversity can occur from low effective population sizes, founder events, or bottlenecks. Observations of reduced diversity for direct developing gastropods in high latitudes has been attributed to recolonization from lower latitudes after a population constriction during the LGM (Kojima et al. 2004, Marko 2004, Keeney et al. 2009). Such a recolonization is indicated from diversity plots of the southern Wairarapa populations. A land bridge between the Wellington region and Marlborough Sounds was formed when sea levels dropped during the LGM. The deep Cook Strait canyon complex, and its associated trenches up the Wairarapa, would have posed a significant barrier to coastal dispersal on the eastern side of the land bridge (Figure 2.9). Slowly rising sea levels would allow crawling dispersal along the coast, which could explain the similarity between NEL and Wellington region populations. However, this assumption of crawling dispersal raises an important question. The southern Wairarapa group is farther away from the Wellington populations than from the northern Wairarapa, if the southern Wairarapa group was colonized by crawling after the removal of the land bridge, why is the Wellington haplotype (Hap 1) present and both East Coast haplotypes absent? The deep trenches occurring along the Wairarapa, between HR and TO, may have acted as a prolonged dispersal barrier consistent with the genetic break found by AMOVA grouping (Figure 2.9, Table 2.10). Crawling between HR, GL, and TO would have been prevented by these trenches, while crawling from south island would have been restricted by the Cook Strait trench (Figure 2.9). However, rafting of egg capsules from a southern refuge population containing the Wellington haplotype may have occurred. Two C. maculosa samples from the Kaikoura Peninsula were downloaded from the National Center for Biotechnology Information (NCBI, http://www.ncbi.nlm.nih.gov/genbank/) and compared to the Wairarapa dataset (reference numbers KP694145 and KP694146, Donald et al. 2015). From the 552 bp that could be aligned, both individuals were identified as the Wellington region haplotype (Hap 1), supporting the hypothesis of a southern refuge population. Sampling of the Chatham Islands and western South Island populations is needed to confirm a southern refuge hypothesis. 


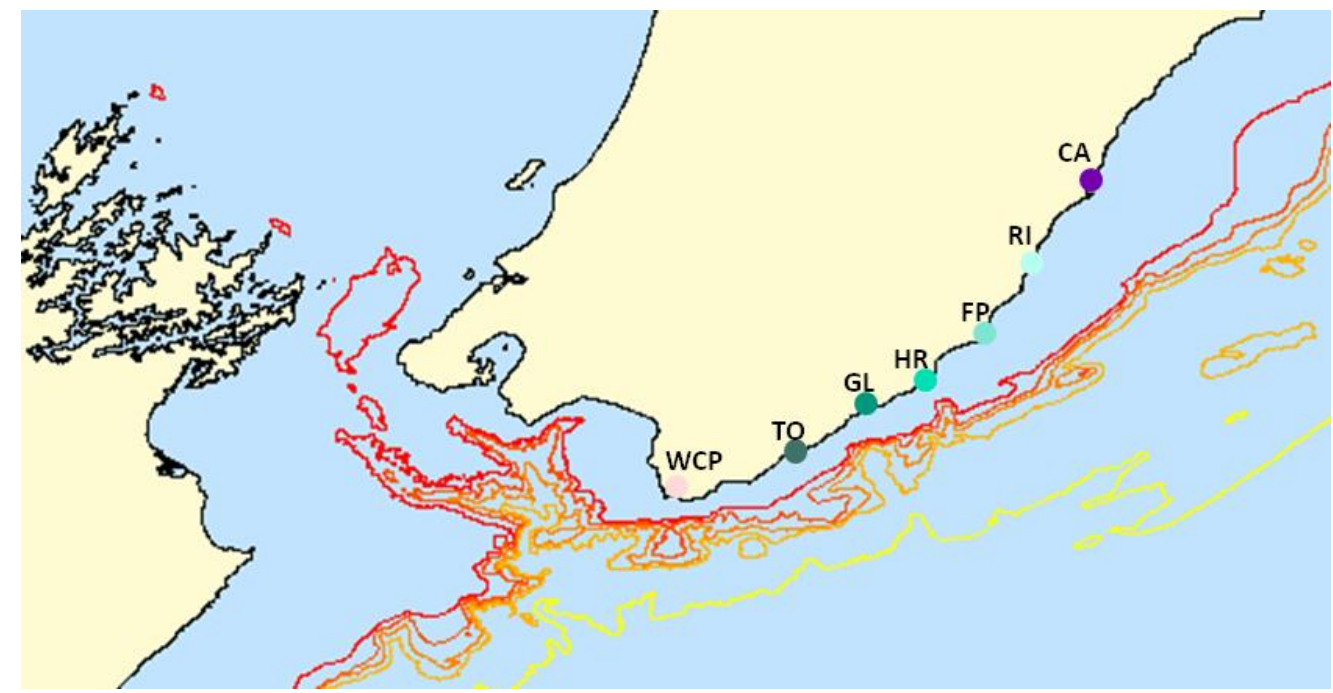

Figure 2.9 Bathymetry around at the Cook Strait and Wairarapa Coast of the North Island. Red, $100 \mathrm{~m}$; orange, $500 \mathrm{~m}$; yellow, $1000 \mathrm{~m}$. Approximate locations of Wairarapa sample sites are marked, see Table 2.6 for site code information. Image taken from NIWA's Coastal and Marine Data Portal (http://www.os2020.org.nz/project-map-sam/), source: Land Information New Zealand. Contour lines were interpreted from a 1960 bathymetric chart (http://www.teara.govt.nz/en/map/5962/bathymetric-chart-1960).

An Auckland origin of divergence was discussed in Section 2.3.3 and is supported by the high frequency of Hap 6 in the Auckland and Bay of Plenty regions. Haplotype 6 occupies a central position in the haplotype network with a star burst pattern of recent haplotypes found in the North and highly divergent haplotypes found in the other regions. If Auckland is the origin site and crawling is the dominant form of dispersal, then the question becomes how was Nelson founded? During the Pliocene (6-2MYA), the North and South islands were separated by a large amount of water, Northland was separated by an ocean channel, and the East Coast was composed of a series of small islands (Figure 2.10, Stevens and Hogg 2004). If rafting of egg capsules is capable of founding distant populations, then dispersal from Auckland could have occurred through the Northland channel or from around the East Coast. Such rafting could have occurred on pumice material created by volcanic activity in the Auckland region, which has been active since the late Pliocene (Kereszturi et al. 2013). The island configuration of the East Coast would explain the large divergence between the two East Coast haplotypes, as multiple founding events could land on different islands and evolve in isolation (Figure 2.10). Once the East Coast islands were connected during the LGM, both haplotypes could crawl by sporadic drifting of egg capsules and continuous crawling of adults. Examining the populations around the Northland Peninsula could illuminate the strength of these historic dispersal pathways. 


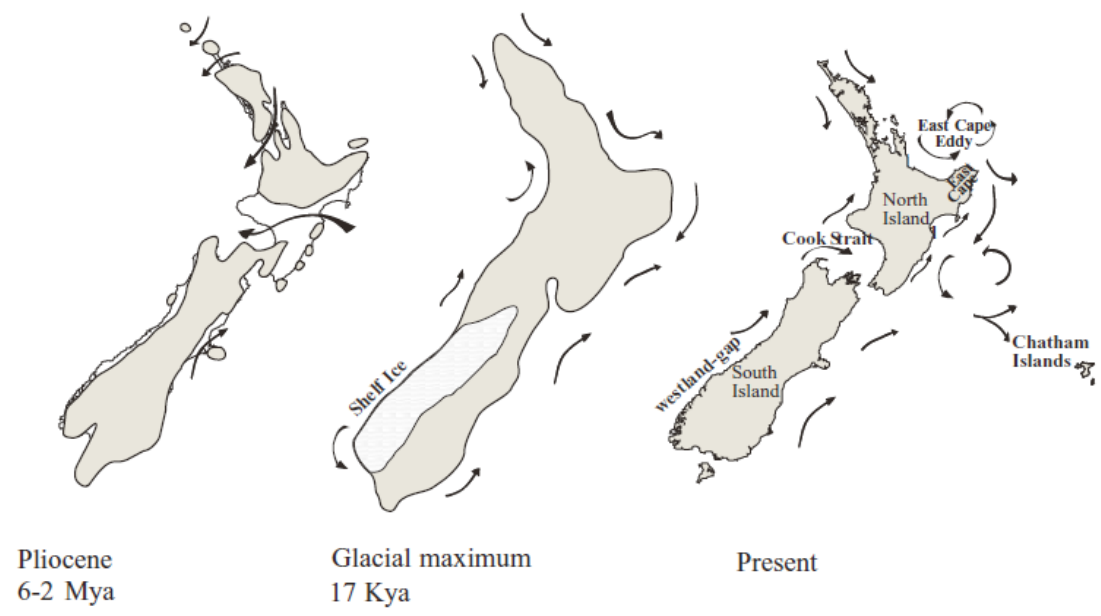

Figure 2.10 Variable coastlines of New Zealand through over the last six million years (Mya). Land above sea level is shaded grey. Modern New Zealand is outlined in black for the Pliocene. Arrows represent the dominant currents. Image taken from Stevens and Hogg (2004).

Overall, the genetic pattern of $C$. maculosa populations at large and small scales indicates discrete populations with low genetic connectivity. This is a pattern seen for many direct developing species (Lee and Boulding 2009, Barbosa et al. 2013, Pálsson et al. 2014). It is unlikely that the genetically differentiated northern populations will experience demographic connectivity; indicting small populations may be at risk of local extinction. The lack of differentiation between southern populations indicates strong genetic connectivity, but it is unlikely they experience demographic connectivity from crawling dispersal. The lack of differentiation between southern populations is probably due to recolonization after the LGM rather than exchange of individuals (Keeney et al. 2009). This study used the conservative mitochondrial $\mathrm{CO} 1$ protein coding region to investigate genetic connectivity. As discussed in Section 1.1, mtDNA is useful in detecting historic patterns of connectivity and investigating demographic trends. The use of microsatellites could give a better picture of contemporary connectivity and current dispersal barriers. However, microsatellites are often species specific and can be time consuming to create. A couple of microsatellites have been developed for commercially harvested buccinidae species (White and Toonen 2008, Wang et al. 2011), but it is unlikely they would amplify for this endemic species. The historic pattern of deeply divergent haplotypes on the East Coast and leapfrog dispersal along the Wairarapa suggests potential rafting of egg capsules as an alternative, though likely rare, mechanism for dispersal. The discrete population pattern and narrow contact zone at HR and FP is consistent with a general dispersal by crawling strategy. Examination of other species with similar life history traits and habitat requirements would strengthen these findings, particularly if studied at the same location. The identification of a genetic break between HR and GL should be used to determine if other species, both direct developing and planktonic, also exhibit a genetic break at this region. If the break is due to the deep coastal trenches during the LGM, it is likely that only direct developers will exhibit a genetic boundary at this location. 


\section{Chapter 3 \\ Dispersal Potential for Cominella maculosa Hatchlings by Drifting}

\subsection{Abstract}

Sessile invertebrates with direct developing life histories are thought to maintain connectivity between populations through passive rafting or drifting dispersal. However, direct observations of such dispersal mechanisms are rare, especially for species that do not associate with rafting substrate. Cominella maculosa offspring are believed to disperse by crawling along the substrate after emergence from egg capsules attached to the benthos. The aim of this study was to determine if these hatchlings might also disperse by drift after being suspended in the water column. To investigate, three laboratory experiments were conducted and field sampling of the water column was undertaken at two sites. Hatchlings placed on rocks were subjected to simulated wave force and still treatments to determine if hatchlings could be dislodged into the water column. Hatchlings were suspended in circular water currents, of variable speed, to determine if they could be carried by water flow over a short period. Hatchlings were maintained in circular water currents for prolonged periods to test whether they could remain in the water column for sufficient periods of time required to facilitate long distance connectivity between populations. Plankton traps were set on rocky coastlines of the Wellington Harbour and the Wellington south coast to examine if hatchlings could be detected in the water column. Laboratory trials indicate hatchlings can be dislodged, suspended into the water column, and transported short distances by water current. However, hatchlings do not remain in drift when subjected to vertically circulated water columns for a prolonged period. Plankton traps were successful in collecting one living Cominella virgata hatchling, supporting the lab results that prolonged suspension in the water column is likely to be rare. It is probable that local water flow conditions will influence small-scale dispersal and distribution, but it is unlikely that long distance drift dispersal of hatchlings will contribute to maintaining population level connectivity. 


\subsection{Introduction}

Dispersal facilitates expansion of a species' distribution and promotes population connectivity at the evolutionary and ecological level. Genetic connectivity maintains high genetic diversity that can allow populations to adapt to a changing environment (Hedgecock 1986, Losos 2011). Demographic connectivity influences metapopulation dynamics, including potential recolonization of habitats after extinction events (Brown and Kodric-Brown 1977, Turgeon and Kramer 2012). Understanding a species' dispersal ability at all life stages is integral for inferring connectivity and interpreting patterns of genetic diversity.

Many marine invertebrates exhibit sessile or sedentary adult stages. Therefore, most benthic species will use the water column to aid dispersal by broadcast spawning gametes (Crimaldi and Zimmer 2014) and/or producing planktonic larvae (Todd et al. 1998). However, in contrast to those strategies, many species have a direct development life history where embryos develop in a protected environment until fully formed. In gastropod molluscs, where this is relatively common, direct development may occur in brood chambers of adults (e.g. Higgs et al. 2009) or in egg capsules attached to a substrate (e.g. Carrasco and Phillips 2014). Once development has been completed, the offspring emerge as miniature versions of the adults. Since dispersal of these hatchlings is assumed to occur by crawling, like the adults, the expected dispersal potential of direct developers is expected to be low.

The ability of sedentary, direct developing species to colonize distant habitat is often attributed to their ability to travel by passive means (Highsmith 1985, Johannesson 1988, Colson and Hughes 2004). Passive dispersal occurs by "rafting" on floating substrata (Thiel and Gutow 2005, Hellberg 2009) or by "drifting" in the water column without being attached to a substrate (Winston 2012). Due to the difficulty in observing drifting and rafting events in a large ocean, genetic methods are often employed to infer levels of connectivity between populations and support or reject these dispersal hypotheses. Such a rafting hypothesis was recently supported by the observance of several direct developing taxa on New Zealand beach-cast bull kelp that had spent months at sea (Nikula et al. 2013, Cumming et al. 2014). In the same South Island area, beach-cast bull kelp (Durvillaea antarctica) has been found to originate as far as $400 \mathrm{~km}$ away in the Subantarctic Islands (Fraser et al. 2011, Bussolini and Waters 2015), suggesting that rafting can create long distance dispersal events and even maintain genetic connectivity over large spatial areas.

The spotted whelk, Cominella maculosa, is a direct developing gastropod associated with intertidal rocky shores of New Zealand (Morton and Miller 1968). Dispersal by adults and hatchlings is assumed to occur by crawling along the substrate, although adults of the related species $C$. glandiformis has been recorded to float by their foot in calm waters (Bimler 1976). Since C. maculosa are carnivorous 
scavengers, they are not expected to associate with algae and the likelihood of dispersal by rafting is expected to be low (Donald et al. 2015). However, analysis of mitochondrial DNA sequences indicates pockets of higher than expected connectivity between North Island populations that may be due to rafting egg capsules (Chapter 2.1 Abstract). C. maculosa hatchlings can be easily disturbed into the water column in a laboratory setting (MD unpublished observations), but it is unknown if they are transported any substantial distance by currents. The purpose of this study was to investigate if drifting could be a potential dispersal mechanism for $C$. maculosa hatchlings.

To examine hatchling drift dispersal, three laboratory experiments were conducted at Victoria University Coastal Ecology Lab (VUCEL) and nearshore plankton sampling was undertaken at two sites in Wellington. The first experiment tested whether hatchlings could be dislodged into the water column. The second experiment tested whether hatchlings caught in a current would be transported with the current or if they would sink. The last experiment was designed to determine if hatchlings in water currents would remain suspended and be able to drift for a prolonged period of time. Plankton traps were not expected to trap a large number of hatchlings, but if even one hatchling was caught then it would indicate that dislodgement and suspension in the water column is possible.

\subsection{Materials and Methods}

\subsubsection{Laboratory Experiments}

\subsubsection{Hatchling Collection, Handling, and Counting}

Egg capsules were collected by either taking small rocks with attached egg capsules from the field to VUCEL or by using a scalpel to detach capsules in the field. Collections occurred in November and December 2015 from the following three Wellington sites: Waitaha Cove (latitude: $-41.341095^{\circ}$, longitude: $174.792412^{\circ}$ ), Point Halswell (latitude: $-41.283981^{\circ}$, longitude: $174.825811^{\circ}$ ), and Shelly Bay (latitude: $-41.300286^{\circ}$, longitude: $174.817154^{\circ}$ ). Detached capsules and the emerging hatchlings were stored in a flowing seawater bath in a $97 \times 97 \times 80 \mathrm{~mm}$ plastic container with $700 \mu \mathrm{m}$ mesh sides and a lid. Rocks collected with egg capsules attached were scraped clean of algae and other sessile fauna and placed in aquaria $(590 \times 300 \times 300 \mathrm{~mm})$ with flowing sea water. Experiments were undertaken when enough hatchlings had emerged from capsules.

Experimental hatchlings were randomly selected from the containers or tanks and transferred to petri dishes for examination under a dissecting microscope where they were classified as either alive or unresponsive. Alive hatchlings were either actively moving or stationary with a visibly extended siphon. Unresponsive hatchlings looked like empty shells or had tissue visible with no extended siphon. Only 
hatchlings categorized as alive were selected and randomly assigned to an experimental treatment (50 per treatment). Unresponsive hatchlings were returned to holding containers.

Initial trials began before large numbers of hatchlings emerged naturally from egg capsules. Therefore, the first trials used an equal mix of hatchlings that had naturally emerged and that had been removed from egg capsules by scalpel. Removal of hatchlings by scalpel does not affect their survival (MD unpublished observation). This mix of hatchlings, hereafter referred to as "mixed harvest", was used in seven drift in current experiments and one dislodgment experiment. Since sustained drift experiments were collected and counted in the mornings, hatchlings were occasionally reassigned to a second experiment. This occurred three times for dislodgement experiments and six times for drift in current experiments. When reuse of hatchlings occurred, the hatchlings were pooled together, re-examined for activity levels, and redivided into groups of 50 for randomized treatment allocation.

In order to account for the fact that each group of hatchlings were collected from different containers or tanks and might have previously undergone experiments, a variable titled "cohort" was created. Each batch of hatchlings collected from the same tank or container was given the same cohort identifier. Hatchings from "mixed harvest" methods were also identified by cohort. If hatchlings were reused from sustained drift treatments, only hatchlings from the same cohort were pooled and redivided. These redivided groupings were then given a new cohort identity. A total of 19 cohorts were identified in this manner for all trials. The cohort variable, as well as the identifier of the transfer petri dish, was considered a random effect for all trials during analysis.

After each experimental trial, hatchlings were collected, placed in the transfer petri dish and examined under a dissecting microscope. The number of alive and unresponsive hatchlings was recorded. Hatchlings that were obviously alive, but had shell damage or missing shells were noted as 'damaged'. Since damaged whelks would be unlikely to survive in the long term, they were pooled with the unresponsive category for data analysis. Once counted, hatchlings were either reused or returned to a mesh container kept in the water bath. All hatchlings were kept until experiments were completed and then they were released at their respective collection locations.

\subsubsection{Dislodgement Experiment}

This experiment was designed to test the hypothesis that intertidal wave action can facilitate hatchling dispersal by dislodging individuals from rocks and into water current. A simple tide pool was simulated by placing an aquarium with an outflow hole into a larger water bath (Figure ). Hatchlings were placed on a large rock in the aquarium and then subjected to artificial waves. An outflow trap caught any dislodged hatchlings that exited the aquarium. It was predicted that the number of hatchlings collected 
from the outflow drain would be significantly greater under a wave treatment compared to a still treatment. The null hypothesis predicted that both treatments would contain a similar number of hatchlings in the outflow water. This experiment was run as a paired test, with hatchlings first undergoing one treatment (randomly assigned) and then undergoing the alternative treatment. This was designed to compare the effect of treatments between the same individuals.

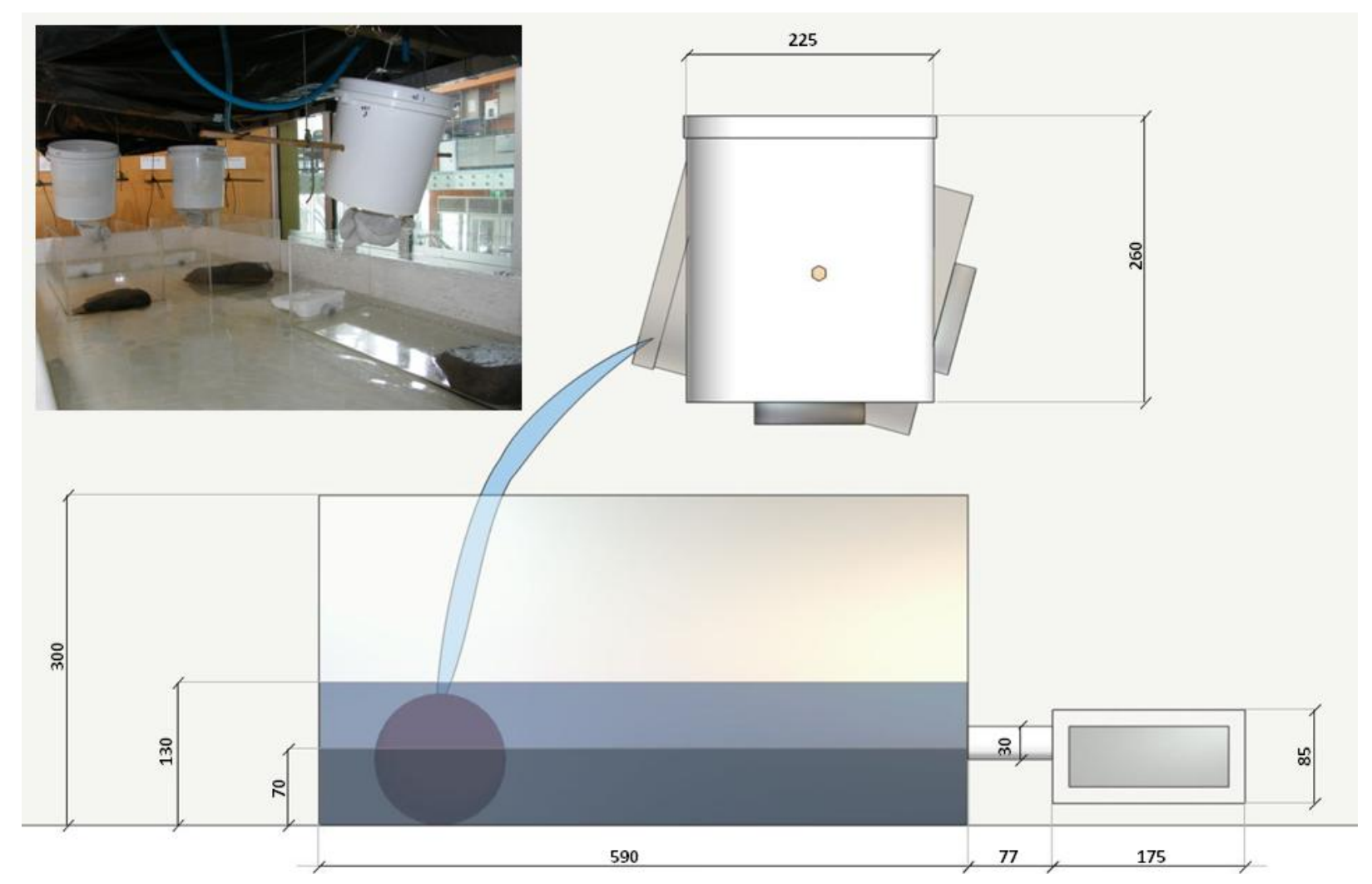

Figure 3.1 Dislodgement experiment setup $(\mathrm{mm})$ with inset of concurrent replicates at shallow depth. Note the actual rocks are flat, the round rock in the diagram is not representative. Rocks were placed inside aquaria ( $300 \mathrm{~mm}$ wide) to replicate a simple intertidal environment at low tide. Two water depths were used: shallow depth $(70 \mathrm{~mm})$ exposed the rock face, deep depth $(130 \mathrm{~mm})$ covered the rock. Wave force was created with tipping buckets positioned above the rocks; buckets were reset by a 35 gram bottom weight. Dislodged hatchlings caught in outflow water were collected in drain traps with mesh sides.

To set up this experiment, three relatively flat rocks of roughly similar size and shape were collected from Point Halswell on 27 December 2015. All rocks were scraped clean of tube worms, although small barnacles remained, and left to dry for two days. Each rock was placed in a separate aquarium with two depth treatments (Figure ). The shallow treatment left the tops of rocks exposed, while rocks were submerged in the deep treatment. Outflow water was directed into a mesh sided collection container via a short plastic pipe affixed opposite the rock (Figure ).

The wave treatment was created by using a tip bucket system suspended above the rocks. Buckets (10 L) were suspended on stakes through two slightly offset holes and filled with raw seawater by hoses fixed overhead (Figure ). Buckets filled with an average of $7.5 \mathrm{~L}( \pm 0.36, n=9)$ before tipping directly onto the rock below. Weights suspended from the bottom of the buckets ensured they reset to the 
upright position for refilling. Hoses were used at full pressure, creating a tip rate of 5 tips in 2 minutes. Aquaria were set in a seawater bath, ensuring a constant water depth for the still control treatment. Three replicate experimental units were set up in the same sea table and run concurrently (Figure inset). The effects from rock differences, as well as any volume variation between buckets, were considered a tank effect. Therefore, rocks were never switched between aquaria and aquaria were never switched between buckets. Hatchlings were always tested in the same tank for the paired design.

Tanks, rocks, and outflow containers were well rinsed before the commencement of each paired trial. Rocks were wetted before individually transferring 50 hatchlings by pipette onto the rocks. Hatchlings were haphazardly placed, with the aim to scatter them across the surface, and left to acclimate for ten minutes. Tanks assigned to the still treatment were covered with plastic to prevent splashing disturbances from the wave treatments of other tanks. Hatchlings were initially exposed to the wave treatment for two hours $(n=3)$. However, all subsequent trials were run for one hour as results were similar and this saved time $(n=15)$. At the end of the trial period, the water bath was drained for hatchling collection. Rocks were placed in buckets and rinsed with a strong hose and wiped down by hand to collect hatchlings. Outflow containers were then detached and set aside while the remaining hatchlings were collected by pipette from the tank. After all hatchlings were counted they were returned to their original transfer petri dish while the tanks were reset for the next trial. The same individuals were then placed on the same rock in the same tank, allowed to acclimate for ten minutes, and subjected to the treatment they had not yet experienced.

Ideally, all hatchlings would be recovered for running the paired design. However, the number of hatchlings in each treatment was not necessarily equal, as the small size of the whelks meant they could be easily lost in transfer, crushed when washing rocks, or possibly dislodged out of the tank by wave splash. Due to the paired nature of the design, lost hatchlings were not replaced to equal 50. Hatchlings identified as unresponsive after the first treatment were recorded, but also not replaced. Eighteen paired trials were performed on six days over a two week period using hatchlings from ten cohorts. Nine paired trials were performed for each depth treatment. Seven cohorts were tested in shallow treatments, including one "mixed harvest" cohort and two cohorts previously subjected to sustained drifting experiments. Only four cohorts were tested in deep treatments.

\subsubsection{Drifting in current}

Continuous circular water currents were set up to test the hypothesis that hatchlings can be transported if they end up suspended up in a current. It was predicted that the number of hatchlings exiting a bucket through outflow drains would be significantly larger in the presence of a fast current 
compared to a slow current or no current. The null hypothesis predicted there would be no difference between any of the current treatments.

Raw seawater hoses were attached to buckets $(10 \mathrm{~L})$ that had three outflow holes drilled $25 \mathrm{~cm}$ apart (Figure 3.1). When turned on, the hose created a constant circular current in the bucket. Hose flow was adjusted so that the inflow matched the outflow at a constant water height between 10.6 and 11.6 $\mathrm{cm}$. Three buckets were used to create slow, fast, and control still treatments. Water currents were altered by changing hose flow, while the still treatment was created by placing the bucket in an aquarium of raw sea water. To ensure equal set up between treatments, an inflow hose was affixed to the still bucket lip, but was turned off to prevent current.
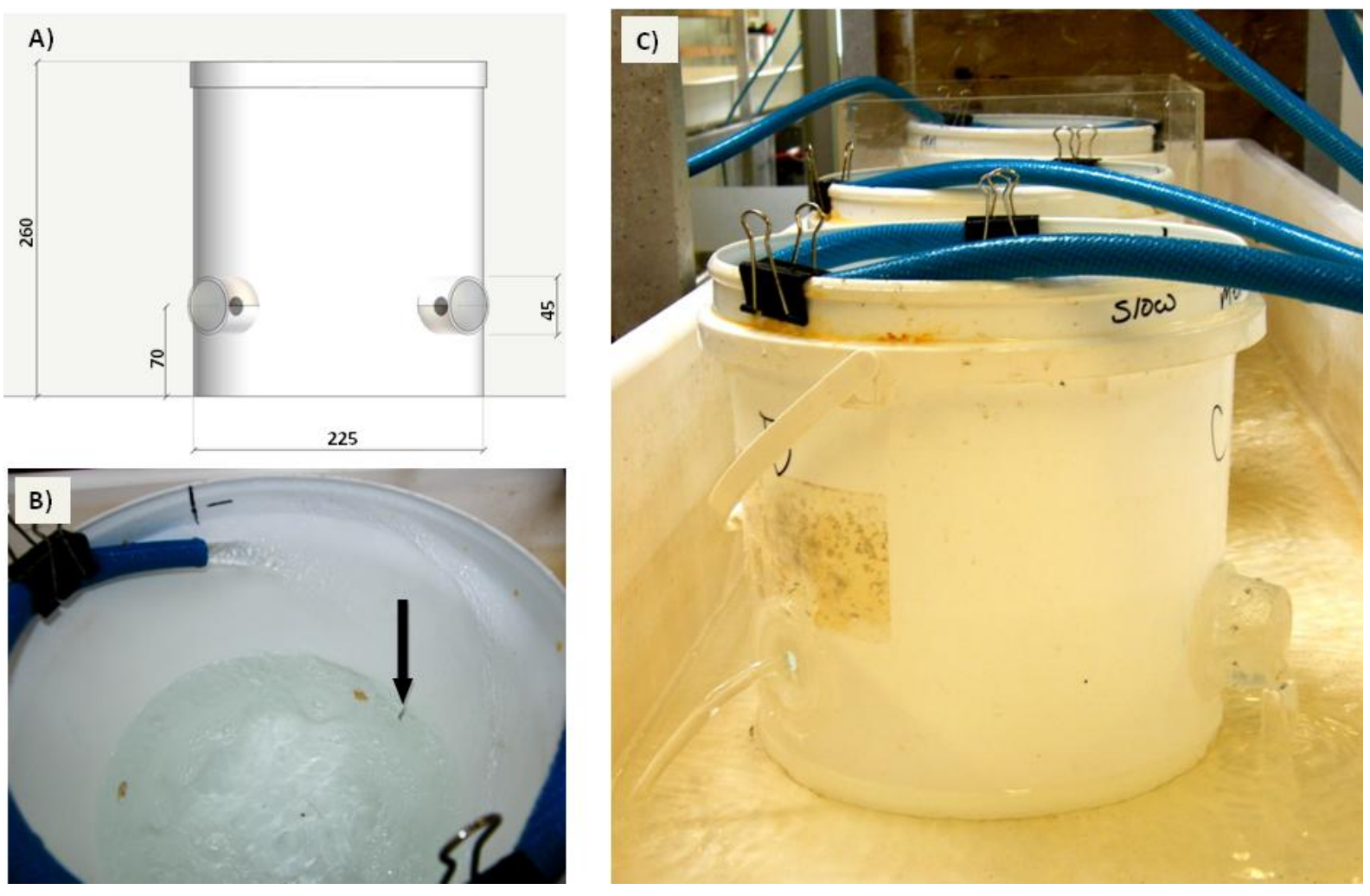

Figure 3.1 Drift in current experiments. A) Side view diagram with bucket and outflow trap dimensions (mm). B) Top view of the fast treatment for the circular water current experiment. Hoses were aligned parallel to the bucket lip until the last $7 \mathrm{~cm}$, where the hose mouth was located $3.3 \mathrm{~cm}$ lower. Hatchlings were added $3.5 \mathrm{~cm}$ up-current from the first outflow hole below the inflow water (black mark below black arrow). C) Three treatments running concurrently. The slow treatment is in the foreground with an outflow trap attached on the right and unattached on the left. The fast treatment in the middle and the still treatment can just be seen in an aquarium $(590 \times 300 \times 300 \mathrm{~mm})$ in the background.

To alter water current speed, yet maintain equal water height between treatments, a larger outflow hole $(15 \mathrm{~mm})$ was used in the fast treatment and a small outflow hole $(10 \mathrm{~mm})$ in the slow treatment. An equal volume of water, as indicated by height, was deemed more important to the outcome of the study than an equal diameter outflow hole. To err on the side of caution, still treatment outflow holes were made at the larger $15 \mathrm{~mm}$. Outflow volumes were determined by measuring the volume of water exiting each outflow over a five second period when water height was at $10.8 \mathrm{~cm}$. These volumes were 
then combined to determine total outflow volume per second. Outflow measurements were taken three times in pre-experiment set up and four times before experimental trials. Total outflow averaged $138.0 \mathrm{~mL}$ per second $( \pm 3.4 \mathrm{~mL}, \mathrm{n}=7)$ for the slow treatment and $319.9 \mathrm{~mL}$ per second $( \pm 10.2 \mathrm{~mL}, \mathrm{n}=7$ ) for the fast treatment. In order to compare experimental currents $(\mathrm{mL} / \mathrm{s})$ to coastal currents $(\mathrm{m} / \mathrm{s})$, the average volume of water exiting all three outflow holes was considered as a cylinder with a radius equal to the outflow hole radius $\left(V=\pi r^{2} h, 1 \mathrm{~mL}=10^{-6} \mathrm{~m}^{3}\right)$. The height of the average cylinder was calculated and considered as the distance of water exiting the bucket in one second. The increased radius of the fast treatment negated the increased volume of water, so that both fast and slow treatments produced a current of $0.6 \mathrm{~m} / \mathrm{s}$.

Set ups were left for 10 minutes for control water to settle and to ensure water height was stable. Plastic cups with $700 \mu \mathrm{m}$ mesh bottoms were affixed to the outside of the buckets to filter outflow water and collect hatchlings (Figure 3.1). At the start of each trial, 50 hatchlings were individually added to the bucket by pipette. To prevent hatchlings from immediately being washed out the first outflow hole, all hatchlings were added $3.5 \mathrm{~cm}$ up-current from the first outflow hole encountered by the incoming hose water (Figure 3.1B). Hatchlings were not forcefully ejected into the water current, but were gently expelled from the tip of the pipette at the surface of the water. Trials were run for 2 hours after the addition of the last hatchling. Buckets were checked every 30 minutes to count the number of hatchlings crawling on the bucket walls. This check was to ensure that hatchlings in the fast and slow treatments weren't actually sinking to the bottom and crawling out the outflow holes. This check also verified that crawling was the means by which hatchlings exited the still treatment. Trials were ended by removing the hoses and allowing the buckets to drain through the outflow holes. The control was gently lifted from the filled aquaria and allowed to drain. Hatchlings were transferred from collection cups and buckets to petri dishes and counted using previously outlined methods. Treatments were concurrently run on seven days over a three week period. Each treatment was replicated nine times. A total of 15 cohorts were used, including three "mixed harvest" cohorts and three cohorts previously subjected to sustained drifting experiments.

\subsubsection{Sustained drifting}

Long distance dispersal will only be possible if hatchlings remain in currents for a prolonged period of time. In order to prevent drifting hatchlings from exiting the experimental container, circular currents were driven by air pumps instead of hoses. It was predicted that after a prolonged period ( $>12$ hours) more hatchlings would be found in the water column of strongly mixed treatments compared to weak or still treatments. 
Air tubes were fixed to the lip of nine glass jars $(4 \mathrm{~L})$ filled with raw seawater and positioned close to the side of the jar, not the centre (Figure 3.2). Six tubes were attached to a Resun LP100, 140L/min air pump to create mixing treatments. The three remaining tubes were used for still control treatments and were not connected to the air pump. Three strong mixing treatments were created by attaching a $26 \mathrm{~mm}$ cylinder airstone to the tubes. Three weak mixing treatments were created by using the air tube with no airstone. Three replicates of each treatment were haphazardly assigned to jars during set up of each session.
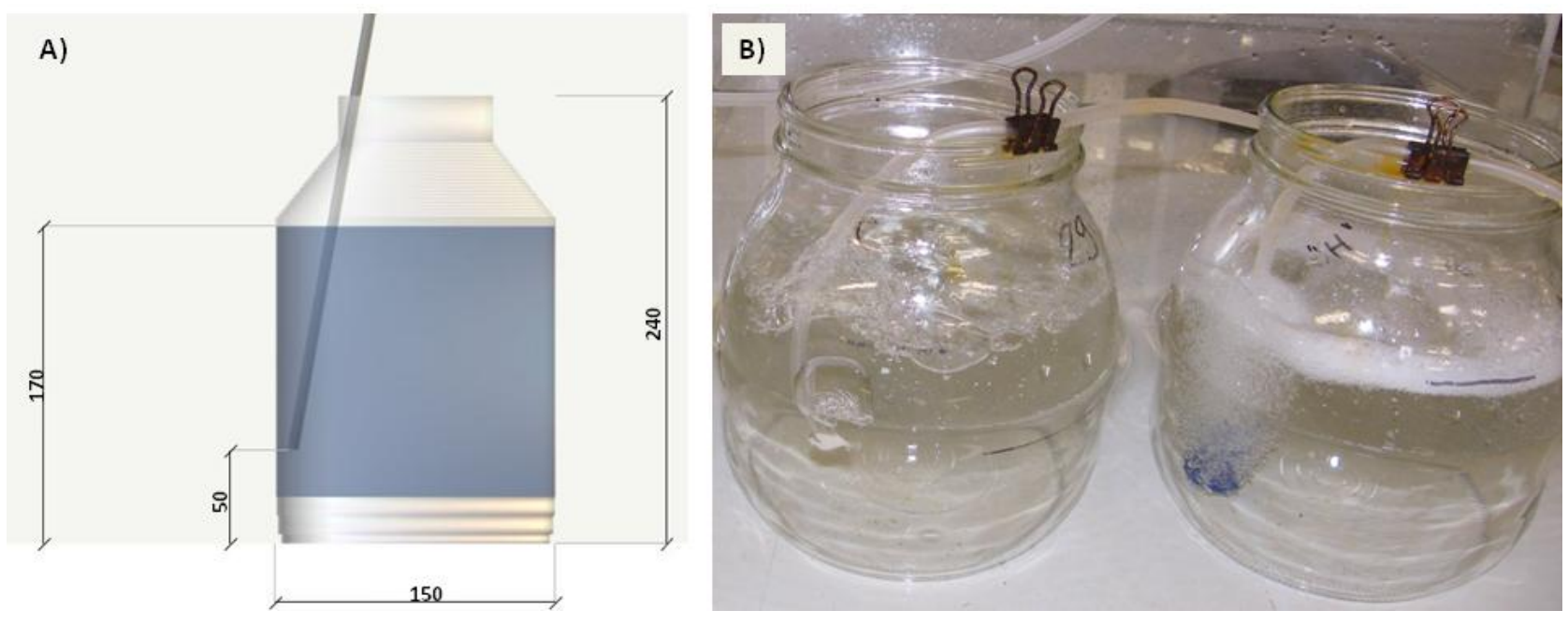

Figure 3.2 Experimental set up for the sustained drifting experiment. A) Diagram showing jar dimensions, water level created with $3 \mathrm{~L}$ of water, and position of air tube $(\mathrm{mm})$. B) Mixing treatments were created by connecting hoses to an air pump. Weak treatments (left) had no attachments on the air tube and strong treatments (right) were created by attaching an airstone to the air tube. Still treatments (not shown) were not connected to an air pump.

An index of mixing strength was created by timing how long it took a drop of dye to mix into a consistent colour. The timer started when a drop of blue food colouring was added by pipette to the centre of the jar $3 \mathrm{~cm}$ above the water surface. Strong mixing treatments mixed to a constant colour in an average of 5.5 seconds $( \pm 1.2 \mathrm{sec}, \mathrm{n}=9$ ), the weak mixing treatment mixed in 9.7 seconds $( \pm 1.6 \mathrm{sec}$, $n=9$ ). The control treatment was not indexed, as one drop of dye had barely diffused from the centre of the water in ten minutes when first trialled.

Before each trial, jars were rinsed with raw sea water, filled with $3 \mathrm{~L}$ of raw seawater, and set in a water bath. Treatment tubes were haphazardly added to each jar and the air pump started. Hatchlings were added by submerging the transport petri dish in the jar and dislodging whelks using water pressure from a turkey baster. The turkey baster was then squeezed 3-5 times to ensure all whelks started the trial suspended in the water column. Trials were run overnight; usually for 15.5 hours, but one trial ran 16.25 hours. At the end of the trial, jars were examined and any drifting hatchlings were collected with a metal strainer ( $1 \mathrm{~mm}$ mesh size). Air tubes were pulled out of the jars and hatchlings collected.

Eleven trials were conducted for each treatment over an eight day period, but twice a hose was found 
disconnected from the air pump and only nine trials from each treatment were analyzed. Of the seven cohorts identified for these trials, none were previously used in sustained drift experiments or collected by "mixed harvest".

\subsubsection{Analysis}

The response variable for the first two experiments (dislodgment and drifting in current) was the number of hatchlings collected in outflow traps. For the sustained drift experiments, the response variable was the number of hatchlings found drifting. Only hatchlings classified as alive were used for analysis. Unresponsive individuals may not actually be dead, but their lack of activity was considered a sign of poor survival probability.

While all experiments began with 50 hatchlings, recovery numbers varied for each trial. Recovery discrepancies were highest for the two experiments with outflow collections. This is likely due to the tiny size of the hatchlings, so any overlooked hole larger than $1.5 \mathrm{~mm}$ was a potential escape route out of the outflow trap. These escapees indicate the missing hatchlings went somewhere, therefore they could likely be added to the outflow count. However, in order to err on the side of caution, all trials were considered to be completed with the total number of hatchlings recovered after the experiment.

All analyses were conducted in R v3.2.2 (R Core Team 2015) using RStudio v0.99.484 (RStudio Team 2015). Generalized linear mixed models (GLMMs) were performed using the g7mer () function in the 7 me4 package (Bates et al. 2015). A binomial distribution, with the associated logit link function, was used so that each hatchling recovered in drift or in outflow was considered a "success" compared to the "failures" (total recovered hatchlings - successful hatchlings). Treatments were set as the fixed effect and the random effects of cohort and container were modelled for the intercept. The paired design of the dislodgment experiment was considered by setting the pair identifier as a random effect. Dislodgement trials also had the random effects of tank number and treatment order (wave or tip experienced first or second). The dislodgment model was also run with a second fixed effect of tank depth. Sustained drift experiments had an extra random effect of jar, but all GLMMs run with any combination of random effects produced variance-covariance warnings. Therefore, a simplified generalized linear model (GLM) was run for this experiment. The GLM excluded all random effects and was run using the $\mathrm{g} 7 \mathrm{~m}$ () function in the MASS package (Venables and Ripley, 2002).

To determine the goodness of fit for each model, pseudo $R^{2}$ values were obtained using the r. squaredGLMM() function of the MuMIn package (Barton 2016). The $r$. squaredGLMM() function

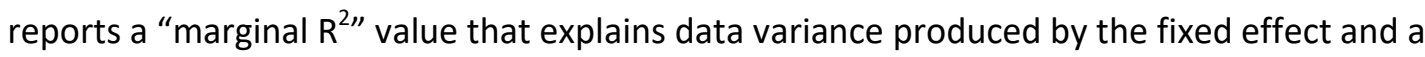

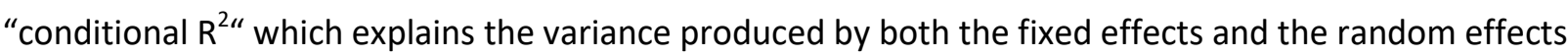


(Nakagawa and Schielzeth 2013). Pseudo $R^{2}$ values for GLMs were produced using the formula [1 - $\left.\frac{\text { residual deviance }}{\text { null deviance }}\right]$ (Zuur et al. 2009). Sustained drifting and drift in current models had three treatment levels, therefore the $\mathrm{g} 7 \mathrm{ht}()$ function in the multcomp package (Hothorn et al. 2008) was used to perform Tukey post hoc tests to compare all treatments.

\subsubsection{Plankton Sampling}

\subsubsection{Trap Construction}

Four intertidal plankton traps, based on the design of Castilla and Varas (1998) and Dudas et al. (2009), were constructed to sample coastal water for the presence of drifting hatchlings (Figure 3.3A). This style of "swash" trap works by draining wave water through a filter during the incoming and outgoing low tides (Chen et al. 2013). A stop valve prevents plankton from escaping the trap when it becomes submerged at high tide. Traps were deployed at low tide on exposed rock substrate, so that approximately one meter of water covered the traps at high tide. The distance from the top of the trap to the nearest rock of equal height was measured to indicate how far away a dislodged hatchling may have travelled. Deployment occurred during known emergence of wild hatchlings from egg capsules, between December and February.

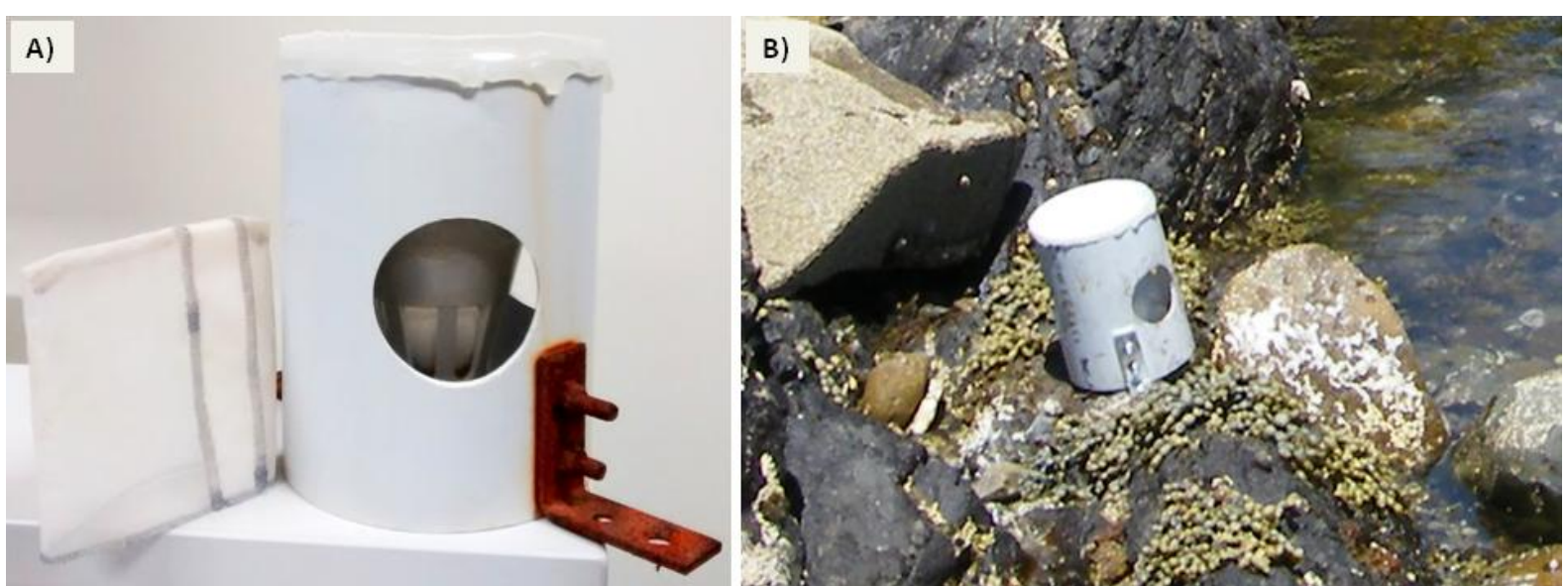

Figure 3.3 A) One of four intertidal plankton traps deployed at two sites in Wellington. Three outflow holes surround the main PVC body, a plastic funnel is adhered to the top of the pipe. A vent cowl with Styrofoam ball inside (visible through the outflow hole) is glued to the bottom of the funnel and acts as a stop valve at high tide. The mesh bag to the right would be zip tied to the vent cowl during deployment. Steel $\mathrm{L}$ brackets are used to bolt the trap to bedrock on site. B) Deployed in the field at Point Halswell during low tide.

The traps consisted of a $145 \mathrm{~mm}$ length of $100 \mathrm{~mm}$ diameter PVC tube with three $50 \mathrm{~mm}$ diameter drainage holes set equidistant around the middle of the pipe. Water entered the trap through a $170 \mathrm{ml}$ plastic funnel that was hot glued to the PVC pipe. The top of the funnel was cut so that less than $6 \mathrm{~mm}$ protruded from the top of the pipe. The funnel outflow was cut to $10 \mathrm{~mm}$ and a $50 \mathrm{~mm}$ plastic vent cowl was glued over it. A $15 \mathrm{~mm}$ diameter Styrofoam ball trapped inside the vent cowl acted as a floating stop valve. Filters were created by sewing $100 \mu \mathrm{m}$ mesh into bags and securing the top of the 
bag over the vent cowl with a zip tie. Two steel "L" brackets, set opposite each other, were fixed to the pipe by four stainless steel bolts. The traps were then secured to bedrock by two stainless steel screws and plastic wall plugs sunk into predrilled holes (Figure 3.3B). Plankton samples were collected by unscrewing the traps from the rock, removing the filter bags from the bottom, fitting a clean filter bag by zip tie, and reattaching the trap to the rock.

\subsubsection{Site Descriptions}

Traps were deployed four times in the Wellington Harbour (Point Halswell) between 27 December 2015 and 12 January 2016. Point Halswell is a rocky shore consisting of bare bedrock littered with boulders and cobble in the intertidal zone. It is a fairly linear coastline with few high tide pools exposed at low tide. Cominella maculosa and egg capsule presence was confirmed at the site before trap deployment. The sheltered position of Point Halswell in the harbour means wave energy at the site is inconsistent. A couple of stormy days occurred during the deployment period, but most of the weather was settled with little wind induced wave action observed. Traps were set 7-22 meters apart along the coastline, with the nearest rock of equal height ranging from $0.75-1.5$ meters. To ensure that any hatchlings entering the trap would remain in the trap, and not just crawl out, hatchlings were planted in two traps at Point Halswell for one sampling period.

Traps were deployed eight times on the Wellington south coast (Waitaha Cove) between 12 and 28 January 2016. This area is a rugged bedrock shelf of peaks and valleys creating a complex network of tide channels, large pools, and many exposed tide pools at low tide. The Wellington south coast is known for its constant southern swells and big seas in rough weather. The rocks extending out to sea at Waitaha cove diffuse the majority of the water energy, but wave action is greater at Waitaha than at Point Halswell. Traps were situated further apart in this area to sample the large network of pools (24$41 \mathrm{~m}$ apart) with $0.1-1$ meter between traps and nearest rock substrate of equal height. Adult $C$. maculosa presence was confirmed at the site, during sampling, but I did not search for egg capsules.

C. maculosa hatchlings collected for experiments were occasionally released at varying distances from the traps. These releases, once at Point Halswell and five times at Waitaha Cove, were done by pipetting the hatchlings from a transfer container to a variety of damp, exposed, sheltered, and/or coralline microhabitats. A large number of $C$. virgata egg capsules were removed from rocks collected for experiments. These egg capsules and the emergent hatchlings were released at one time in the area near the Point Halswell traps. 


\subsubsection{Collecting and Sorting}

Filter bags were collected every two days and placed in a Ziploc bag for transport and sorting. One trap was deployed for four days at Point Halswell, due to rough seas. When immediate sorting was not possible, filtered sea water was added to the Ziploc and the bag was set in a water bath. Filter bags were rinsed with filtered salt water into a clear container with two $700 \mu \mathrm{m}$ mesh sides, so that small particulates could easily be strained. This straining container was set inside a white container to maximize contrast for searching by eye. Particulates larger than $700 \mu \mathrm{m}$ were removed by forceps or pipette. Algae blades were agitated within the straining container to dislodge any attached hatchlings. Highly filamentous or branching algae were examined under a dissecting microscope to ensure hatchlings were not well attached and hidden. Once emptied, filter bags were thoroughly rinsed in warm freshwater and dried until the next deployment.

\subsection{Results}

\subsubsection{Dislodgement Experiment}

An average of 46.1 hatchlings were recovered from each dislodgement trial, with recovery ranging from 35-51. The large number of missing hatchlings could be due to their forceful ejection out of the tank during wave treatments or from being lost when rocks were transferred for rinsing. Hatchling recovery was not biased by the trial order or treatment. Very few hatchlings were classified as unresponsive (mean $=1.53 \pm 1.50, n=36$ ). The full GLMM model indicated that significantly more hatchlings were collected in outflow containers under wave treatments than under still treatments, but there was no effect of tank depth (Table 3.1, Figure 3.4). All random effects (pair identity, cohort, container, tank, and treatment order) in the full model explained only slight variance. The full model explained a large portion of the variance in the data when considering just the fixed effects (marginal pseudo $R^{2}=0.8713$ ) and when considering fixed and random effects (conditional pseudo $R^{2}=0.8735$ ).

Table 3.1 Full GLMM model results for the dislodgement experiment considering wave and tank depth effects. Fixed effect variables are on the left, with estimate coefficients, standard error, z-test values, and the associated $p$ values. Random effect variables are on the right, with estimated variance contribution and standard deviation for each variable.

\begin{tabular}{rrrrr|rrr}
\hline Fixed Effect & Estimate & Std.Error & $\mathbf{z}$ value & $\mathbf{p}$ & Random Effect & Variance & Std. Dev \\
\hline Intercept & -7.1031 & 1.0289 & -6.904 & $<0.0001$ & Pair & 0.0115 & 0.3391 \\
Wave & 9.4655 & 1.0236 & 9.247 & $<0.0001$ & Cohort & $<0.0001$ & $<0.0001$ \\
Shallow & 0.5462 & 0.3219 & 1.697 & 0.0897 & Container & $<0.0001$ & $<0.0001$ \\
& & & & & Tank & 0.0006 & 0.0760 \\
& & & & & Order & $<0.0001$ & $<0.0001$ \\
\hline
\end{tabular}




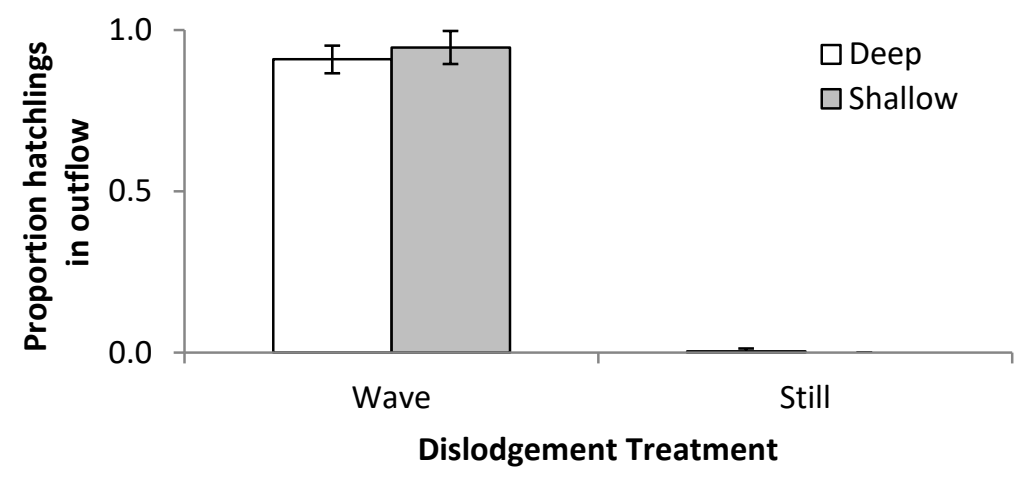

Figure 3.4 Average proportion of hatchlings captured in outflow traps for dislodgement experiments with wave and still treatments, separated by tank depth. Error bars represent standard deviation.

\subsubsection{Drifting in Current}

The average recovery rate for hatchlings from this experiment was high $(48.41 \pm 3.82)$, but there was a standout low recovery of 32 hatchlings in one slow current trial. It is likely that these hatchlings escaped through a hole in the outflow trap, but have still been considered lost. The average number of unresponsive hatchlings was low $(0.78 \pm 1.53, \mathrm{n}=27)$.

The GLMM model identified a significant treatment effect influencing the number of hatchlings found in the outflow traps (Table 3.2). Tukey tests verified that, compared to still treatments, significantly more hatchlings exited the experimental buckets through drift when subjected to either slow $(z=11.691, p<$ $0.0001)$ or fast currents $(z=-7.454, p<0.0001)$. Approximately $88 \%$ and $79 \%$ of hatchlings were found in outflow traps for fast and slow currents, respectively (Figure 3.5). Conversely, only $7 \%$ of hatchlings were found in outflow traps when dropped into still current (Figure 3.5). Considering the similar percentage of hatchlings found in outflow traps for the fast and slow treatments, the significant difference between the two treatments is surprising (Tukey post hoc test: $z=-3.717, p=0.0006$ ). The random effect of cohort had an influence on hatchling outflow (variance $=2.50 \pm 1.58$ ), while the effect of transfer container was minimal (variance $=0.87 \pm 0.94$ ). The GLMM fixed effects explained $44 \%$ of the variation in the data (marginal pseudo $\mathrm{R}^{2}=0.4436$ ) while the fixed and random effects explained $63 \%$ of the variation (conditional pseudo $R^{2}=0.6257$ ). 
Table 3.2 GLMM model results for the drift in current experiment. Fixed effect treatment variables are on the left, with estimate coefficients, standard error, z-test values, and the associated $p$ values. Random effect variables are on the right, with estimated variance contribution and standard deviation for each variable.

\begin{tabular}{rrrrr|rrr}
\hline Fixed Effect & Estimate & Std.Error & z value & $\mathbf{p}$ & Random Effect & Variance & Std. Dev \\
\hline Intercept & 1.5532 & 0.5638 & 2.755 & 0.0059 & Cohort & 2.4679 & 1.5805 \\
Still flow & -3.206 & 0.4301 & -7.454 & $<0.0001$ & Container & 0.8772 & 0.9366 \\
Fast flow & 1.5243 & 0.4101 & 3.717 & 0.0002 & & & \\
\hline
\end{tabular}

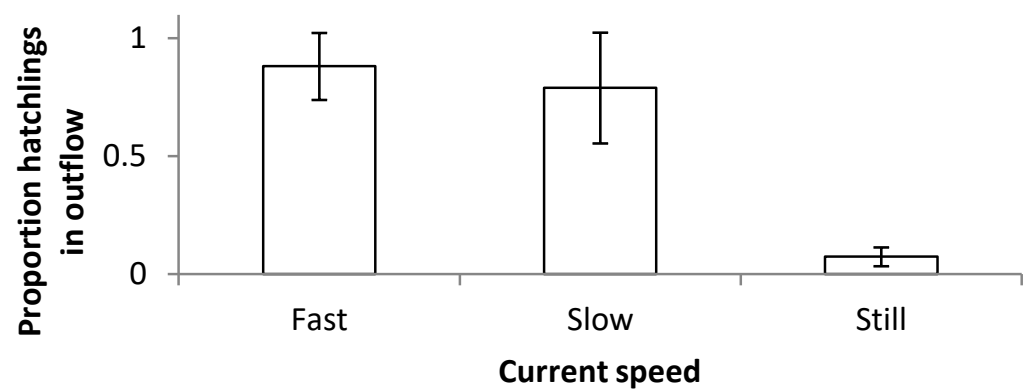

Figure 3.5 Average proportion of hatchlings captured in outflow traps for drift in current experiments with fast, slow, and still current treatments. Error bars represent standard deviation.

The means by which hatchlings were carried into the outflow traps was obviously different between still and current treatments. During the three 30 minute crawl checks, an average of 20 hatchlings $( \pm 6$, $\mathrm{n}=9$ ) were observed on the bucket walls in still trials (Figure 3.6) and no hatchlings were ever observed on bucket walls of fast or slow trials. This indicates hatchlings deposited in currents were transported out of the bucket by the flow, whereas hatchlings in still conditions dispersed by crawling. Hatchlings that drifted to the bottom of the weak and strong treatments within the first 30 minute interval would often be swept away at the next interval. However, there were 2 trials where less than $60 \%$ of hatchlings exited the current treatments. 


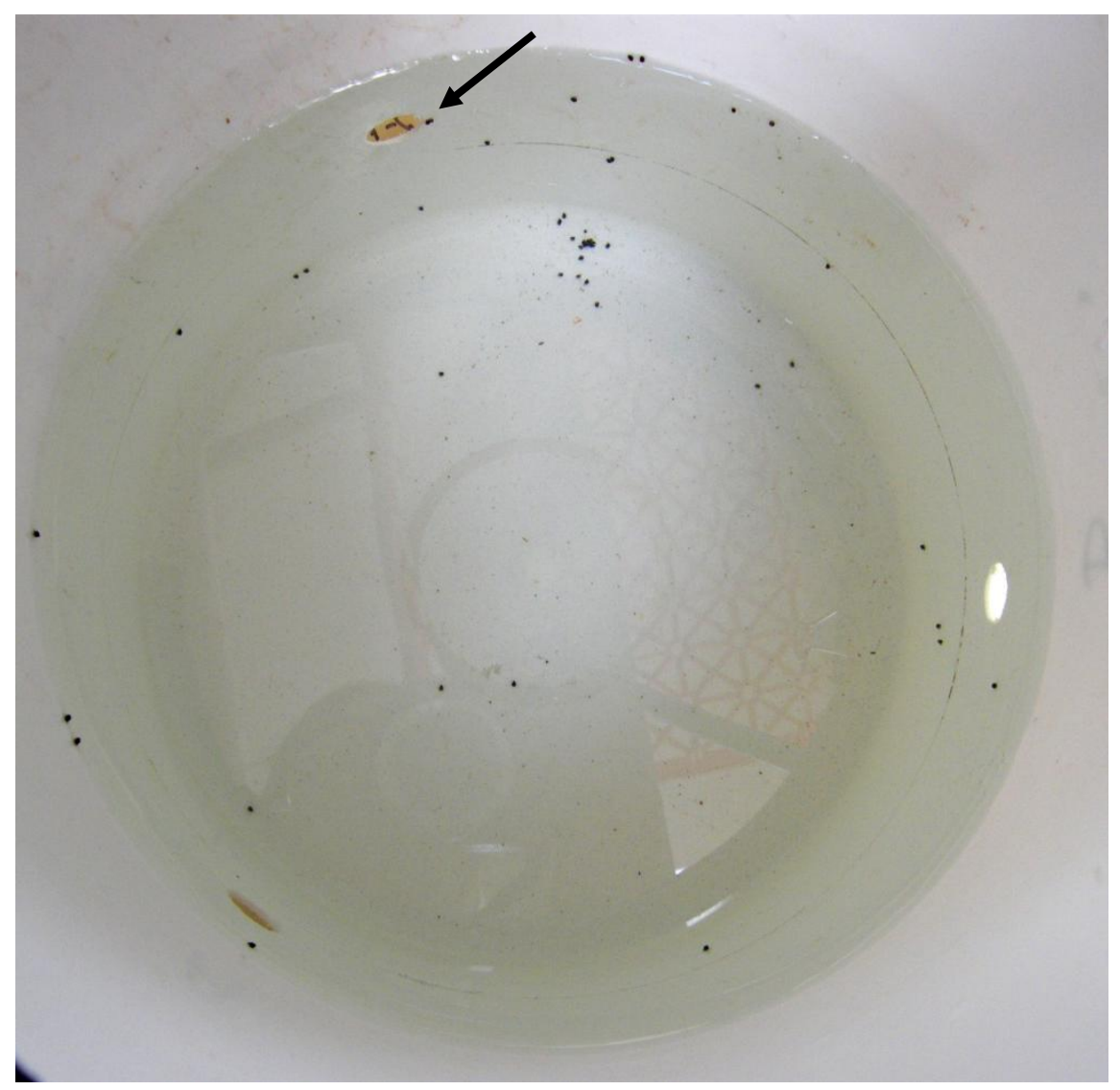

Figure 3.6 Hatchling dispersal after an hour in the still treatment for drift in current experiments. 24 hatchlings are positioned on the walls, with one about to exit an outflow hole (black arrow).

\subsubsection{Sustained Drifting}

Hatchling recovery rates were high for this experiment with an average of $49.88( \pm 0.58, n=27)$ and a range of 48 to 51 . Hatchling losses likely occurred from miscounts at addition or loss when transferring from jar to petri dish. While the still treatment often had hatchlings found above the water line inside the jars, hatchlings were never found outside of the jars indicating the hatchlings did not crawl out. The recovery of 51 hatchlings likely resulted from a miscount at the start of the trial. An average of 0.30 hatchlings ( $\pm 0.54, n=27$ ) were classified as unresponsive overall.

The number of hatchlings found drifting was surprisingly low for all treatments (maximum of 9) and no drifters were classified as unresponsive. Drifters found in still conditions were rarely found within the water column. They were always floating at the surface, apparently using the surface tension of the water to suspend by their foot under the air-water interface. When disturbed these drifters would sink. Conversely, drifters in the strong treatment were always found moving in the circular pattern of the water column. 
The GLM model, excluding random effect due to variance-covariance errors, identified a significant treatment effect of mixing on the number of hatchlings found drifting in the treatment container (Table 3.3). The pseudo $R^{2}$ for the model was quite high, indicating $61.4 \%$ of the data's variation was described by the treatment factor. Significantly more hatchlings drifted in still treatments than in strong mixing treatments (Tukey post hoc test: $z=4.084, p<0.0001$ ). This result is supported by the observation that less than $10 \%$ of hatchlings drifted in still treatments, while less than $1 \%$ of hatchlings drifted in strong treatments (Figure 3.7). Since $0 \%$ of hatchlings were found drifting in weak treatments, an insignificant difference between weak and strong treatments (Tukey post hoc test: $\mathrm{z}=$ $-0.008, p=1$ ) was expected. However, the insignificant difference between weak and still treatments (Tukey post hoc test: $z=0.009, p=1$ ) was surprising.

Table 3.3 GLM model results for the sustained drift experiment. Fixed effect variables are presented with estimate coefficients, standard error, z-test values, and the associated $p$ values.

\begin{tabular}{rrrrr}
\hline Fixed Effect & Estimate & Std.Error & $\mathbf{z}$ value & $\mathbf{p}$ \\
\hline Intercept & -4.7118 & 0.5022 & -9.381 & $<0.0001$ \\
Weak & -17.9189 & 2346.583 & -0.008 & 0.994 \\
Still & 2.18 & 0.5338 & 4.084 & $<0.0001$ \\
\hline
\end{tabular}

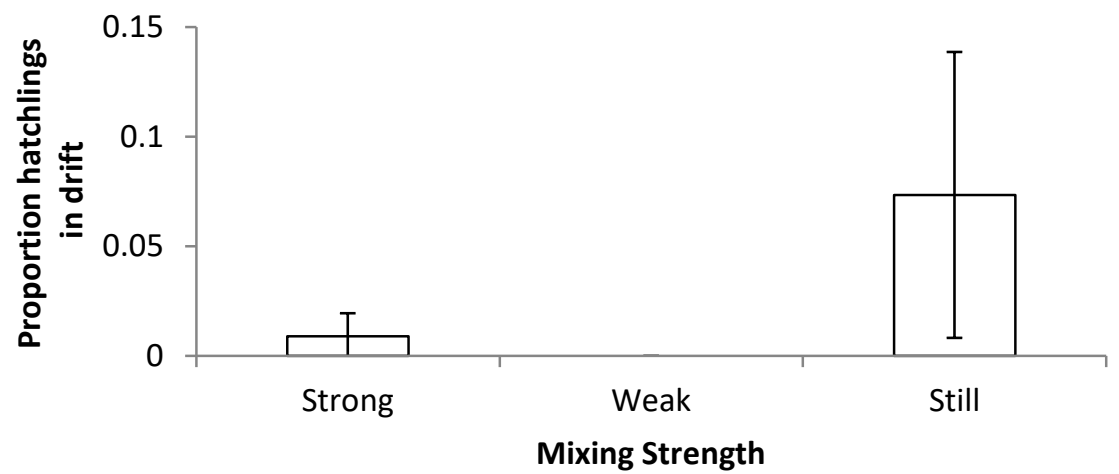

Figure 3.7 Average proportion of hatchlings found drifting for sustained drifting experiments with strong, weak, and still mixing treatments. Error bars represent standard deviation.

\subsubsection{Plankton Sampling}

At Point Halswell, weather and maintenance issues prevented continual deployment of all traps. Plankton samples were successfully collected 14 times, with only one sampling period lasting four days instead of two days. For the two traps that had hatchlings planted to test retention, all hatchlings were successfully identified as alive. This finding indicates that the searching protocol was sufficient for finding hatchlings and that any trapped hatchlings would not escape by crawling. A lot of algae and silt was collected in the traps at Point Halswell, as well as a mix of unidentified crustaceans. A single living C. virgata hatchling was found in one trap deployed on the same day that $C$. virgata were released in the surrounding pools. Two small unidentified gastropods were found in one trap. These unknown 
gastropods have been observed to associate with algae and may have entered the trap on algae also found in the sample.

Poor weather did not prevent the continuous deployment of Waitaha Cove traps throughout the two week sampling period. However, maintenance issues for several of the traps meant that occasionally only two traps were deployed at a time. A total of 29 plankton samples were obtained, with all sample periods occurring over two days. Filter bags contained less silt and algae then Point Halswell. No living Cominella hatchlings were collected at Waitaha Cove, but a C. virgata shell full of debris was found once and an empty $C$. maculosa shell was found after the mass release of the experimental hatchlings. Three unidentified species of living gastropods were found four times. One of these species was the algaeassociated gastropod found at Point Halswell and commonly observed at Waitaha. The other two appeared to be two top shell species.

\subsection{Discussion}

Laboratory experiments in this study indicate that Cominella maculosa hatchlings can be dislodged by wave action and can be carried short distances by drifting in currents. However, sustained drifting experiments imply hatchlings are unlikely to remain drifting for prolonged periods in a vertically mixed water column. These experiments indicate that wave dislodgement and local flow regime will likely result in small-scale displacement of hatchlings, but it is unlikely hatchlings will remain in drift long enough to undergo events of long distance dispersal over hundreds of kilometres. The capture of a single living $C$. virgata hatchling in a Point Halswell plankton trap supports the potential for dislodgement and suspension into the water column for the smaller $C$. maculosa. Suspension into the water column is the first step of the drifting processes, which requires time in currents to facilitate dispersal. Due to the nearshore position of the traps, the captured hatchling is only evidence that suspension into the water column can occur, but the unknown time that the hatchling was in the water column prevents a conclusion of drifting.

The dislodgement experiment used to investigate drifting out of tide pools was not designed to test the likelihood of hatchlings being dislodged from the rock. If this was the aim of the experiment then hatchlings would need to be placed on all sides of the rock to vary the effects of the tip bucket energy and the micro-position of the hatchling (in a crack or on a steep slope) would also need to be considered. Rather, the aim of this study was to determine if successfully dislodged hatchlings would be caught in the outflow current created by the wave and dragged out of the "tide pool" (tank). The significant treatment effect of the wave factor supports this possibility. Since hatchlings were not found in outflow traps from still treatments, it is unlikely that hatchlings in the wave trials crawled out 
of the tanks. This finding supports the conclusion that the water current is the mechanism of hatchling movement. Several studies have been conducted to determine the tenacity of gastropods subjected to intertidal hydrology (Trussell et al. 1993, Prowse and Pile 2005, Rilov et al. 2008), but few are aimed at determining the fate of dislodged individuals. Miller et al. (2007) found that over $50 \%$ of adult periwinkles (Littorina keenae) successfully returned to the supralittoral habitat after being manually dislodged into intertidal waves. While periwinkles are quite small (>7 mm used by Miller et al. 2007), they are far larger than the hatchlings considered in this study (c. $1.5 \mathrm{~mm}$ ).

The dislodgement experiment was initially undertaken using the shallow tank depth, but placing hatchlings on exposed rock is likely an unrealistic situation. While it is possible that hatchlings will occasionally find themselves left high and dry, it is more likely that as the tide recedes the hatchlings would seek refuge from desiccation. Furthermore, hatchlings placed on dry petri dishes were rarely observed to actively crawl. This means the shallow treatment was also not conducive to comparing wave and still treatments for the mechanism of moving out of the tank (crawling vs current). In the end, tank depth did not produce a significant response in this experiment, as even in deep tanks hatchlings rarely crawled out of the outflow drain in still treatments.

It was predicted that hatchlings subjected to currents, in the drift in current experiments, would more often be found in the outflow traps of the bucket. The prediction was supported with significantly greater proportion of hatchlings found in outflow traps for slow and fast currents, compared to still treatments, indicating that hatchlings suspended in water columns can be transported by local currents. However, the random effect of cohort explained some variation in hatchling outflow. Though cohorts were not replicated through enough trials to draw conclusions, this variation may be caused by variance in hatchling size. While no hatchlings appeared larger than others when selected, variances in shell thickness could change the rate at which hatchlings exit currents. Contrary to the initial prediction, hatchlings were equally likely to be transported into outflow traps by slow currents as fast currents. The similar response between treatments is likely due to the fact that while the volume of water transported was different, the actual velocity of the water was the same $(0.6 \mathrm{~m} / \mathrm{s})$. In order for long distance dispersal to occur, hatchlings would need to remain in alongshore currents for a prolonged period of time. The northward flowing Wairarapa Coastal Current found off the southeast coast of the North Island (Figure 2.1A) has an average velocity of $0.21 \mathrm{~m} / \mathrm{s}$ (Chiswell 2000), suggesting that the velocity of lab experiments $(0.6 \mathrm{~m} / \mathrm{s})$ is greater than an average offshore current. While surf zone velocities on the rocky shore can be as high as $25 \mathrm{~m} / \mathrm{s}$ (Denny et al. 2003), the direction of the turbulent water is chaotic (Denny and Gaylord 2010) and is unlikely to lead to linear transport offshore. Assuming a rare high flow current is able to transport a hatchling to an offshore current, the velocity of the current may actually be too slow to prevent sinking of the hatchlings. 
When hatchlings were found in the bucket of current treatments, they were generally lodged against the small edge $(<1 \mathrm{~mm})$ of a $75 \mathrm{~mm}$ diameter circular feature on the bottom of the bucket. This indicates that hatchlings could exit currents if they encounter features that may alter water flow on a small scale. Preliminary trials for this experiment included using a small cobble substrate. It was observed that hatchlings caught in a downdraft of the current were able to adhere directly to the cobbles or exit the current by going under the rocks. The likelihood of encountering a rock in the middle of an ocean current is unlikely, but encountering substrate on a receding tidal current is highly likely. Therefore, it is probable that a hatchling dislodged into a tidal current could exit the current before being transported offshore.

The sustained drifting experiments, using circular air-driven currents, aimed to investigate the likelihood of hatchlings remaining suspended in a water column for a sufficient amount of time to be transported long distances. However, the vertical circular current created by the air pump was not optimal for addressing this question. A horizontal current, similar to the drift in current trials, would be better suited to the question. Ideally, a horizontally circular flume would be built out of wide clear tubing that could be filled to create a continuous flow of variable currents. Hatchlings could then be added to this flume and observed for their ability to sink or drift. Recently, a redesign of the bucket set up used for the drifting in current experiment has been considered. Using elevated outflow drains at the centre of the bucket instead of the edges might reduce hatchling transport out of the bucket while keeping hatchlings subjected to a horizontal current.

The sustained drifting experiment may not directly answer the question of hatchlings drifting in a horizontal current, but it does suggest that hatchlings dislodged into the chaotic turbulence of the rocky coastline (Denny and Shibata 1989, Denny and Gaylord 2010) may not actually be pulled into offshore waters. It is likely that once dislodged, hatchlings will be tumbled into various substrata that they may be able to adhere too. Juvenile snails (Lacuna spp.) and limpets (Helcion pellucidus) are able to produce mucus threads that they can use to aid drifting and facilitate capture of a stationary object to exit the water column (Vahl 1983, Martel and Chia 1991b, Martel and Diefenbach 1993). There is no indication that Cominella spp. produce mucus threads, but mucus production is probably not necessary if pebbles and cobble facilitate hatchlings exiting the water current, as noticed in preliminary trials. Recent hydrological studies indicate that vertical mixing, due to wind and wave energy, is more common above the thermocline of surface currents than previously considered (Qiao et al. 2016). However, the sustained drifting design can't be said to directly address the likelihood of hatchlings becoming trapped in this micro current either, as a larger volume of water would be required to ensure that contact with container walls did not facilitate exit of the current. 
An interesting finding of the sustained drift experiment was that significantly more hatchlings drifted on the surface tension of the still treatment than drifted in the water column of the strong mixing treatment. This behaviour was also observed under a dissecting microscope when hatchlings were viewed in a small amount of water. Several hatchlings crawled to the barrier of the water puddle, crawled up the vertical wall of water, and proceeded to crawl upside down under the water. Similar floating-by-foot behaviours have been observed in low energy environments for adult Cominella glandiformis (Bimler 1976) and juvenile Japanese turret shells (Batillaria cumingi) (Adachi and Wada 1999). Adachi and Wada (1999) attributed the disparity between frequent observations of floating juveniles in soft bottomed habitats and rare observations in rocky habitats to the increased wave intensity of the rocky environment. This disruption to surface tension is likely why zero hatchlings were found drifting at the surface of the weak mixing treatment. It is likely the mixing was too weak to suspend hatchlings into the water column, but the air bubbles sufficiently disrupted the surface of the water to prevent floating. Tukey tests identified a significant difference between still and strong mixing treatments, but not between still and weak mixing treatments. I am unable to explain this discrepancy.

The successful capture of one $C$. virgata hatchling in plankton traps is important, as it indicates that dislodgement into the water column can occur. Since $C$. virgata hatchlings are larger than $C$. maculosa hatchlings (Carrasco et al. 2012), it can be inferred that C. maculosa hatchlings are also likely to be dislodged. Dislodgement and retention in the water column is probably uncommon for Cominella spp., as only one living $C$. virgata was captured out of hundreds released and unknown numbers of wild hatched. Rare collections of direct developers in plankton traps have also been observed by Martel and Chia (1991b). Of the four species of direct developing gastropods (Barleeia spp., Onchidella borealis, Nucella emarginata, and Littorina sitkana) found in their off-bottom collectors, only Barleeia spp. was captured more than three times over the 30 days of sampling (Martel and Chia 1991b). Martel and Chia (1991b) concluded that frequent drifting by these algae-associated taxa would increase chance rafting and long distance dispersal events. However, further investigation with similar off bottom collectors was unsuccessful in trapping the snail Nucella emarginata and drifting dispersal was considered infrequent (Gosselin and Chia 1995). This variation in observance indicates that rare events of drift dispersal can occur, but the frequency with which they occur cannot be extrapolated. While these collectors were suspended off the rock substrate, these traps were deployed near shore and really only reflect the process of dislodgement into the water column. Conclusions of long distance dispersal from presence in the trap should be made with caution.

Swash traps may not be the most effective tool for detecting drift, as only a small portion of surface water enters the trap through wave or wind energy. During calm periods, like many days at Point Halswell, the incoming tide may produce very little wave energy and the stop valve may close before a 
large amount of surface water has entered the trap. A better collection method might be a settlement tube in which a dense fixative agent (formaldehyde or formalin) sits at the bottom to preserve any organisms that drift into the tube (Yund et al. 1991, Landry and Miron 2011). However, the likelihood of positioning these tubes in areas where at least one hatchling would settle out of the water column is low. Ideally, a plankton trap that filters a large area of the water column would be used, such as that employed by Martel and Chia (1991b), who suspended nets filled with red algae off the bottom of surge channels. This design allows a larger volume of water to contact the collector, but it also assumes that the captured species associate with the red algae and don't leave looking for better habitat or fall off. Algal filled collectors are likely not ideal for attracting a scavenging species. It would be interesting to fill an off bottom collector, supported by copper pipes to prevent crawling into the net, with decaying bait to see what was collected. However, it is likely that large, mobile scavengers such as crustaceans and fish would disturb, or predate on, the attracted gastropods.

We currently don't know what processes affect survival and dispersal of Cominella spp. hatchlings. It is assumed that hatchlings, like adults, feed as scavengers. Cominella maculosa and $C$. virgata hatchlings have been successfully maintained in the lab with Perna canaliculus tissue for short time periods (van der Sman et al. 2009, Carrasco and Phillips 2012, Carrasco et al. 2012), but prolonged rearing and food preference trials have not been undertaken. Attempts to determine the food preference for $C$. glandiformis hatchlings ended in death when a crab was accidentally introduced (Morley 2013). Determining hatchling food and habitat preferences could provide important clues to actual dispersal rates by indicating crawling rates for food or affiliating with potential rafting substrata.

There is also a lack of knowledge about hatchling behaviour. Hatchlings were observed to crawl a lot. Unfortunately, several of the hatchling holding containers had tiny, unnoticed holes that facilitated a steady supply of hatchling escapees into the sea table water bath. At the end of most nights, escapees would be collected and put into a container (marked unknown origin and not used in tests). The next morning, hatchlings could be found at the far end of the sea table again (4.1 m). Rajasekharan and Crowe (2006) observed that when periwinkles (Littorina littorea) were found in naturally dense populations, they exhibited higher rates of movement than individuals from naturally sparse populations. This behaviour may have contributed to the large distances the escapee hatchlings wandered. Hatchlings kept in the aquaria were often found at, or slightly above, the water line. This behaviour was also observed for adults, and could be related to the expectation of a tidal cycle. When hatchlings from the more populous Waitaha Cove tank were dislodged, they were observed along the water line 30 minutes later. In contrast, those from the less populous Point Halswell tank appeared slower to respond. Obviously, until hatchling habitat is identified, natural densities of hatchlings in the field are also unknown, but crowding could be a trigger for hatchlings to disperse more widely. 
Mucus production by C. maculosa hatchlings was not observed on an individual level. However, when separating individuals from aggregations ( $>50$ hatchlings together) it was common to observe one hatchling being pulled behind another, as if by an invisible thread. Sometimes hatchlings were so connected by the mucus that they would have to be moved to a dry area of the petri dish to break the thread. Active mucus thread production for promoting drift and reducing sinking speeds has been observed for juvenile snails, Lacuna spp. (Martel and Chia 1991b), indicating a potential mechanism for hatchlings to get caught in currents. However, mucus production observed in the lab may be a reaction to stress and artificially high densities of the holding containers. All hatchlings used in the experiments were added individually to ensure there was no mucus thread connection influencing one of the hatchlings.

The rare events of dispersal by drifting individuals can never be completely rejected, as the absence of observation is not the same as absence of occurrence. Drifting and rafting are common dispersal mechanisms used to explain why direct developing benthic species have such large geographic distributions (Johannesson 1988, Colson and Hughes 2004) and how their populations maintain genetic connectivity (Hoskin 2000, Bell 2008, Cumming et al. 2014). The results of this study indicate that longdistance dispersal by individually drifting C. maculosa hatchlings is uncommon, though rare events may occur. Local flow regimes likely influence distribution on the small scale, but will not contribute to large geographic transport. However, depending on where hatchlings ultimately settle, long-term exposure to dislodgement and small-scale transport may facilitate significant movement along a coast line. These tiny gastropod hatchlings can be suspended in the water column by wave force and get washed off rocks. However, the position of the individual in the microhabitat of the rock and tidepool are likely to influence how prone it is to the dislodgment force. The behaviour of the individual within the water column will likely influence its fate as well. Drift experiments in this study were not conducted with a floating substrate, so it is unknown if drifting hatchlings can attach and be subjected to rafting dispersal. Future areas of research into the habitat and feeding ecology of hatchlings would contribute to further determining the actual dispersal potential of $C$. maculosa. 


\section{Chapter 4 \\ General Discussion}

Uncovering genetic and demographic connectivity between populations facilitates a better understanding of the ecological and evolutionary process operating on a species and its distribution. Genetic analyses can elucidate historical and contemporary exchange of genes between populations, but it can often be difficult matching it to the demographic influences of migration. Discrete genetic population structure is generally evidence that populations exist in demographic isolation and are unlikely to form a metapopulation that can recolonize locally extinct sites. Conversely, high levels of genetic connectivity do not necessarily reflect demographic connectivity (Ovenden 2013). The decoupling of genetic and demographic connectivity in "crinkled" populations can be caused by founder events, migration into large populations, or the appearance of a recent barrier to dispersal.

The dispersal potential of an organism could be used to infer the likelihood of a crinkled population occurring during high levels of genetic connectivity. The production of planktonic larvae greatly enhances the dispersal potential of a species and therefore the likelihood that demographic connectivity is occurring when gene flow is high. Sedentary, direct-developing species are more likely to be genetically similar due to low immigration rates or founder events that have not had time to differentiate from the source population. However, dispersal potential is not necessarily equal to realized dispersal; which is the actual distance travelled by a disperser. There are many studies that indicate larval behaviour, coastal features, and local currents play an important role in reducing the distance planktonic offspring actually disperse, with self-recruitment being much more common than previously believed (Barber et al. 2002, Swearer et al. 2002). Higher than expected levels of genetic connectivity for direct developers is attributed to long-distance dispersal events through rafting on a substrate or hitchhiking on birds (Hoskin 2000, Miura et al. 2012). These same mechanisms are often proposed to describe the wide spread distribution of direct developing species across large bodies of water (Johannesson 1988, Wilhelmesen 1998).

Realized dispersal of a species is influenced by its inherent dispersal potential (mode of development, ability to raft), the costs of dispersal (predation, post-settlement mortality), and local landscape features (inhospitable habitat, ocean currents) (Grantham et al. 2003, Burgess et al. 2012, Smith et al. 2015). The description of Cominella maculosa as a low realized dispersal species is supported by the discrete genetic population structure observed over large and small spatial scales (Chapter 2.1). The genetic similarity and appearance of genetic connectivity between some populations, particularly the southern Wairarapa, is more likely due to rare dispersal events of numerous eggs rather than drifting of 
individual hatchlings (Chapter 3.1 Abstract). Drifting egg capsules have been observed for the speckled whelk $C$. adspersa (MD unpublished observation) and the top shell Margarella antarctica (Hoffman et al. 2011). The large number of hatchlings with identical mitochondrial lineages from rafting or drifting egg capsules would produce a large immigrant population of low genetic diversity. Assuming low posthatching mortality, this influx of homogeneous immigrants could be large enough to create a high frequency signature of the haplotype in the population. Conversely, if landing at an unpopulated location, the large number of hatchlings could create a "founder takes all" effect where the levels of crawling immigration from neighbouring populations is too low to contribute long term genetic lineages (Waters et al. 2013). A founder take all effect is a reasonable explanation for the genetic patterns of the populations in Southern Wairarapa, where a major recolonization after the LGM is now blocking the northern haplotypes from spreading down the coast into the southern populations. Large stretches of sandy habitat between the two locations may further reduce the possibility for new immigrants to enter a population through crawling. However, large stretches of sandy beaches are not obviously visible on Google Earth images between Honeycomb Rock and Glendhu, where a genetic barrier appears to be present.

While larvae are often the main dispersers in the marine environment, adult migration can also influence colonization (Grantham et al. 2003, Armitage and Fong 2004). Colonization of distant breakwaters in Belgium has been suggested to occur from the dislodgement of adults that are rolled by water currents along the sand (Johannesson and Warmoes 1990). When subjected to dislodgment trials, adult C. maculosa withdrew into their shells and rolled to the bottom of tanks (MD unpublished observations). Whelks remained withdrawn well after the wave energy dissipated; indicating that a strong water current over a sandy subtidal habitat could promote dispersal across an inhospitable habitat. However, dispersal by rolling is unlikely to occur in the rocky habitats where spotted whelks would most likely get lodged in rocks before reaching flat habitat. Chapman (2000) found that three intertidal grazing snails moved in a random daily pattern that accumulated into long term retention in a local area. The carnivorous $C$. maculosa were successfully collected by baiting tide pools, suggesting whelk movement is strongly influenced by the ability to detect food. Bait detection distances for the scavenging snails Ergalatax contracuts and Nassarius festivus were found to be greater than $80 \mathrm{~cm}$ in flowing water (Morton and Yuen 2000, Morton 2006). This relatively short detection limit, coupled with the personal observation that captive Cominella maculosa burrow and wait for food before emergence, suggests that large dispersal distances for adults will be uncommon. There is no support for Cominella species engaging in homing behaviours. However, field-based capture-mark-recapture (CMR) studies for $C$. maculosa support the conclusion that adults do not move large distances and may exhibit low levels of philopatry (MD unpublished data). While only $6 \%$ of 680 marked C. maculosa were recovered one year after marking 16 tidepools, $80 \%$ of the marked whelks were recovered from the same pool in 
which they were last caught. The one-year recapture result is consistent with the original markrecapture study performed over 2.5 months where $95 \%$ of the total recaptured whelks were found in the same pool they had last been captured. The low rates of recapture recovery are typical of gastropod CMR (Janson 1983, Johnson and Black 1995, Boulding et al. 2007, Castro et al. 2006) and may indicate transient movements, satiation that prevents detection at bait traps, or high mortality. High mortality for $C$. maculosa is not supported by CMR analysis conducted on the 2.5 month study (MD unpublished data), indicating low recovery is due to satiation in a highly productive environment or transient movements are occurring.

The low probabilities of observing rafting egg capsules, detecting drifting hatchlings, or recapturing migrating adults at large distances is problematic for determining accurate realized dispersal for direct developing gastropods. Mass marking hatchlings with a chemical marker could potentially be of use, but knowledge of where to find the hatchlings after marking is currently lacking. While Cominella spp. hatchlings have been raised on mussel flesh (van der Sman et al. 2009, Carrasco et al. 2012), it is unclear if food or habitat preference is exhibited at this life stage. Indirect estimates of migration can be made from genetic data, but the population sizes must be known. If population sizes are known, then the standard deviation of the lifetime dispersal displacements $(\sigma)$ can be determined from the slope of a line fitted to differentiation vs geographic distance plots (Rousset 1997). This method successfully estimated $\sigma$ from microsatellite DNA data for a periwinkle (Littorina subrotundata) that matched the lower range of $\sigma$ observed from CMR experiments (Boulding et al. 2007). Therefore, the best method to gain insight into realized dispersal and population connectivity for direct developing species may be to use accurate population-size survey methods that can be carried out at the time of genetic sampling.

Demographic surveys of populations at areas of genetic disjunction, such as the Wairarapa, could illuminate how recently founded populations differ from historically isolated populations. It is likely that the southern Wairarapa group contains low genetic diversity and the appearance of genetic connectivity due to recent founding events. Founding events of direct developing species may lead to successful, permanent populations since the hatchlings are unlikely to be displaced by water currents (Johannesson 1988). However, a recent study suggests that species with planktonic dispersal are more temporally stable because realized connectivity can buffer population fluctuations (Sahara et al. 2016). The low diversity in recently founded populations would be maintained if the population fails to expand or if the location is subject to frequent local extinction and recolonization events. Population surveys of abundance and age class structure could indicate size and stability of the Wairarapa populations. Initial sampling at Cape Palliser required 3 days to collect the 27 whelks used in genetic analysis and only a handful were found in the following years, indicating that Cape Palliser may be a small population that 
could be at risk of local extinction from unpredictable environmental events. Conversely, the Tora population appears to be quite large, with the 35 samples easily found in a few hours of searching. Short term CMR coupled with transect and quadrat surveys could be used to estimate extinction probabilities. Contemporary connectivity from nuclear molecular markers should then be used and analyzed in light of this demographic information. When possible, genetic and demographic data should be combined with information regarding habitat composition (presence of rafting substrate) and hydrological models that can predict connectivity if rafting occurs. Such large scale population surveys of remote locations are logistically difficult and costly. Therefore, genetic examination of species with similar life history traits should be compared to the patterns observed for Cominella maculosa. Two direct developing whelk species commonly found in the rocky shores inhabited by Cominella maculosa are the oyster borer (Haustrum scobina) and dark rock whelk (H. haustorium). Genetic analysis of these two species with the mitochondrial $\mathrm{CO} 1$ gene would allow a comparison of connectivity patterns at locations subjected to the same environmental and hydrological conditions.

The genetic analysis and ecological experiments of this study confirmed that the realized dispersal of Cominella maculosa is typically limited by crawling short distances. However, random events of egg capsule rafting or drifting eggs may still promote site recolonization and spread genetic variation. These findings support the reports in the broader literature that indicate demographic isolation and low genetic connectivity in direct developing species (e.g. Barbosa et al. 2013, Ellingson and Krug 2016). While some species of algae-associated direct developers can maintain genetic connectivity across long distances (Nikula et al. 2010), this study supports the assumption that populations of direct developers not associated with rafting substrate appear to form isolated populations. On the one hand, long-term isolation can lead to local extinction and cause a reduction of genetic diversity. On the other hand, isolation can promote local adaptation and speciation. 


\section{References}

Adachi N, Wada K. 1999. Distribution in relation to life history in the direct-developing gastropod Batillaria cumingi (Batillariidae) on two shores of contrasting substrata. Journal of Molluscan Studies 65: 275-288.

Almany GR, Berumen ML, Thorrold SR, Planes S, Jones GP. 2007. Local replenishment of coral reef fish populations in a marine reserve. Science 316: 742-744.

Andrews RD, Pitman RL, Ballance LT. 2008. Satellite tracking reveals distinct movement patterns for Type B and Type C killer whales in the southern Ross Sea, Antarctica. Polar Biology 31: 14611468.

Apte S, Gardner JPA. 2002. Population genetic subdivision in the New Zealand greenshell mussel (Perna canaliculus) inferred from single-strand conformation polymorphism analysis of mitochondrial DNA. Molecular Ecology 11: 1617-1628.

Armitage AR, Fong P. 2004. Gastropod colonization of a created coastal wetland: potential influences of habitat suitability and dispersal ability. Restoration Ecology 12: 391-400.

Avise JC. 2000. Phylogeography: The history and formation of species. Cambridge, Mass: Harvard University Press. p. 143-145.

Ayers KL, Waters JM. 2005. Marine biogeographic disjunction in central New Zealand. Marine Biology 147: 1045-1052.

Azuma N, Miranda RM, Goshima S, Abe S. 2015. Phylogeography of Neptune whelk (Neptunea arthritica) suggests sex-biased impact of tributyltin pollution and overfishing around northern Japan. Journal of Molluscan Studies 81: 131-138.

Bandelt HJ, Forster P, Rohl A. 1999. Median-joining networks for inferring intraspecific phylogenies. Molecular Biology and Evolution 16: 37-48.

Barber PH, Palumbi SR, Erdmann MV, Moosa MK. 2002. Sharp genetic breaks among populations of Haptosquilla pulchella (Stomatopoda) indicate limits to larval transport: patterns, causes, and consequences. Molecular Ecology 11: 659-674.

Barbosa SS, Klanten SO, Puritz JB, Toonen RJ, Byrne M. 2013. Very fine-scale population genetic structure of sympatric asterinid sea stars with benthic and pelagic larvae: influence of mating system and dispersal potential. Biological Journal of the Linnean Society 108: 821-833.

Barrows TT, Juggins S. 2005. Sea-surface temperatures around the Australian margin and Indian ocean during the last glacial maximum. Quaternary Science Reviews 24: 1017-1047.

Barton K. 2016. MuMIn: multi-model inference. R package version 1.15.6. http://CRAN.Rproject.org/package=MuMIn

Bates D, Maechler M, Bolker B, Walker S. 2015. Fitting linear mixed-effects models using Ime4. Journal of Statistical Software, 67: 1-48.

Bell JJ. 2008a. Connectivity between island marine protected areas and the mainland. Biological Conservation 141: 2807-2820.

Bell JJ. 2008b. Similarity in connectivity patterns for two gastropod species lacking pelagic larvae. Marine Ecology Progress Series 357: 185-194.

Bell JJ. 2012. High connectivity between sea lough populations of a planktonic larval disperser with the adjacent open coast. Marine Ecology-an Evolutionary Perspective 33: 516-521.

Bimler A. 1976. Effects of overcrowding on floating behaviour in the mud whelk Cominella glandiformis (Mollusca: Gastropoda). New Zealand Journal of Marine and Freshwater Research 10: 715-720.

Bird CE, Holland BS, Bowen BW, Toonen RJ. 2007. Contrasting phylogeography in three endemic Hawaiian limpets (Cellana spp.) with similar life histories. Molecular Ecology 16: 3173-3186.

Bohonak AJ. 1999. Dispersal, gene flow, and population structure. The Quarterly Review of Biology 74: 21-45.

Bonfil R, Francis MP, Duffy C, Manning MJ, O'Brien S. 2010. Large-scale tropical movements and diving behavior of white sharks Carcharodon carcharias tagged off New Zealand. Aquatic Biology 8: 115-123. 
Boulding EG, Hay T, Holst M, Kamel S, Pakes D, Tie AD. 2007. Modelling the genetics and demography of step cline formation: gastropod populations preyed on by experimentally introduced crabs. Journal of Evolutionary Biology 20: 1976-1987.

Brown JH, Kodric-Brown A. 1977. Turnover rates in insular biogeography: effect of immigration on extinction. Ecology 58: 445-449.

Buchanan J, Zuccarello GC. 2012. Decoupling of short- and long-distance dispersal pathways in the endemic New Zealand seaweed Carpophyllum maschalocarpum (Phaeophyceae, Fucales). Journal of Phycology 48: 518-529.

Burgess SC, TremI EA, Marshall DJ. 2012. How do dispersal costs and habitat selection influence realized population connectivity? Ecology 93: 1378-1387.

Bussolini LT, Waters JM. 2015. Genetic analyses of rafted macroalgae reveal regional oceanographic connectivity patterns. Journal of Biogeography 42: 1319-1326.

Cañete Jl, Gallardo CS, Romero M, Ambler R. 2007. Planktonic drifting dispersal of early juvenile Trochita calyptraeaformis Born 1778 [Gastropoda: Calyptraeidae]. Journal of Experimental Marine Biology and Ecology 346: 1-7.

Carrasco SA, Phillips NE. 2012. Differential vulnerability to predation in two sympatric whelks is mediated by juvenile traits. Invertebrate Biology 131: 187-196.

Carrasco SA, Phillips NE. 2014. Encapsulation and development of three New Zealand neogastropods with contrasting embryo packaging and maternal provisioning. New Zealand Journal of Zoology 41: 171-186.

Carrasco SA, Phillips NE, Pérez-Matus A. 2012. Offspring size and maternal environments mediate the early juvenile performance of two congeneric whelks. Marine Ecology Progress Series 459: 7383.

Carson HS, Cook GS, López-Duarte PC, Levin LA. 2011. Evaluating the importance of demographic connectivity in a marine metapopulation. Ecology 92: 1972-1984.

Castilla JC, Varas MA. 1998. A plankton trap for exposed rocky intertidal shores. Marine Ecololgy Progress Series 175:299-305.

Castro M, Gaspar MB, Pereira AM, Vasconcelos P. 2006. Growth rate estimation of Hexaplex (Trunculariopsis) trunculus (gastropoda: muricidae) based on mark/recapture experiments in the Ria Formosa lagoon (Algarve coast, southern Portugal). Journal of Shellfish Research 25: 249-256.

Chapman MG. 2000. A comparative study of differences among species and patches of habitat on movements of three species of intertidal gastropods. Journal of Experimental Marine Biology and Ecology 244: 181-201.

Chen H-N, Todd CD, Williams GA, Chan BKK. 2013. A new passive plankton trap to quantify the supply of crustacean and molluscan larvae to rocky shores. Journal of Experimental Marine Biology and Ecology 441: 80-89.

Chiswell SM. 2000. The Wairarapa Coastal Current. New Zealand Journal of Marine and Freshwater Research 34: 303-315.

Colson I, Hughes RN. 2004. Rapid recovery of genetic diversity of dogwhelk (Nucella lapillus L.) populations after local extinction and recolonization contradicts predictions from life-history characteristics. Molecular Ecology 13: 2223-2233.

Crandall ED, Treml EA, Liggins L, Gleeson L, Yasuda N, Barber PH, Wörheide G, Riginos C. 2014. Return of the ghosts of dispersal past: historical spread and contemporary gene flow in the blue sea star Linckia laevigata. Bulletin of Marine Science 90: 399-425.

Crimaldi JP, Zimmer RK. 2014. The physics of broadcast spawning in benthic invertebrates. In: CA Carlson and SJ Giovannoni, editor. Annual Review of Marine Science 6: 141-165.

Cumming RA, Nikula R, Spencer HG, Waters JM. 2014. Transoceanic genetic similarities of kelpassociated sea slug populations: long-distance dispersal via rafting? Journal of Biogeography 41: 2357-2370.

Cummings VJ, Pridmore RD, Thrush SF, Hewitt JE. 1993. Emergence and floating behaviours of post-settlement juveniles of Macomona liliana (Bivalvia: Tellinacea). Marine Behaviour and Physiology 24: 25-32. 
Denny MW, Gaylord B. 2010. Marine ecomechanics. Annual Review of Marine Science 2: 89-114.

Denny MW, Miller LP, Stokes MD, Hunt LJ, Helmuth BST. 2003. Extreme water velocities:

Topographical amplification of wave-induced flow in the surf zone of rocky shores. Limnology and Oceanography 48: 1-8.

Denny MW, Shibata MF. 1989. Consequences of surf-zone turbulence for settlement and external fertilization. The American Naturalist 134: 859-889.

Diniz-Filho JAF, Soares TN, Lima JS, Dobrovolski R, Landeiro VL, de Campos Telles MP, Rangel TF, Bini LM. 2013. Mantel test in population genetics. Genetics and Molecular Biology 36: 475-485.

Donald KM, Winter DJ, Ashcroft AL, Spencer HG. 2015. Phylogeography of the whelk genus Cominella (Gastropoda: Buccinidae) suggests long-distance counter-current dispersal of a direct developer. Biological Journal of the Linnean Society 115: 315-332.

Drummond AJ, Rambaut A, Shapiro B, Pybus OG. 2005. Bayesian coalescent inference of past population dynamics from molecular sequences. Molecular Biology and Evolution 22: 11851192.

Dudas SE, Rilov G, Tyburczy J, Menge BA. 2009. Linking larval abundance, onshore supply and settlement using instantaneous versus integrated methods. Marine Ecology Progress Series 387: 81-95.

Dupanloup I, Schneider S, Excoffier L. 2002. A simulated annealing approach to define the genetic structure of populations. Molecular Ecology 11: 2571-2581.

Ellingson RA, Krug PJ. 2016. Reduced genetic diversity and increased reproductive isolation follow population-level loss of larval dispersal in a marine gastropod. Evolution 70: 18-37.

Elliot NB, Cushman SA, Macdonald DW, Loveridge AJ. 2014. The devil is in the dispersers: predictions of landscape connectivity change with demography. Journal of Applied Ecology 51: 1169-1178.

Excoffier L, Lischer HEL. 2010. Arlequin suite ver 3.5: a new series of programs to perform population genetics analyses under Linux and Windows. Molecular Ecology Resources 10: 564-567.

Excoffier L and Lischer H. 2015. Arlequin Ver 3.5: an integrated software package for population genetics data analysis. Bern, Switzerland: Swiss Institute of Bioinformatics. p. 145. http://cmpg.unibe.ch/software/arlequin35

Excoffier L, Smouse PE, Quattro JM. 1992. Analysis of molecular variance inferred from metric distances among DNA Haplotypes: Application to human mitochondrial DNA restriction data. Genetics 131: 479-491.

Fattebert J, Balme G, Dickerson T, Slotow R, Hunter L. 2015. Density-dependent natal dispersal patterns in a leopard population recovering from over-harvest. PLOS ONE 10: e0122355.

Féral J-P. 2002. How useful are the genetic markers in attempts to understand and manage marine biodiversity? Journal of Experimental Marine Biology and Ecology 268: 121-145.

Folmer O, Black M, Hoeh W, Lutz R, Vrijenhoek R. 1994. DNA primers for amplification of mitochondrial cytochrome c oxidase subunit I from diverse metazoan invertebrates. Molecular Marine Biology and Biotechnology 3: 294-299.

Fraser $\mathrm{Cl}$, Nikula R, Waters JM. 2011. Oceanic rafting by a coastal community. Proceedings of the Royal Society of London B: Biological Sciences 278: 649-655.

Fu YX. 1997. Statistical tests of neutrality of mutations against population growth, hitchhiking and background selection. Genetics 147: 915-925.

Fu YX, Li WH. 1993. Statistical tests of neutrality of mutations. Genetics 133: 693-709.

Galindo HM, Olson DB, Palumbi SR. 2006. Seascape genetics: A coupled oceanographic-genetic model predicts population structure of Caribbean corals. Current Biology 16: 1622-1626.

Gardner JPA, Bell JJ, Constable HB, Ritchie PA, Zuccarello GC. 2010. Multi-species coastal marine connectivity: a literature review with recommendations for further research. NZ Aquatic Environment Biodiversity Report 58: 1-47.

van der Geest M, van Gils JA, van der Meer J, Olff H, Piersma T. 2011. Suitability of calcein as an in situ growth marker in burrowing bivalves. Journal of Experimental Marine Biology and Ecology 399: $1-7$.

Gilg MR, Hilbish TJ. 2003. The geography of marine larval dispersal: Coupling genetics with fine-scale physical oceanography. Ecology 84: 2989-2998. 
Gosselin LA, Chia F-S. 1995. Distribution and dispersal of early juvenile snails: effectiveness of intertidal microhabitats as refuges and food sources. Marine Ecology Progress Series 128: 213-223.

Grant WS, Bowen BW. 1998. Shallow population histories in deep evolutionary lineages of marine fishes: insights from sardines and anchovies and lessons for conservation. Journal of Heredity 89: 415-426.

Grantham BA, Eckert GL, Shanks AL. 2003. Dispersal potential of marine invertebrates in diverse habitats. Ecological Applications 13: S108-S116.

Gunn J, Block B. 2001. Advances in acoustic, archival, and satellite tagging of tunas. In: BB and E Stevens, editor. Fish Physiology Academic Press. p. 167-224.

Hall LA, Beissinger SR. 2014. A practical toolbox for design and analysis of landscape genetics studies. Landscape Ecology 29: 1487-1504.

Hanski I, Gilpin M. 1991. Metapopulation dynamics: brief history and conceptual domain. Biological Journal of the Linnean Society 42: 3-16.

Hauser L, Adcock GJ, Smith PJ, Ramírez JHB, Carvalho GR. 2002. Loss of microsatellite diversity and low effective population size in an overexploited population of New Zealand snapper (Pagrus auratus). Proceedings of the National Academy of Sciences 99: 11742-11747.

Hedgecock D. 1986. Is gene flow from pelagic larval dispersal important in the adaptation and evolution of marine invertebrates? Bulletin of Marine Science 39: 550-564.

Hellberg ME. 2009. Gene flow and isolation among populations of marine animals. Annual Review of Ecology Evolution and Systematics: 291-310.

Henry P-Y, Jarne P. 2007. Marking hard-shelled gastropods: tag loss, impact on life-history traits, and perspectives in biology. Invertebrate Biology 126: 138-153.

Hernández S, Daley R, Walker T, Braccini M, Varela A, Francis MP, Ritchie PA. 2015. Demographic history and the South Pacific dispersal barrier for school shark (Galeorhinus galeus) inferred by mitochondrial DNA and microsatellite DNA mark. Fisheries Research 167: 132-142.

Hickey AJR, Lavery SD, Hannan DA, Baker CS, Clements KD. 2009. New Zealand triplefin fishes (family Tripterygiidae): contrasting population structure and mtDNA diversity within a marine species flock. Molecular Ecology 18: 680-696.

Higgins KL, Semmens JM, Doubleday ZA, Burridge CP. 2013. Comparison of population structuring in sympatric octopus species with and without a pelagic larval stage. Marine Ecology Progress Series 486: 203-212.

Higgs ND, Reed AJ, Hooke R, Honey DJ, Heilmayer O, Thatje S. 2009. Growth and reproduction in the Antarctic brooding bivalve Adacnarca nitens (Philobryidae) from the Ross Sea. Marine Biology 156: $1073-1081$.

Highsmith R. 1985. Floating and algal rafting as potential dispersal mechanisms in brooding invertebrates. Marine Ecology Progress Series 25: 169-179.

Ho SYW, Shapiro B. 2011. Skyline-plot methods for estimating demographic history from nucleotide sequences. Molecular Ecology Resources 11: 423-434.

Hoffman JI, Clarke A, Linse K, Peck LS. 2011. Effects of brooding and broadcasting reproductive modes on the population genetic structure of two Antarctic gastropod molluscs. Marine Biology 158: 287-296.

Holland SM. 2003. Analytic Rarefaction 1.3. UGA Stratigraphy Lab. [accessed 2016 May 02]. http://strata.uga.edu/software/anRareReadme.html

Holsinger KE, Weir BS. 2009. Genetics in geographically structured populations: defining, estimating and interpreting F-ST. Nature Reviews Genetics 10: 639-650.

Hoskin MG. 1997. Effects of contrasting modes of larval development on the genetic structures of populations of three species of prosobranch gastropods. Marine Biology 127: 647-656.

Hoskin MG. 2000. Effects of the East Australian Current on the genetic structure of a direct developing muricid snail (Bedeva hanleyi, Angas): variability within and among local populations. Biological Journal of the Linnean Society 69: 245-262.

Hothorn T, Bretz T, Westfall P. 2008. Simultaneous inference in general parametric models. Biometrical Journal 50: 346-363. 
Hussey NE, MacNeil MA, Olin JA, McMeans BC, Kinney MJ, Chapman DD, Fisk AT. 2012. Stable isotopes and elasmobranchs: tissue types, methods, applications and assumptions. Journal of Fish Biology 80: 1449-1484.

Jacobson B, Peres-Neto PR. 2010. Quantifying and disentangling dispersal in metacommunities: how close have we come? How far is there to go? Landscape Ecology 25: 495-507.

Janson K. 1983. Selection and migration in two distinct phenotypes of Littorina saxatilis in Sweden. Oecologia 59: 58-61.

Johannesson K. 1988. The paradox of Rockall: why is a brooding gastropod (Littorina saxatilis) more widespread than one having a planktonic larval dispersal stage (L. littorea)? Marine Biology 99: 507-513.

Johannesson K, Warmoes T. 1990. Rapid colonization of Belgian breakwaters by the direct developer, Littorina saxatilis (Olivi) (Prosobranchia, Mollusca). Hydrobiologia 193: 99-108.

Johnson MS, Black R. 1995. Neighbourhood size and the importance of barriers to gene flow in an intertidal snail. Heredity 75: 142-154.

Kamel SJ, Grosberg RK, Addison JA. 2014. Multiscale patterns of genetic structure in a marine snail (Solenosteira macrospira) without pelagic dispersal. Marine Biology 161: 1603-1614.

Kearse M, Moir R, Wilson A, Stones-Havas S, Cheung M, Sturrock S, Buxton S, Cooper A, Markowitz S, Duran C, Thierer T, Ashton B, Meintjes P, Drummond A. 2012. Geneious Basic: An integrated and extendable desktop software platform for the organization and analysis of sequence data. Bioinformatics 28: 1647-1649.

Keeney DB, King TM, Rowe DL, Poulin R. 2009. Contrasting mtDNA diversity and population structure in a direct-developing marine gastropod and its trematode parasites. Molecular Ecology 18: 45914603.

Keeney DB, Szymaniak AD, Poulin R. 2013. Complex genetic patterns and a phylogeographic disjunction among New Zealand mud snails Zeacumantus subcarinatus and Z. Iutulentus. Marine Biology 160: 1477-1488.

Kojima S, Hayashi I, Kim D, lijima A, Furota T. 2004. Phylogeography of an intertidal direct-developing gastropod Batillaria cumingi around the Japanese Islands. Marine Ecology Progress Series 276: 161-172.

Kritzer JP, Sale PF. 2004. Metapopulation ecology in the sea: from Levins' model to marine ecology and fisheries science. Fish and Fisheries 5: 131-140.

Laikre L, Palm S, Ryman N. 2005. Genetic population structure of fishes: implications for coastal zone management. Ambio 34:111-119.

Landry S, Miron G. 2011. Effect of vertical planktonic distribution of competent larvae on spat location in a soft-bottom intertidal zone: A case study for the softshell clam (Mya arenaria) and the blue mussel (Mytilus edulis). Journal of Experimental Marine Biology and Ecology 410: 87-100.

Lee HJ, Boulding EG. 2009. Spatial and temporal population genetic structure of four northeastern Pacific littorinid gastropods: the effect of mode of larval development on variation at one mitochondrial and two nuclear DNA markers. Molecular Ecology 18: 2165-2184.

Levin LA. 2006. Recent progress in understanding larval dispersal: new directions and digressions. Integrative and Comparative Biology 46: 282-297.

Levins, R. 1970. Extinction. In M. Gerstenhaber (Ed.), Some Mathematical Problems in Biology: 77-107. Providence, R.I. American Mathematical Society.

Librado P, Rozas J. 2009. DnaSP v5: a software for comprehensive analysis of DNA polymorphism data. Bioinformatics 25: 1451-1452.

Losos JB. 2011. Convergence, adaptation, and constraint. Evolution 65: 1827-1840.

Lowe WH, Allendorf FW. 2010. What can genetics tell us about population connectivity? Molecular Ecology 19: 3038-3051.

Manríquez PH, Galaz SP, Opitz T, Hamilton S, Paradis G, Warner RR, Carlos Castilla J, Labra FA, Lagos NA. 2012. Geographic variation in trace-element signatures in the statoliths of near-hatch larvae and recruits of Concholepas concholepas (loco). Marine Ecology Progress Series 448: 105-118.

Mantel N. 1967. The detection of disease clustering and a generalized regression approach. Cancer Research 27: 209-220. 
Marko PB. 2004. 'What's larvae got to do with it?' Disparate patterns of post-glacial population structure in two benthic marine gastropods with identical dispersal potential. Molecular Ecology 13: 597-611.

Martel A, Chia F. 1991a. Foot-raising behavior and active participation during the initial phase of postmetamorphic drifting in the gastropod Lacuna spp. Marine Ecology Progress Series 72: 247254.

Martel A, Chia F-S. 1991b. Drifting and dispersal of small bivalves and gastropods with direct development. Journal of Experimental Marine Biology and Ecology 150: 131-147.

Martel A, Diefenbach T. 1993. Effects of body-size, water current and microhabitat on mucous-thread drifting in post-metamorphic gastropods Lacuna spp. Marine Ecology Progress Series 99: 215220.

Martin P. 2011. Phylogeny, phylogeography and population connectivity of Lessonia (Phaeophyceae). Unpublished doctoral dissertation. Victoria University of Wellington. Wellington, New Zealand.

McQuaid CD, Phillips TE. 2000. Limited wind-driven dispersal of intertidal mussel larvae: in situ evidence from the plankton and the spread of the invasive species Mytilus galloprovincialis in South Africa. Marine Ecology Progress Series 201: 211-220.

Meirmans PG. 2012. The trouble with isolation by distance. Molecular Ecology 21: 2839-2846.

Miller LP, O'Donnell MJ, Mach KJ. 2007. Dislodged but not dead: survivorship of a high intertidal snail following wave dislodgement. Journal of the Marine Biological Association of the United Kingdom 87: 735-739.

Mills LS, Allendorf FW. 1996. The One-migrant-per-generation rule in conservation and management. Conservation Biology 10: 1509-1518.

Miura O, Torchin ME, Bermingham E, Jacobs DK, Hechinger RF. 2012. Flying shells: historical dispersal of marine snails across Central America. Proceedings of the Royal Society B: Biological Sciences 279: 1061-1067.

Moran AL. 2000. Calcein as a marker in experimental studies newly-hatched gastropods. Marine Biology 137: 893-898.

Morley MS. 2013. In a whorl with Cominella glandiformis. Poireria 37: 4-7.

Morton B. 2006. Scavenging behaviour by Ergalatax contractus (Gastropoda : Muricidae) and interactions with Nassarius nodifer (Gastropoda : Nassariidae) in the Cape d'Aguilar Marine Reserve, Hong Kong. Journal of the Marine Biological Association of the United Kingdom 86: 141-152.

Morton B, Yuen WY. 2000. The feeding behaviour and competition for carrion between two sympatric scavengers on a sandy shore in Hong Kong: the gastropod, Nassarius festivus (Powys) and the hermit crab, Diogenes edwardsii (De Haan). Journal of Experimental Marine Biology and Ecology 246: 1-29.

Morton JE, Miller MC. 1968. The New Zealand sea shore. Liverpool: C. Tinling and Co.

Muteveri T, Matthee CA, Bowie RCK, Heyden S von der. 2015. High population connectivity and Pleistocene range expansion in the direct-developing plough shell Bullia rhodostoma along the South African coast. African Journal of Marine Science 37: 21-31.

Nakagawa S, Schielzeth H. 2013. A general and simple method for obtaining R2 from generalized linear mixed-effects models. Methods in Ecology and Evolution 4: 133-142.

Nikula R, Fraser Cl, Spencer HG, Waters JM. 2010. Circumpolar dispersal by rafting in two subantarctic kelp-dwelling crustaceans. Marine Ecology Progress Series 405: 221-230.

Nikula R, Spencer HG, Waters JM. 2011. Evolutionary consequences of microhabitat: population-genetic structuring in kelp- vs. rock-associated chitons. Molecular Ecology 20: 4915-4924.

Nikula R, Spencer HG, Waters JM. 2013. Passive rafting is a powerful driver of transoceanic gene flow. Biology Letters 9: 20120821.

Ortiz M, Prince ED, Serafy JE, Holts DB, Davy KB, Pepperell JG, Lowry MB, Holdsworth JC. 2003. Global overview of the major constituent-based billfish tagging programs and their results since 1954. Marine and Freshwater Research 54: 489-507. 
Ovenden JR. 2013. Crinkles in connectivity: combining genetics and other types of biological data to estimate movement and interbreeding between populations. Marine and Freshwater Research 64: 201-207.

Ovenden JR, Berry O, Welch DJ, Buckworth RC, Dichmont CM. 2015. Ocean's eleven: a critical evaluation of the role of population, evolutionary and molecular genetics in the management of wild fisheries. Fish and Fisheries 16: 125-159.

Pálsson S, Magnúsdóttir H, Reynisdóttir S, Jónsson ZO, Örnólfsdóttir EB. 2014. Divergence and molecular variation in common whelk Buccinum undatum (Gastropoda: Buccinidae) in Iceland: a trans-Atlantic comparison. Biological Journal of the Linnean Society 111: 145-159.

Palumbi SR. 1994. Genetic divergence, reproductive isolation, and marine speciation. Annual Review of Ecology and Systematics 25: 547-572.

Palumbi SR. 2003. Population genetics, demographic connectivity, and the design of marine reserves. Ecological Applications 13: S146-S158.

Prince RIT, Chaloupka M. 2012. Estimating demographic parameters for a critically endangered marine species with frequent reproductive omission: hawksbill turtles nesting at Varanus Island, Western Australia. Marine Biology 159: 355-363.

Prowse TAA, Pile AJ. 2005. Phenotypic homogeneity of two intertidal snails across a wave exposure gradient in South Australia. Marine Biology Research 1: 176-185.

Qiao F, Yuan Y, Deng J, Dai D, Song Z. 2016. Wave-turbulence interaction-induced vertical mixing and its effects in ocean and climate models. Phil. Trans. R. Soc. A 374: 20150201.

$\mathrm{R}$ Core Team. 2015. R: A language and environment for statistical computing. R Foundation for Statistical Computing. Vienna, Austria. https://www.R-project.org/.

Rabone M, Lavery SD, Little A, Clements KD. 2015. Discordance between nuclear and mitochondrial DNA analyses of population structure in closely related triplefin fishes (Forsterygion lapillum and F. capito, F. Tripterygiidae) supports speciation with gene flow. Marine Biology 162: 16111624.

Rajasekharan M, Crowe TP. 2007. Intrinsic differences in dispersal between populations of gastropods separated by a few metres: Evidence from reciprocal experimental transplantation. Journal of Experimental Marine Biology and Ecology 341: 264-273.

Ramos-Onsins SE, Rozas J. 2002. Statistical properties of new neutrality tests against population growth. Molecular Biology and Evolution 19: 2092-2100.

Reichlin TS, Hobson KA, Wassenaar LI, Schaub M, Tolkmitt D, Becker D, Jenni L, Arlettaz R. 2010. Migratory connectivity in a declining bird species: using feather isotopes to inform demographic modelling. Diversity and Distributions 16: 643-654.

Reisser CMO, Bell JJ, Gardner JPA. 2014. Correlation between pelagic larval duration and realised dispersal: long-distance genetic connectivity between northern New Zealand and the Kermadec Islands archipelago. Marine Biology 161: 297-312.

Rieseberg LH, Burke JM. 2001. A genic view of species integration. Journal of Evolutionary Biology 14: 883-886.

Rilov G, Dudas SE, Menge BA, Grantham BA, Lubchenco J, Schiel DR. 2008. The surf zone: a semipermeable barrier to onshore recruitment of invertebrate larvae? Journal of Experimental Marine Biology and Ecology 361: 59-74.

Ross PM, Hogg ID, Pilditch CA, Lundquist CJ. 2009. Phylogeography of New Zealand's coastal benthos. New Zealand Journal of Marine and Freshwater Research 43: 1009-1027.

Ross PM, Hogg ID, Pilditch CA, Lundquist CJ, Wilkins RJ. 2012. Population genetic structure of the New Zealand estuarine clam Austrovenus stutchburyi (Bivalvia: Veneridae) reveals population subdivision and partial congruence with biogeographic boundaries. Estuaries and Coasts 35 : 143-154.

Rousset F. 1997. Genetic differentiation and estimation of gene flow from F-Statistics under isolation by distance. Genetics 145: 1219-1228.

RStudio Team. 2015. RStudio: Integrated Development for R. RStudio, Inc. Boston, MA http://www.rstudio.com. 
Sahara R, Fukaya K, Okuda T, Hori M, Yamamoto T, Nakaoka M, Noda T. 2016. Larval dispersal dampens population fluctuation and shapes the interspecific spatial distribution patterns of rocky intertidal gastropods. Ecography 39: 487-495.

Schaub M, Reichlin TS, Abadi F, Kéry M, Jenni L, Arlettaz R. 2011. The demographic drivers of local population dynamics in two rare migratory birds. Oecologia 168: 97-108.

Schmidt DJ, Crook DA, Macdonald JI, Huey JA, Zampatti BP, Chilcott S, Raadik TA, Hughes JM. 2014. Migration history and stock structure of two putatively diadromous teleost fishes, as determined by genetic and otolith chemistry analyses. Freshwater Science 33: 193-206.

Selkoe KA, Watson JR, White C, Horin TB, lacchei M, Mitarai S, Siegel DA, Gaines SD, Toonen RJ. 2010. Taking the chaos out of genetic patchiness: seascape genetics reveals ecological and oceanographic drivers of genetic patterns in three temperate reef species. Molecular Ecology 19: 3708-3726.

Shanks AL. 1986. Vertical migration and cross-shelf dispersal of larval Cancer spp. and Randallia ornata (Crustacea: Brachyura) off the coast of southern California. Marine Biology 92: 189-199.

Shears NT, Smith F, Babcock RC, Duffy CAJ, Villouta E. 2008. Evaluation of biogeographic classification schemes for conservation planning: Application to New Zealand's coastal marine environment. Conservation Biology 22: 467-481.

Shima JS, Noonburg EG, Swearer SE. 2015. Consequences of variable larval dispersal pathways and resulting phenotypic mixtures to the dynamics of marine metapopulations. Biology Letters 11: 20140778.

Slatkin M. 1987. Gene flow and the geographic structure of natural populations. Science 236: 787-792.

van der Sman J, Phillips NE, Pfister CA. 2009. Relative effects of maternal and juvenile food availability for a marine snail. Ecology 90: 3119-3125.

Smith KE, Reed AJ, Thatje S. 2015. Intracapsular development and dispersal polymorphism in the predatory gastropod Ocenebra erinaceus (Linnaeus 1758). Helgoland Marine Research 69: 249258.

Smouse PE, Long JC, Sokal RR. 1986. Multiple regression and correlation extensions of the Mantel test of matrix correspondence. Systematic Biology 35: 627-632.

Stevens MI, Hogg ID. 2004. Population genetic structure of New Zealand's endemic corophiid amphipods: evidence for allopatric speciation. Biological Journal of the Linnean Society 81: 119-133.

Swearer SE, Shima JS, Hellberg ME, Thorrold SR, Jones GP, Robertson DR, Morgan SG, Selkoe KA, Ruiz GM, Warner RR. 2002. Evidence of self-recruitment in demersal marine populations. Bulletin of Marine Science 70: 251-271.

Tajima F. 1989. The effect of change in population size on DNA polymorphism. Genetics 123: 597-601.

Thiel M, Gutow L. 2005. The ecology of rafting in the marine environment. II. The rafting organisms and community. Oceanography and Marine Biology 44: 279-418.

Thiel M, Haye PA. 2006. The ecology of rafting in the marine environment. III. Biogeographical and evolutionary consequences. Oceanography and Marine Biology 44: 323-429.

Thorrold SR, Jones G, Hellberg ME, Burton RS, Swearer SE, Neigel JE, Morgan SG, Warner RR. 2002. Quantifying larval retention and connectivity in marine populations with artificial and natural markers. Bulletin of Marine Science 70: 291-308.

Todd CD, J. Lambert W, Thorpe JP. 1998. The genetic structure of intertidal populations of two species of nudibranch molluscs with planktotrophic and pelagic lecithotrophic larval stages: are pelagic larvae "for" dispersal? Journal of Experimental Marine Biology and Ecology 228: 1-28.

Trewick SA, Bland KJ. 2012. Fire and slice: palaeogeography for biogeography at New Zealand's North Island/South Island juncture. Journal of the Royal Society of New Zealand 42: 153-183.

Trussell GC, Johnson AS, Rudolph SG, Gilfillan ES. 1993. Resistance to dislodgement: habitat and size specific differences in morphology and tenacity in an intertidal snail. Marine Ecology Progress Series 100:135-144.

Turgeon K, Kramer DL. 2012. Compensatory immigration depends on adjacent population size and habitat quality but not on landscape connectivity. Journal of Animal Ecology 81: 1161-1170. 
Vahl O. 1983. Mucus drifting in the limpet Helcion (= Patina) pellucidus (Prosobranchia, Patellidae). Sarsia 68: 209-211.

Veale A, Lavery S. 2012. The population genetic structure of the waratah anemone (Actinia tenebrosa) around New Zealand. New Zealand Journal of Marine and Freshwater Research 46: 523-536.

Venables WN, Ripley BD. 2002. Modern Applied Statistics with S. Fourth Edition. Springer, New York.

Vincent C, Mcconnell BJ, Ridoux V, Fedak MA. 2002. Assessment of Argos location accuracy from satellite tags deployed on captive gray seals. Marine Mammal Science 18: 156-166.

Wang Y, Lu H, Zheng J, Long K, Shi YH, Gu ZF, Wang AM. 2011. Eight polymorphic microsatellite markers for the spotted babylon, Babylonia areolata (Buccinidae). Genetics and Molecular Research 10: 3230-3235.

Waples RS. 1998. Separating the wheat from the chaff: patterns of genetic differentiation in high gene flow species. Journal of Heredity 89: 438-450.

Waples RS, Gaggiotti O. 2006. What is a population? An empirical evaluation of some genetic methods for identifying the number of gene pools and their degree of connectivity. Molecular Ecology 15: 1419-1439.

Waters JM, Fraser $\mathrm{Cl}$, Hewitt GM. 2013. Founder takes all: density-dependent processes structure biodiversity. Trends in Ecology \& Evolution 28: 78-85.

Waters JM, King TM, O'loughlin PM, Spencer HG. 2005. Phylogeographical disjunction in abundant highdispersal littoral gastropods. Molecular Ecology 14: 2789-2802.

Weersing K, Toonen RJ. 2009. Population genetics, larval dispersal, and connectivity in marine systems. Marine Ecology Progress Series 393: 1-12.

Wei K, Wood AR, Gardner JPA. 2013. Population genetic variation in the New Zealand greenshell mussel: locus-dependent conflicting signals of weak structure and high gene flow balanced against pronounced structure and high self-recruitment. Marine Biology 160: 931-949.

Weng KC, Boustany AM, Pyle P, Anderson SD, Brown A, Block BA. 2007. Migration and habitat of white sharks (Carcharodon carcharias) in the eastern Pacific Ocean. Marine Biology 152: 877-894.

West JB, Bowen GJ, Cerling TE, Ehleringer JR. 2006. Stable isotopes as one of nature's ecological recorders. Trends in Ecology \& Evolution 21: 408-414.

White C, Toonen RJ. 2008. Isolation and characterization of polymorphic microsatellite and COI loci from the whelk Kelletia kelletii. Molecular Ecology Resources 8: 881-883.

Whitlock MC, McCauley DE. 1999. Indirect measures of gene flow and migration: F-ST not equal $1 /(4 \mathrm{Nm}+1)$. Heredity $82: 117-125$.

Wilcox RZ. 2015. A population genetic analysis of the New Zealand spotty (Notolabrus celidotus) using mitochondrial DNA and microsatellite DNA markers. (Unpublished master's thesis). Victoria University of Wellington. Wellington, New Zealand.

Wilhelmsen U. 1998. Rapid colonization of new habitats in the Wadden Sea by the ovoviviparous Littorina saxatilis (Olivi). Helgoländer Meeresuntersuchungen 52: 325-335.

Will M, Hale ML, Schiel DR, Gemmell NJ. 2011. Low to moderate levels of genetic differentiation detected across the distribution of the New Zealand abalone, Haliotis iris. Marine Biology 158: 1417-1429.

Wilson CA, Beckman DW, Dean JM. 1987. Calcein as a fluorescent marker of otoliths of larval and juvenile fish. Transactions of the American Fisheries Society 116: 668-670.

Winston JE. 2012. Dispersal in marine organisms without a pelagic larval phase. Integrative and Comparative Biology 52: 447-457.

Wright S. 1951. The genetical structure of populations. Annals of Eugenics 15: 323-354.

Wright S. 1931. Evolution in Mendelian populations. Genetics 16: 97-159.

Yund P 0., Gaines SD, Bertness MD. 1991. Cylindrical tube traps for larval sampling. Limnology and Oceanography 36: 1167-1177.

Zuur AF, leno EN, Walker N, Saveliev AA, Smith GM. 2009. Mixed effects models and extensions in ecology with R. New York, NY: Springer New York. Pp 218-223. 


\section{Appendix}

Mismatch distributions for combined Wairarapa populations and separated by populations. Analysis performed in DnaSP 5.10 .01 (Librado and Rozas 2009).
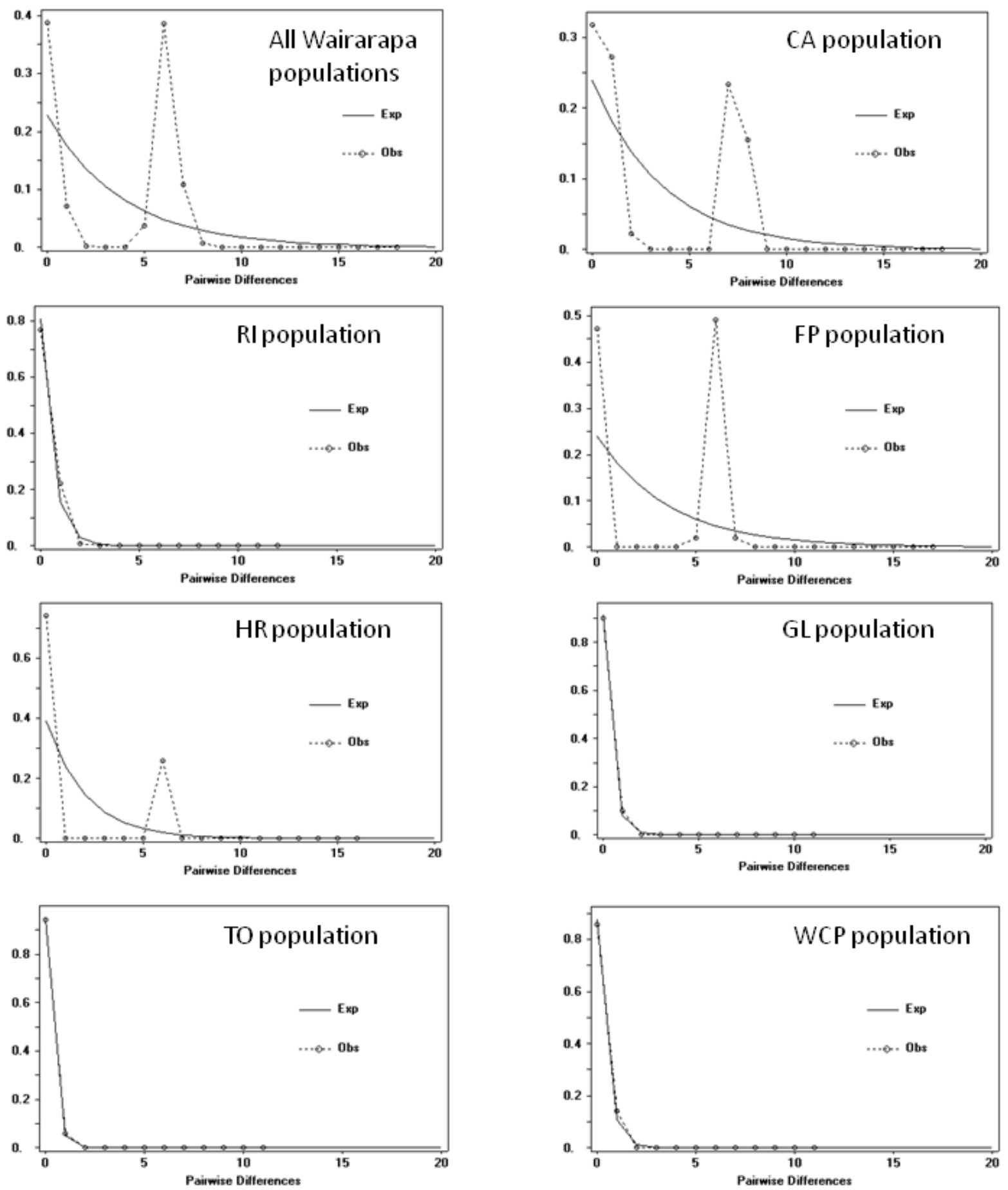